\title{
ADSORÇÃO E DESLOCAMENTO DOS METAIS PESADOS, CROMO, CHUMBO E CADMIO EM ALGUNS SOLOS DO ESTADO DE SÃO PAULO
}

SATORU OMAE

Orientador: Prof. Dr. TOSHIAKI KINJO

Tese a presentada à Escola Superior de Agricultura "Luiz de Queiroz", da Universidade de São Paulo, para obtenção do Título de Doutor em Agronomia. Área de concentração: solos $\theta$ nutrição de planta.

PIRACICABA

Estado de São Paulo - Brasil

Junho - 1986 
. iii.

A meus pais

que queriam fosse eu "ITININ-MAE" (capaz),

a minha homenagem

Dedico

A minha esposa Hideko

e aos meus filhos

Alexis, Elocy e Virna 


\section{AGRADECIMENTOS}

- Ao Prof.Dr. Toshiaki kinjo, pela orientacão segura e eficien te, amizade e apoio prestado durante o curso e na realizacão deste trabalno;

- Ao Prof.Dr. Mizton Caetano Eerreroni pela cuidadosa leitura do original e valiosa sugestão na adsorcão e equilíbrio químico;

- Aos Professores do Curso de Pós-Graduasão pela orientacão se gura e eficiēncia nos cursos realizados;

- Aos Senhores Euncionários da Biblioteca e da secretaria do Curso de Pós-Graduasão da Escola superior de Agricultura "Luiz de Queiroz", pela prestimosa atencão durante o curso;

- Aos Senhores Funcionários da E.S.A. "Luiz de Queiroz", e especialmente do Departamento de Solos, Geologia e Fertizizantes pela colaboracão nas anāitises físicas e quĩmicas das amostras de Solo; 
$\therefore$ Ao CENA - Centro de Energia Nuclear na Agricultura da Univer sidade de São Paulo atravēs do Dr. Froncisco Krugg, pelas anälises quĩmicas efetuadas;

- A Escola Superior de Agricultura "Luiz de Queiroz", por todas as facilidades oferecidas no desenvolvimento dos estudos;

- A Fundacão Amando Alvares Penteado, através dos Senhores Prof.Dr. Roberto Pinto de Souza - Diretor Tesoureiro pela concessão parcial da Bolsa de Estudos, e Prof. Evaristo ValZadares Costa - Presidente do Conselho das Faculdades pela concessão do Laboratōrio para pesquisas;

A Faculdade de Engenharia da Fundacão Armando Alvare Pentea do, através do seu Diretor Prof. Antonio calafiomi neto pela condução a bolsa de estudo para tese de doutorado e Profá é sefa Alvares Alvares, pela inestimävel ajuda na conciliacăo dos horārios de aula para a consecucão do curso de doutorado;

- Aos Prof. Caetano Belliboni pelo encaminhamento a minha carreira universitāria e Prof.Dr. José Mizton Nogueira pelo estîmulo ao aperfeiçoamento universitārio; 
Ao Centro de Informática da FAAP, atravēs do seu Coordenador Prof. Simpson Simão Kalmus, pelo processamento de dados no computador;

Aos Senhores Funcionärios e Técnicos de Laboratörio da Funda Gao Armando Alvares Penteado, especialmente aos Srs. Carlos Alberto Portscheler, Orlando Chaves Bitencourt e Salvador Ga lego no auxĩlio a montagem das experiências e extração das amostras;

A CNPq - Conseito Nacional de Desenvoivimenio Cientifico e Tecnológico pela concessão da bolsa de estudos para o Doutoramento.

A todos que direta ou indiretamente, contribuirram para a rea lização deste trabalho. 


\section{ADSORCÃO E DESLOCARERTO LE METAIS PESALOS, CROMD, CRUMBO E CÁMIO EM ALCUNS SCUCS DO ESTADO DE SÃC PAULO}

AUTOR: Satoru Onae

ORIENTADOR: Prof.Dr. TOShiaki Kinjo

RESUMO

Em solos de uma ārea nunca cultivada do litoral paulista no Vale do Ribeira com fodzölico vermelho Ama relo-orto e Glei Hūmico do município de Juquiá SP e Tarra Foxa estruturada do municipio de Piracicaba SP estudou-se a adsorcão e deslocamento de alguns metais pesados, $\mathrm{Cr}, \mathrm{Pb}$ e Ca.

No estido da adsorção adotou-se a metodologia de JOHN (1972) aplicando-se as isotermas de Langmuir e Freundich. A adsorcão foi verificada ao nível de 1 a $1.000 \mathrm{ppm}$ para os trēs metais. A seletividade da adsorcão dos trēs metais e solos observou-se da seguinte forma:

- em relação a massa, mg/100g solo

$\mathrm{Pb}>\mathrm{Cd} \geqslant \mathrm{Cr}$

$T E \geqslant P V$-orto $>G H$ 
- em relação a meq, meq/100g solo

$\mathrm{Cr}>\mathrm{Cd} \geqslant \mathrm{Pb}$

$T E \geqslant P V$-orto $>G H$

os deslocamentos dos metais pesados forali estudados en colunas de solos, aplicando-se um pulso de metais em solucão de sais provenientes de nitrato e cloretos. Após a inoculacão, foram efetuados percolaçc̄es com àgua destilada em 5,10 e 20 vezes o volume de poros. As amostras foram retiradas a cada $\Delta x=5 \mathrm{~cm}$ da coluna de solo imediatamente após haver percolado o volume de poros. Os resultados mostraram que o deslocamento dos metais através das colunas estão correlaciona dos com as características físicas e químicas dos solos. Verificou-se ainda, que no deslocamento dos metais pesados, o pH mostrou-se fundamental no seu mecanismo de equilibrio químico assim como a CTC do solo, tendo a TE maior capacidade de reten cão dos metais pesados em relacão a PV-orto e GH. 


\section{ADSORPTION AND DISPLACERENT OF FEANi METALS ( $\mathrm{Cr}, \mathrm{Pb}, \mathrm{AND} \mathrm{Cd}$ ) IN SONE SOILS OF SÃO PAULO STATE}

AUTHOR: Satoru Omae

ADVISER: Prof.Dr. Toshiaki Kinjo

\section{SUMEARY}

The purpose of this study was to evaluate adsorption and displacement of chromium, lead, and cadmium in an Ultisol (Podzolico Vermelho Amarelo-orto), an Alfisol (Terra Roxa Estruturada), and a Humic Glei soil (Glei Hūmico) of São Paulo State. Soil samples were collected from the A horizon, airdried, and crushed to pass a $2 \mathrm{~mm}$ sieve.

The adsorption of heavy metals was determined by the method of John (1972). The soil samples were equilibrated with solutions containing the heavy metal, concentration of which varied from 1 to $1,000 \mu \mathrm{g} / \mathrm{ml}$. The equilibrium solution was analyzed and the amount of the heavy metal adsorbed was calculated by the difference of the solution concentration before and after the equil ibrium. The Freundlich 
and the Langmuir equations were used to evalute the chromium lead, and cadmium adsorption in the soils. At the same equilibrium concentration $(\mu g / m l)$, the adsorption of heavy metals in terms of mass (mg/luog soil) decreased in the following order: $\mathrm{Pb}>\mathrm{Cd} \geqslant \mathrm{Cr}$, and in terms of chemical equivalence (meq/100g soil): $\mathrm{Cr}>\mathrm{Cd} \geqslant \mathrm{Pb}$. Among the three soils, the magnitude of adsorption was related to their effective cation exchange capacity and decreased in the following order: Alfisol z Ultisol > Humic Glei soil.

The displacement of heavy metals in soil columrs was studied by applying solution containing Crcla, $\mathrm{Pb}\left(\mathrm{NO}_{3}\right)_{2}$, or $\mathrm{CdCl}_{2}$ on the top of soil column, and 5, 10 or 20 pore-volumes of water. Immediately after the percolation of water, soil samples were collected from the column at the interval of $s \mathrm{~cm}$ and analyzed. The results showed that the displacement of heavy metals in the soils is correlated to the physical and chemical characteristics of the soils. The main factors which influenced the displacement of these elements were the soil reaction and the effective cation exchange capacity. The Alfisol had a greater capacity to retain the heary metals than the Ultisol and the Humic Glei soil. 


\section{$S \cup M A R I O$}

\section{PÁG.}

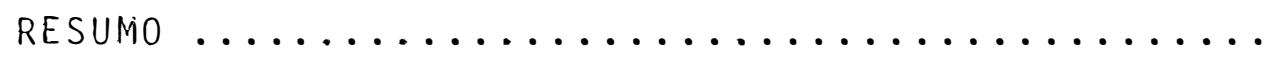

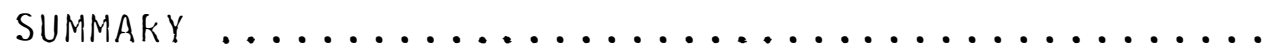

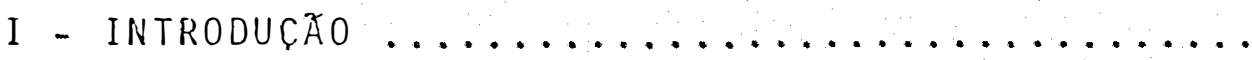

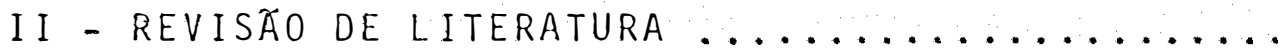

2. 1. Modelos teōricos para estudo do equilí-

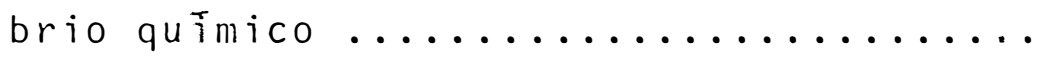
2.1.1. Expressão geral do equilíbrio ... 2.1.1.1. Equacão fundamental para sistemas abertos ....... 2.1.1.2. Constante de equilibrio.

2.1.2. Transformacão da constante de

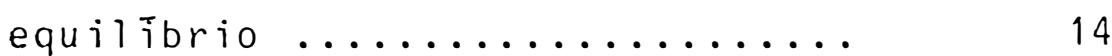

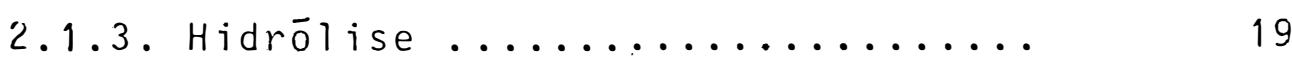

2.1.3.1. Hidrölise de sais ..... 20

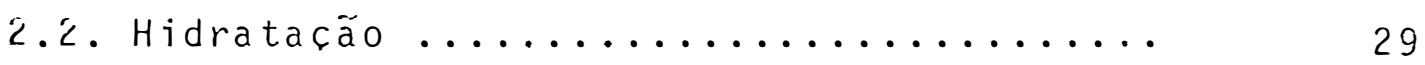

z.3. Modelos matemáticos para movimento da

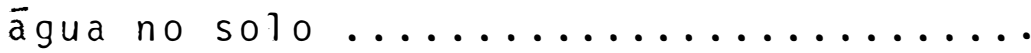

2.3 .1 . Deslocamento miscível .........

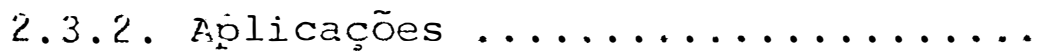

C.4. Consideracões teōricas sobre adsorcão ..

2.4.1. Estudo geral da isoterma de adsor

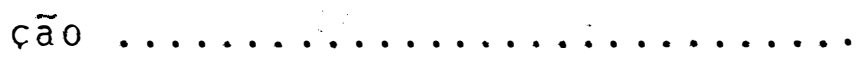

2.4.2. Adsorcăo dos solutos obtidos pela

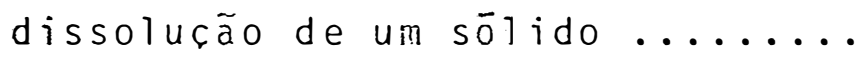

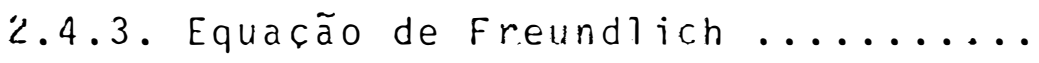

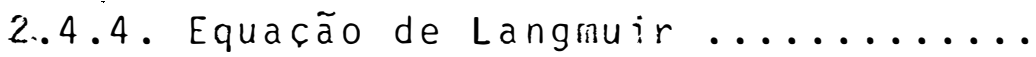


PÁO.

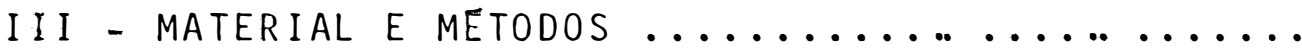

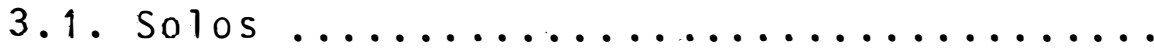

3.2. Experimento de adsorcão de metais pesa-

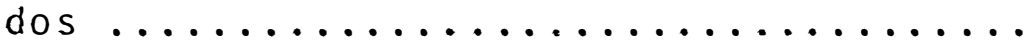

3.3. Experimento de deslocamento de metais

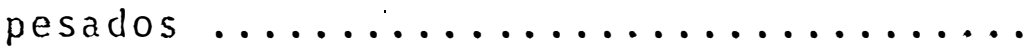

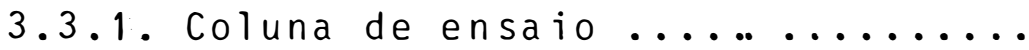

3.3.2. Câlculo do volume de poros na co-

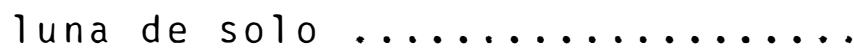

3.3.3. Estudo de deslocamento de cromo, chumbo e cādmio ...............

3.3.3.1. Unidade de experimento.

3.3.3.2. Aplicacão do pulso de me tais $\mathrm{Cr}^{2}{ }^{+} \mathrm{Pb}^{2}{ }^{+} \mathrm{e} \mathrm{Cd}^{2}$.

3.3.3.3. Identificação dos tratamentos na coluna de solo

3.4. Determinação dos metais pesados $\mathrm{M}^{2}+\mathrm{na}$

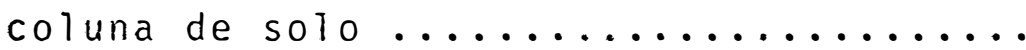

3.5. Medida da velocidade do soluto na coluna

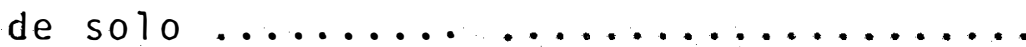

3.6. Cälculo de quantidade de metais $\mathrm{M}^{2}$ reti

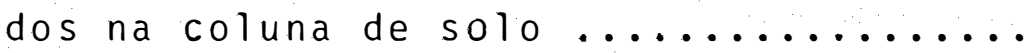

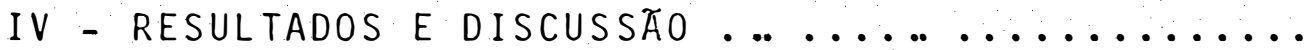

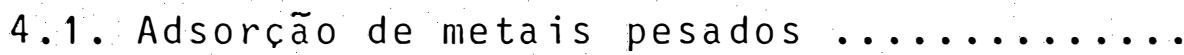

4.1.1. Adsorcão seletiva por solos ......

4.1.2. Adsorção seletiva por metal $\mathrm{M}^{2+}$..

4.z. Deslocamento dos metais $\mathrm{H}^{2}{ }^{+}$através da co

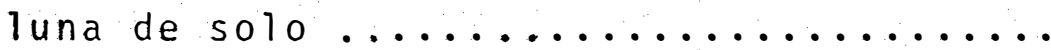

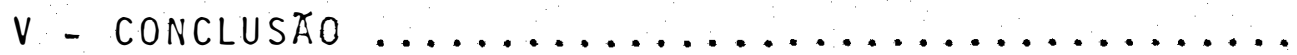




\section{LISTA DE TABELAS}

Tabela

1 Caracteristicas químicas das Terras Roxa Estruturada (TE), Podzólico Vermelho Amare lo-orto (PV-orto), Glei Hūmico (GH) ......

¿ Anālise granulométrica de solos Podz̄olico Vermelho Amarelo-orto, Glei Hümico e Terra

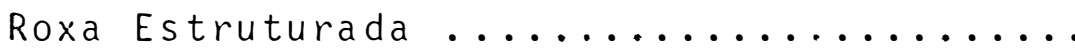

3 Volumes de poros $\left(V_{p}^{M}\right)$ por unidade de massa na coluna de solo e densidades aparentes

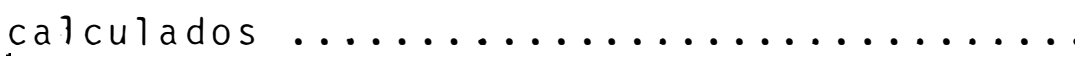

4 Esquema dos tratamentos de deslocamento

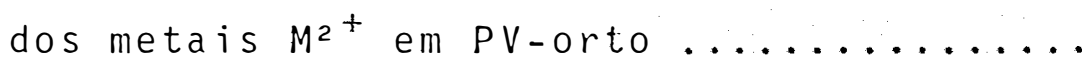

5 Esquema dos tratamentos de deslocamento dos metais $\mathrm{M}^{2}{ }^{+}$er $\mathrm{GH} \ldots \ldots \ldots \ldots \ldots \ldots$

6 Esquema dos tratamentos de deslocamento

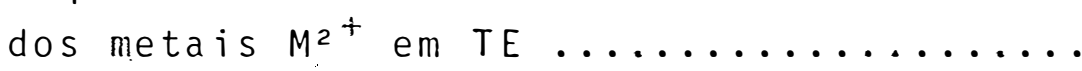

7 Caracteristica da coluna de solo no trata-

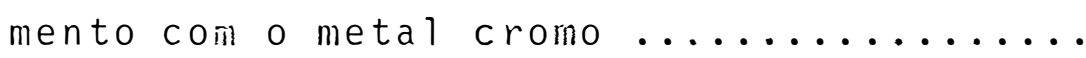

8 Característica da coluna de solo no tratamento com o metal cromo com correcão de pH 
Tabela

Pāgina

y Caracteristica da coluna de solo no trata-

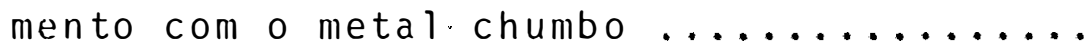

10 Caracteristica da coluna de solo no tratamento com o metal com correcão de pH .....

11 Característica da coluna de solo no trata-

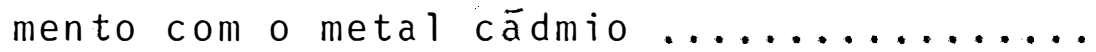

12 Caracteristica da coluna de solo no tratamento com o metal cädmio com correcão de

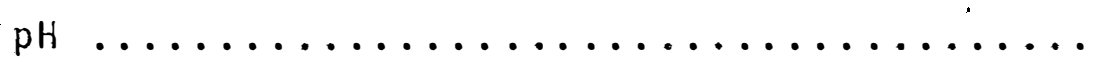

13 Ajuste de curvas obtidas no computador CP 500 Prolōgica com os dados das anālises de terra na coluna de PV-orto, GH e TE do me-

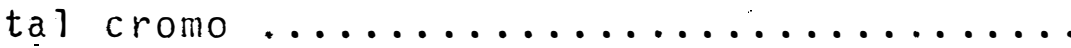

14 Ajustes de curvas obtidas no computador CP 5 uc prolōgica com o dados das anālises de terra na coluna de PV-orto e TE com metal

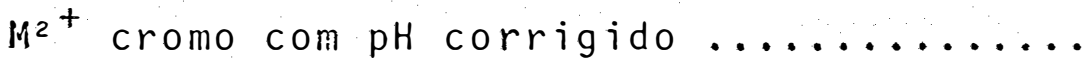

15 Ajustes de curvas obtidas no computador CP 500 Prológica com os dados das anālises de terra na coluna de PV-orto, GH e TE com o

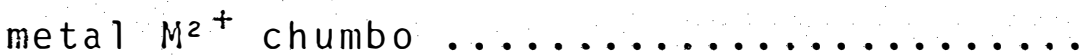

16 Ajuste de curvas obtidas no computador CP 500 com os dados das anālises de terra da coluna de PV-orto e TE com o metal $\mathrm{H}^{2}{ }^{+}$chum

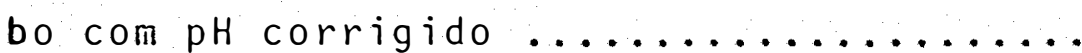


17 Ajuste de curvas obtidas no computador CP 500 Proiōgica coni os dacios anālises de terra na coluna de PV-orto, GH e TE com o metal

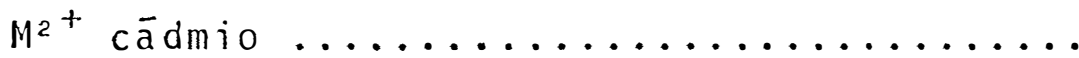

18 Ajuste de curvas obtidas no computador CP 500 Prológica com os dados das anālises de terra na coluna de PV-orto e TE com meta? $\mathrm{M}^{2}{ }^{+} \mathrm{c} \overline{\mathrm{a} d m i o} \mathrm{com} \mathrm{pH}$ corrigido ............

19 Valores de $C, x / m$ e $C /(x / m)$ da àdsorção de

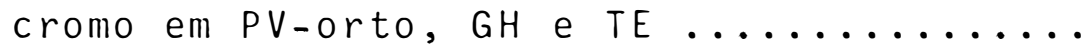

Lo Valores de $C, x / m$ e $C /(x / m)$ da adsorcão de

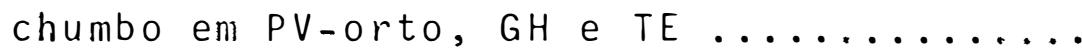

21 Valores de $C, x / m$ e $C /(x / m)$ da adsorção de

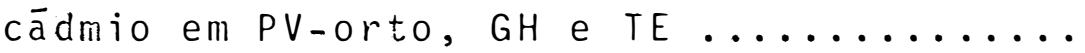

22 Coeficientes da equação de Freundi ich, obtidos a partir das solucões no equilibrio.

23 Valores de $\Delta G r^{0}$ de reações de hüdrōlise calculados pela equação 2.45 e $2.45^{\prime} \ldots .$.

24 Constantes de hidrōlises dos sais calculados corn a equação $2.63,2.782 .82 \mathrm{e} \mathrm{pH.}$

25 Equação de Langmuir na forma linear, na ad sorcão de $\mathrm{Cr}, \mathrm{Pb}$ e $\mathrm{Ca}$ e os valores de ad-

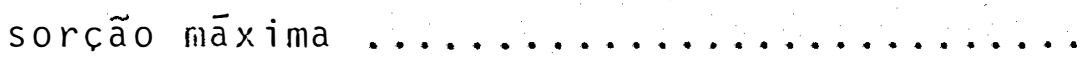


26 Teor de cromo nas diferentes profundidade

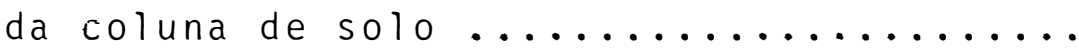

27 Teor de cromo nas diferentes profundidade da coluna de solo com o pH corrigido .....

¿8 Teor de chumbo nas diferentes profundidade

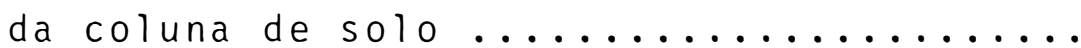

¿9 Teor de chumbo nas diferentes profundidade da coluna de solo com pH corrigido .......

30 Teor de cādmio nas diferentes profundidade

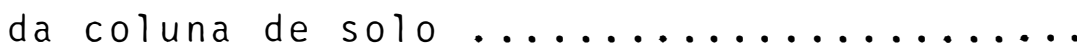

31 Teor de cădmio nas diferentes profundidade da coluna de solo com pH corrigido .......

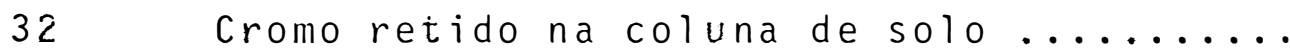

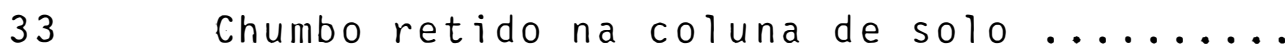

34 Cádmio retido na coluna de solo ........

35 Concentracöos molares do metal $M^{2}+$ no in ${ }^{+}-$

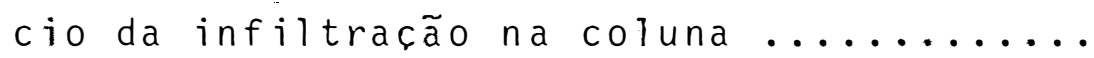

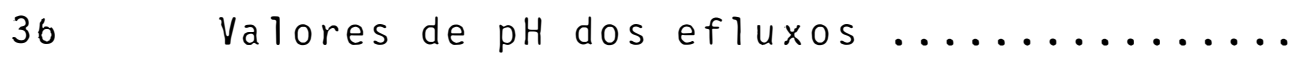


.$x v i i$.

Tabela

Pāgina

37 Concentracões de cations $\left[\mathrm{M}^{2}\right]$ calculadas graficamente em funcão do $\mathrm{pH}$ dos efluxos

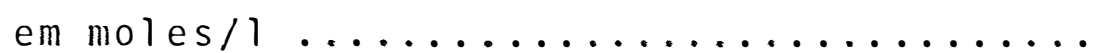

38

Condutividade hidräulica e velocidade da

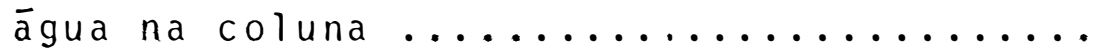




\section{LISTA DE FIGURAS}

Figura

Pāg ìna

1 Entalpia de hidratacão absoluta en função do raio iōnico (HARVEY e PORTER 1967, pāg.

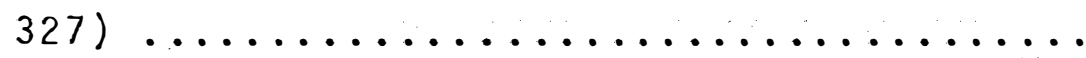

$\varepsilon$

Isotermas de adsorcão que apresentam māxi-

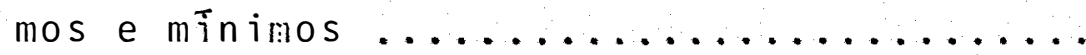

3 Isotermas de adsorcão compostas e indivi-

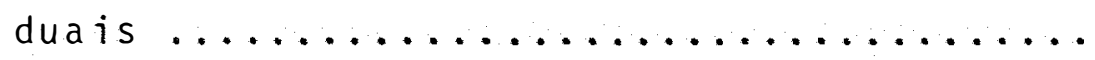

4 Aspecto tîpico da isoterma de adsorção de solucões obtidas pela dissolucão de solu-

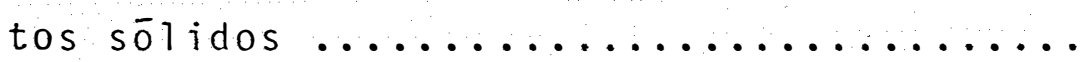

5 Isotermas individuais e compostas para adsorção de solucõos de ãcido laurico em tetrācloreto de carbono (KIPLING e WRIGHT

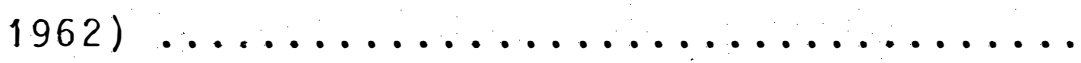

6 Detal.he da coluna de solo construído com

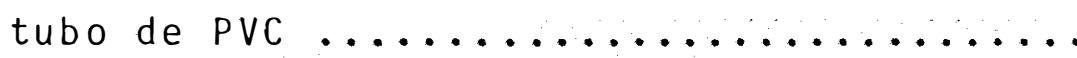

T Esquema de montagem da coluna de solo para

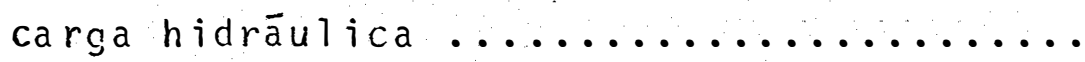

8 Isoterma de adsorcão de cromo, chumbo, cād

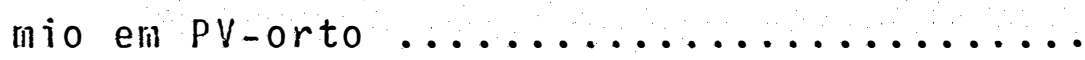


9 Isoterma de adsorcão de cromo, chumbo e

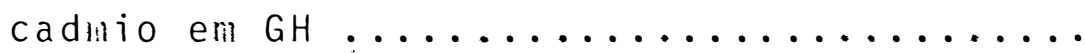

10 Isoterma de adsorção de cromo, chumbo e

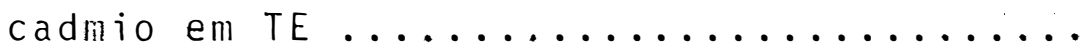

11 Isoterma de adsorção dos metais $\mathrm{M}^{+}$de acordo com a equacão de Freundlich em PV-

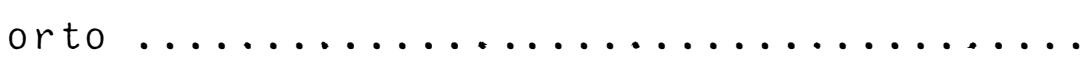

12 Isoterma de adsorção dos metais $\mathrm{M}^{2}{ }^{+}$de acordo com a equação de Freundrich em GH.

13 Isoterma de adsorção dos metais $\mathrm{M}^{+}$de acordo com a equação de Freundlich em TE.

14 Isoterma de adsorção de cromo em PV-orto,

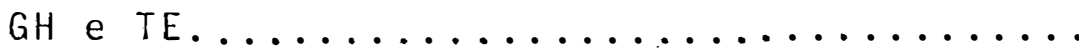

15 Isoterma de adsorção de chumbo em PV-orto, $\mathrm{GH}$ e TE.

16 Isoterma de adsorção de cädmio em PV-orto, GH e TE.

17 Isoterma de adsorcão de cromo de acordo com equação de Freundlich em PV-orto, GH e $T E \ldots \ldots \ldots \ldots \ldots \ldots \ldots \ldots \ldots \ldots \ldots \ldots \ldots \ldots \ldots \ldots \ldots$ 
Figura

18 Isoterma de adsorcão de chumbo de acordo com a Equacão de Freundlicí em PV-orto, GH

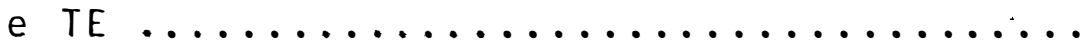

Isoterma de adsorcão de cádmio de acordo com a Equação de Freundlich em PV-orto, GH

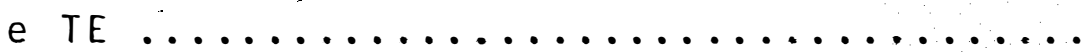

¿0 Deslocamento dos metais $\mathrm{M}^{2}$ cromo, chumbo, cādmio em PV-orto em $\mu \mathrm{g} / \mathrm{g}$ terra ............

21 Deslocamento dos metais $\mathrm{M}^{2}{ }^{+}$cromo, chumbo, cădmio em PV-orto com pH corrigido em $\mu \mathrm{g} /$

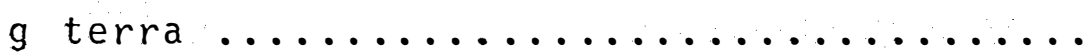

22 Deslocamento dos metais $\mathrm{N}^{2}+$ cromo, chumbo

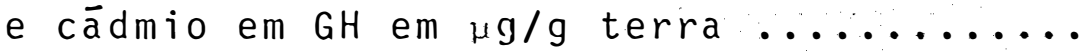

¿3 Deslocamento dos metais $\mathrm{M}^{2}+$ cromo, chumbo e cādmio em TE em $\mu \mathrm{g} / g$ terra ............

24 Deslocamento dos metais $\mathrm{M}^{2}+$ cromo, chumbo e cădmio com pH corrigido em TE em $\mu g / g$ ter

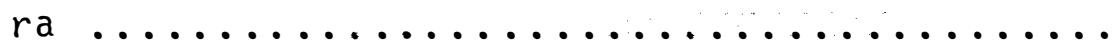

25 Deslocamento dos metais $\mathrm{M}^{2}$ cromo, chumbo e cādmio em meq $M^{2}+100 \mathrm{~g}$ TFSA de PV-orto ..

26 Deslocamento dos metais $\mathrm{M}^{2}+$ cromo, chumbo e

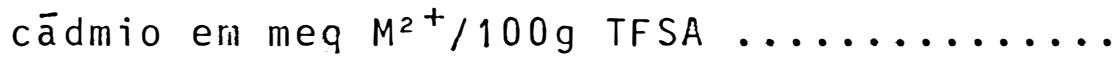


Figura

27 Deslocamento de metais $\mathrm{M}^{2}$ cromo, chumbo e cădmio en meq $M^{2+} / 100 \mathrm{~g}$ TFSA de GH .......

28 Deslocamento de metais $\mathrm{M}^{2}+$ cromo, chumbo e cādmio em meq $M^{2+} / 100 \mathrm{~g}$ TFSA de TE ........

29 Destocamento de metais $\mathrm{M}^{2}{ }^{+}$cromo, chumbo e cádmio em meq $M^{2+} / 100 \mathrm{~g}$ TFSA com pH corrig

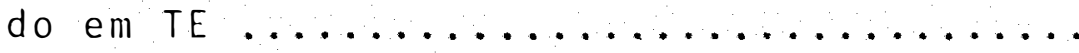

30 Diagrama de variáveis dos hidróxidos de $\mathrm{Cr}(\mathrm{OH})_{2}, \mathrm{~Pb}(\mathrm{OH})_{2}$ e $\mathrm{Cd}(\mathrm{OH})_{2} \ldots \ldots \ldots \ldots \ldots$ 


\section{I - INTRODUCÃO}

A evolucão tecnológica trouxe consigo vārios problemas anbientais. A selva amazōnica impenetrável hä alcumas décadas, hoje está rasgada por modernas rodovias asfaltadas e com elas nasceu o que a geração de hoje conhece com ? nome de poluicão ambiental. LAGERWERFF (1972) relata em suas pesqui sas ao longo de uma rodovia movimentada a uma distância de 15 m uma concentração de $121 \mathrm{mg} \mathrm{Pb} / \mathrm{rr}^{3}$ por ano no sudoeste da Cali fórnia. Esta quantidade não seria de se alarmar, se a quantida de máxima permitida para una criança de até 5 anos não fosse de 5 ppb de Pb/diärios. O chumbo causa danos irreversiveis de retardamento mental, provavelmente alojando-se no cérebro (LAGERWERFF, 1972). 
No solo aparece näo sō o chumbo, pela queima dos combustiveis que são levados a longo da rodovia, mas também o cādmio pelo desgaste dos pneus já que esse elemento entra na sua fabricação. Temos conhecimento pelos relatos de SCHOROEDER e BALASSA (1901) que o cādmio causa enormes malefícios ao homem como por exemplo anemia, hipertensão, proteinūria, enfizema pulmonar, degeneracão do miocărdio e problemas fisiológicos gastrointestinais, renais e gāstricos.

Estes malefícios são causados pela ingestão destes metais, já que a maioria dos metais pesados são tóxicos.

A ingestão pode ocorrer, quando estes metais entram na nossa cadeia alimentar, como jā se viu na ocorrência de graves intoxicacões em Minamata - Japão (SLOYAN, 1971), através das plantas que absorveram estes elementos tóxicos. Para algumas plantas a sua absorcão não causa toxiciez, como nas alfaces e tomates (GARCIA et alii 1981, REUS et alii 1976), pa ra outras, como em soja inibem seu crescimento, folhas clorót cas e enroladas e propenso a abcissão para altas concentracões de cadmio (LEE et alii, 1976), pequenos desenvolvimentos ou to talmente prejudicados pelos metais pesados para cultura de repOlhos (HARA e SONODA, 1979).

Desafortunadamente os solos já desenvorveram-se com alguns meta is pesados tóxicos (LAGERHERFF e BROWER, 1972) e seus teores a inda são incrementados por ferti- 
lizantes, principalmente os fosfatados que contēm cădmio in na tura. (SHOROEDER e BALASSA, 1963). Aliado a estes infortūnios, te mos ainda os descartes de toda sorte de residuos de grandes llie trópoles, tanto de origem agrícola como da moderna tecnologia industrial, carreados a un único depösito de lixo, por cima,fer mentados para reutilização como fertil izantes agrícolas. São vārias, as pesquisas neste sentido do lixo fermentado.

Desse modo, o presente trabalho tem por objetivo estudar o comportamento da deslocação dos metais pesa dos tóxicos cromo, chumbo e cädmio, devido o alto risco que poderā advir na contaminacão da camada de solo agriculturāvel e do sub-solo ou indo até o lençol freàtico.

- As amostras utilizadas foram de uma ārea virgem de baixa fertilidade, tendo-se escolhido podzólico vermelho smarelo - orto (PV-orto) e Glei Hūmico (GH) e outra de uma àrea cultivada e adubada nor vārios anos de boa fertilidade, tendo-se coletado a amostra de Terra roxa estruturada(TE).

Para isso, o presente trabalho consta de uma parte de experimento clässico de adsorcão comos metais cromo, chumbo e cādmio e outra de deslocamento destes metais atravēs da coluna de solo con: pH original e outra compH corrigi do. 


\section{II - REVISÃO DE LITERATURA}

2.1. Modelos teóricos para estudo do equilíbrio quĩmico

A idéia da reversibilidade nas reacoes quîmicas foi pela primeira vez mostrado em 1.799 pelor. Berthollet, assessor cientifico de Napoleão no Egito. Na ocasião, èle notou depósitos de carbonato de sódio nos lagos e concluiu que a formacão era devida a alta concentracão de cloreto de só dio e o carbonato de cálcio dissolvido, em experiēncia de labo ratōrio, na reação reversa produziu precipitado de carbonato cie cālcio reagindo carbonato de sódio e cloreto de cálcio. Em $1.863 \%$. Berthelot e Saint-Gilles conforme relatos de ALBERT e DANIELS ( 1980 capitulo 4) verificou que as concentracões do àl cool etỉlico e àcido acético tem influência na concentração do 
acetato de etila. Os mesmos autores, citam ainda, que em 1.864 Guldberg e Wage mostrou experimentalmente que em uma reação química o equilíbrio é atingido em ambos os sentidos, e em 1.877 Van't hoff, sugeriu na expressão do equilibrio da hidrōlise do acetato de etila em que deve aparecer a concentração de cada reagente em primeiro lugar com os seus coeficientes unitārios no balanço da equação quĩmica. A vista das observa cões dos pesquisadores da época é possĩvel ter-se uma relação matemātica entre a concentração dos reagentes e os produtos nos equilibrios.

Nos capitulos seguintes usaremos a termodinämica nos equilibrios químicos ilustrados com conceito de potencial químico.

\subsection{Expressão geral do equilî́brio}

A reaçao química de dois reagentes $A_{1}$ e $A_{2}$ e dois produtos $A_{3}$ e $A_{4}$ pode ser representadz por:

$v_{1} A_{2}+v_{2} A_{2} \stackrel{\rightarrow}{\leftarrow} v_{1}^{\prime} A_{3}+v_{2}^{\prime} A_{4} \ldots \ldots$

onde $v$ é o coeficiente estequiométrico. Adotaremos a convenção de que os coeficientes serão positivos para o produto e negati vo para os reagentes. A equação geral da reação química pode ser escrita: 
$\sum v_{i} A_{i}=0$

2.1.1.1. Equação fundamental para

sistemas abertos

A energia de Gibbs em um sistema homogénio contendo diferentes substāncias pode ser considerado emi função de T, $P, n_{1}, n_{2}, \ldots n_{k}$, e a diferencial total de G pode ser escrita:

$d G=\left(\frac{\partial G}{\partial T}\right)_{P_{1} n_{i}} d T+\left(\frac{\partial G}{\partial P}\right)_{T, n_{i}} d P+\sum_{i}^{k}=1\left(\frac{\partial G_{i}}{\partial n_{i}}\right)_{T}, P, n_{j} d n_{i}(2.3)$ onde:

G - energia de Gibbs ou energia livre de Gibbs

$\mathrm{T}$ - temperatura absoluta $\mathrm{K}^{\mathrm{O}}$

P - pressão

$n_{i}$ - nūmero de moles do componente i no sistema

Como os membros das equações $(2.3)$ são di ferenciais exatas podemos escrever:

$\left(\frac{\partial G}{\partial T}\right)_{P,} n_{i}=-S$

$\left(\frac{\partial G}{\partial P}\right)_{T, n_{i}}$ 
$\left(\frac{\partial G}{\partial n_{i}}\right) T, P, n_{j}=\mu_{i}$

onde:

$S=$ entropia

$V=$ volume

$\mu_{i}=$ potencial quirmico do componente $i$.

substituindo a equação (2.4), (2.5) e (2.6) em (2.3) temos:

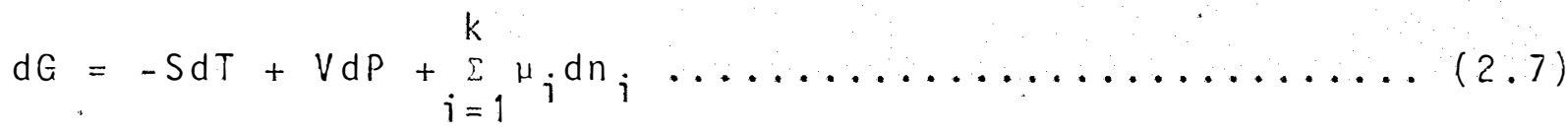

Das ieis da termodinämica, conclui-se que:

$\mu_{i}=\left(\frac{\partial U}{\partial n_{i}}\right)_{S}, U, n_{j}=\left(\frac{\partial H}{\partial n_{i}}\right)_{S}, P, n_{j}=\left(\frac{\partial A}{\partial n_{i}}\right)_{T}, v, n_{j} \ldots \ldots(2.8)$

onde:

U é. a energia interna

H é a entalpia

A é a energia de Helmholtz

Rearranjando a equação 2.7 com equação 2.8

e integrando temos:

$G=\sum_{i=1}^{k} \mu_{i} n_{i}$ 
Se inicialmente no sistema em reacão exis tem $n_{\text {io }}$ moles $n_{i}$ e apōs um tempo $t$, poderemos escrever

$n_{i}=n_{i O}+v_{i}$

onde:

$\xi$ è o grau de àvanco da reacão, ou seja o nümero de vezes que a transformacão indicada em (2.1) ocorre e $v_{i}$ represen ta o coeficiente estequiomētrico, jā definido.

substituindo a equaçõo 2.10 em 2.9 temos:

$G=n_{10} \mu_{1}+n_{20} \mu_{2}+\ldots+\left(v_{1} \mu_{2}+v_{2} \mu_{2}+\ldots\right) \xi$ ou

$G=\sum n_{i 0}^{\mu}+\xi \Sigma v_{i}^{\mu}{ }_{i}$

Derivando a equação 2.11 em relacão a $\xi$ com a tenperatura $e$ pressões constantes, pode se escrever:

$\frac{d G}{d \bar{\xi}}=\sum_{i=1}^{K} v_{i}{ }^{\mu} i$

e no equilíbrio químico, a temperaturas e pressões constantes, a derivada da equação (2.12) é igual a zero, pois g passa por um mínimo.

$\sum_{i=1}^{K} v_{i}{ }^{\mu}=0$ 
0 conceito acima pode ser aplicado de for ma geral em reacões quĩmicas envolvendo gases, liquidos, sōlidos ou solucões. O potencial químico poderā ser expresso ainda em termos de atividade conforme definido por G.N. Lewis (citado por ALBERT e DANIELS, 1980)

$\mu_{i}=\mu_{i}^{0}+R \operatorname{RIn} a_{i}$

onde:

$\mu_{i}^{0}=\bar{e}$ o potencial quĩmico no estado padrão

$R=$ constante dos gases perfeitos

$T=j \bar{a}$ definido

$a_{j}=$ atividade do componente $i$

Substituindo a equação 2.14 em 2.13 temos:

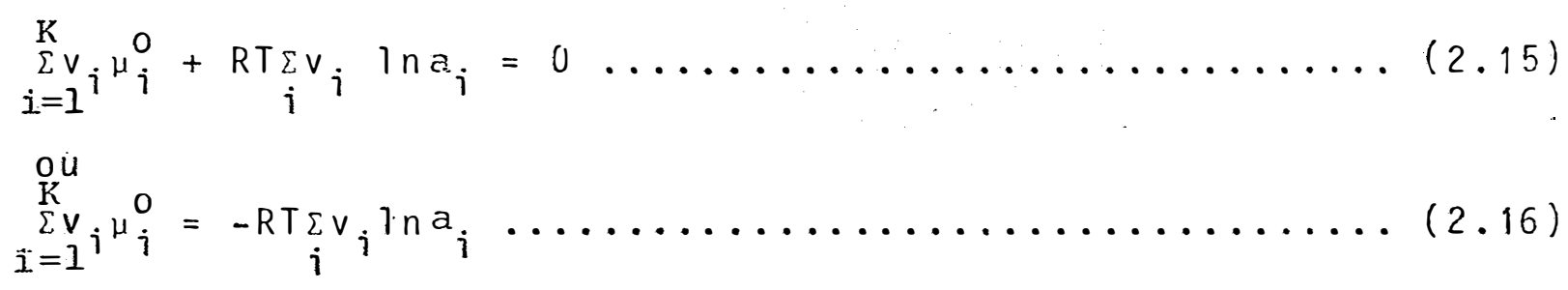




\subsubsection{Constante de equilíbrio}

A constante de equilíbrio pode ser deduzi da termodinamicamente, conforme demonstraram A. Horstmann(1873) e J. Willard Gibbs $(1.876)$ e J.H. van't Hoff (1.886) citado por GLASTONE (1.976). Consideremos a equação abaixo em equilĩbrio de gases perfeitos de quatro espēcies em dois volumes: $V_{1}$ e $V_{i}$ ligados por uma torneira.

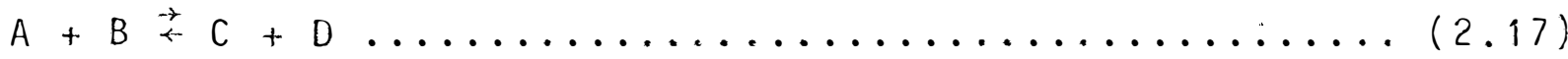

Sendo:

$P_{A}, P_{B}, P_{C}$ e $P_{D}$ as pressões parciais em um volume $v_{1}$

e

$P_{A}^{\prime}, P_{B}^{\prime}, P_{C}^{\prime}$ e $P_{D}^{\prime}$ as pressões parciais em outro volume $v_{2}$

Consideremos os componentes da equação 2.17 como sendo gases ideais, passando de $v_{1}$ a $v_{2}$ a variação de energia livre de Gibbs resulta:

$$
\begin{aligned}
\Delta G_{A} & =R T \operatorname{In} P_{A}^{\prime} / P_{A} \\
\Delta G_{B} & =R T \operatorname{nn} P_{B}^{\prime} / P_{B}
\end{aligned}
$$

e o processo realizado isotermicamente, reversivelmente, a variação de energia livre de Gibhs resulta:

$$
\Delta G_{C}=R T I \cap P_{C} / P_{C}
$$




$$
\Delta G_{D}=R T \ln P_{D} / P_{D}^{\prime}
$$

A variacão total da energia serä as somas das quatro variações, logo

$$
\Delta G=R T \ln P_{A}^{\prime} / P_{A}+R T \ln P_{B}^{\prime} / P_{B}+R T \ln P_{C} / P_{C}^{\prime}+R T \ln P_{D} / P_{D}^{\prime} \cdots
$$

Se no sistema permanecem em equilibrio, e a temperatura e pressão constante, a variação da enerçia será igual a zero, isto é

$\Sigma \Delta G=0 \ldots \ldots$

Substituindo equação 2.23 na equaçăo 2.22

temos:

$\ln P_{A}^{1} / P_{A}+\ln P_{B}^{\prime} / P_{B}=\ln P_{C}^{1} / P_{C}+\ln P_{D}^{1} / P_{D}$

ou

$\frac{P_{C} \times P_{D}}{P_{A} \times P_{B}}=\frac{P_{C}^{\prime} \times P_{D}^{\prime}}{P_{A}^{\prime} \times P_{B}^{\prime}}=$ constante $=k$

A constante $k_{p}$ é formada a uma temperatura definida e no equilibrio é chamada de constante de equilí. brio. Como as pressões parciais são proporciona is as concentra cões molares $C$, e substituindo na equacão 2.25 temos: 
$\frac{C_{C} \times C_{D}}{C_{A} \times C_{B}}=$ constante $\left(K_{C}\right)$

a. Equilibrio em sistemas lĩquidos

0 potencial quimico de qualquer constituinte de uma mistura liqquida ideal, para a qual é vālida a lei de Raoult ou Henry, è dado por:

$\left.\mu=\mu_{i}^{0}+R T\right] n x$

onde:

$x$ = fracão molar de quaiquer constituinte da mistura

De maneira anāloga do îtem 2.1.1.2. podese deduzir a constante de equilíbrio para a reacão abaixo no equilionio

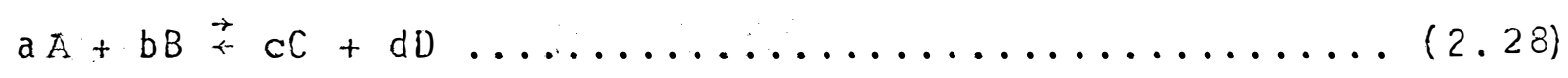

Aplicando os conceitos dos itens anteriores, facilmente deduz-se a constante de equilibrio

$K=\frac{C^{c} \times 0^{a}}{A^{a} \times B^{b}}$ 


\section{b. Atividades e concentração}

A definicão de constante de equilíbrio foi exposta em termos gerais. Diferentes espécies de constantes de equilíbrio conhece-se atualmente. Quando ela é expresso em termos de atividade se define como constante de atividade.

A razão da atividade do Ton a pela concentracão $C_{j}$, é chamado de coeficiente de atividade $y_{i}$ :

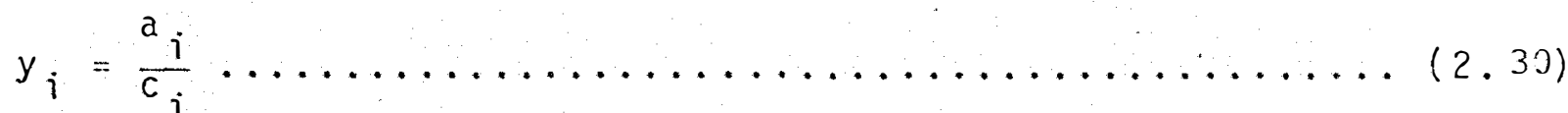

Nas solucões infinitamente dilữdas
$a_{i}=c_{i}$
$\mathrm{e}$
$y_{i}=1$

Segundo I INDSAY (1.979), ceralmente a for ca iōnica aumenta, e os ions de carga oposta interagem na concentracão "efetiva" ou decresce a atividade.

As constantes de equilibrio expresso em termos de atividades são calculados termodinamicamente, e elas são constantes verdadeiras para toda a forca iōnica da soluçã c. Entretanto, tem as suas desvantagens para muitos reagentes e produtos, cujas atividades especificas dos ions ou moléculas são dificeis de serem medidas. Por esta razão é que são usadas as concentracões frequentemente, e as constantes são chamadas de constante de concentração. 
2.1.2. Transformação de constantes de equilî̉brio

As constantes de equilibrio são determina das frequentemente pela forca iónica, porém por uma necessi dade se fōr usar outra forca iónica, deve--se conhecer ou deve ser possivel de calcular os coeficientes de atividade desse outro ion.

As forcas ionnicas podem ser definidas da seguinte forma:

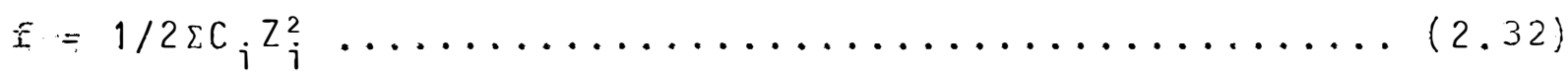

onde:

$c_{i}=$ concentracão de ion moles por litro do íon $i$

$z_{i}=$ valēncia do Ton $i$

$\Sigma \quad$ indica a somatōria

A teoria de Debye Huckel, para o cálculo de coeficientes de atividade é baseada nas leis da eletrostāti ca e termodināmica cujo cālculo nas solucões aquosas é dado por:

$\log y_{i}=-A Z_{i}^{2} f^{1 / 2}$

onde:

$A=$ constante $\left(0,509\right.$ para àgua a $\left.25^{\circ} \mathrm{C}\right)$ 
Extendendo a teoria de Debye - Huckel, pa ra medida efetiva do ion hidratado, com melhor precisăo é obti da pela equação:

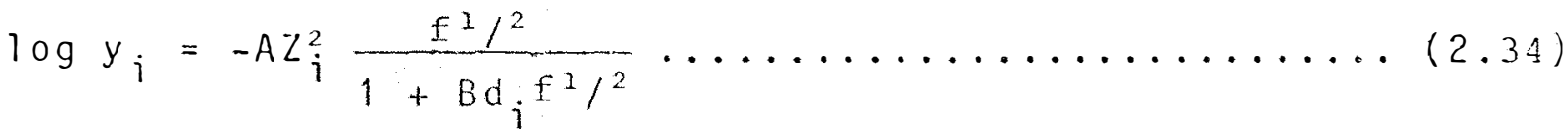

onde:

$B=$ constante $\left(0,328 \times 10^{8}\right.$ para àgua a $\left.25^{\circ} \mathrm{C}\right)$

$d_{i}=$ diāmetro efetivo do îon hidratado.

As equacões de Debye - Huckel são de confiabilidade para soluções de concentrações menores ciue 0,2M. Porém para altas concentrações são difícis de predizer e os coeficientes de atividade são de grandes valores e maiores que a unidade, devi da a repulsão entre os ĩons. Do exposto concluímos que não existe nenhuma constante de equilibrio geral, porque dependem dos solutos e de suas concentracões. Teril abaixo as constantes mais usadas e suas transformacões:

$K_{C}=$ constante, de equilîbrio em termos de concentracão

$K_{m}=$ constante de misturas, exceto dos $\mathrm{H}^{+}, \mathrm{OH}^{-}$e $\mathrm{K}^{0}=$ constante de atividade de pares iōnicos

Para transformaça, ilustra -se da seguinte forma: 
( ) para indicacão de atividades

[ ] para concentração

e com a seguinte equacão de reacăo:

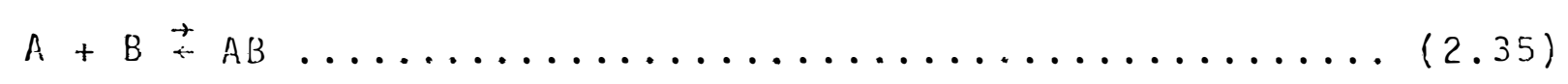

a. Conversão $K^{0}$ para $K_{C}$

Da equacão 2.35 temos

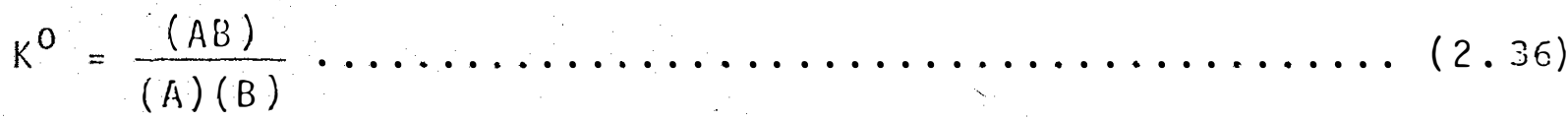

$K_{C}=\frac{[A B]}{[A][B]}=\frac{(A B) / y_{A B}}{(A)(B) / y_{A} y_{B}}=\frac{(A B)}{(A)(B)} \cdot \frac{y_{A} y_{B}}{y_{A B}} \ldots \ldots \ldots \ldots(2.37)$

$K_{C}=K^{0} \frac{y \text { reagentes }}{y \text { produto }}$

$\mathrm{ou}$

$K^{0}=K_{c} \frac{y \text { produto }}{y \text { reagente }}$

b. Conversão $K^{0}$ para $K_{m}$

Da equacão 2.35 temos

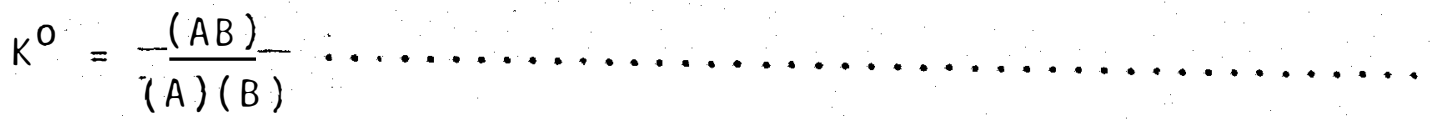




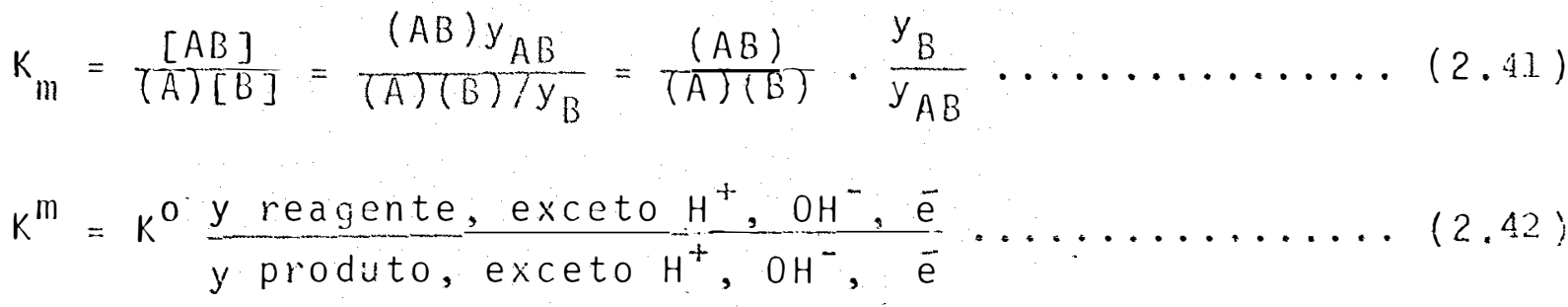

$\mathrm{ou}$

$K_{0}=K_{m} \frac{y \text { produto, exceto } \mathrm{H}^{+}, \mathrm{OH}^{-}, \overline{\mathrm{e}}}{y \text { reagente, exceto } \mathrm{H}^{+}, \mathrm{OH}^{-}, \overline{\mathrm{e}}} \ldots \ldots \ldots \ldots$

\section{c. Conversão de $\Delta G^{0}$ para $K^{0}$}

Quando o sistema acha-se em equilibrio, não hā entrada ou saîda de energia neste sistema. Como não é possível medir a variação da energia no sistema em equilíbrio, mede-se a variação da energia livre de formacões de produtos e reagentes no seu estado padrão. Logo, a variação da energia li vre no estado padrão é:

$\Delta G_{r}^{0}=\Sigma \Delta G_{f p}^{0}-\Sigma \Delta G_{f r}^{0}$

onde:

$\Delta G_{r}^{O}=$ variacão da energia livre de reação no estado padrão $\Delta G_{f p}^{0}=$ variacão da energia livre de formação no estado padrão de produtos

$\Delta G_{f r}^{0}=$ variacão da energia livre de formação no estado padrão do reagente 
substituindo nas equacöes 2.18 a 2.21 o conceito da energia 1 i vre de formação no estado padrão e rearranjando a equacão 2.44 resulta:

$\Delta G_{r}^{0}=-R T \ln \quad K^{0}$

e calculando a $25^{\circ} \mathrm{C}$ a equação 2.43 fica:

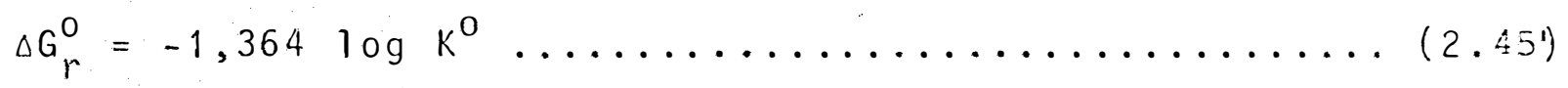
ou

$\log K_{0}=-\frac{\Delta G_{r}^{0}}{1,364}$

Como a energia livre $\left(\sigma_{r}^{0}\right)$, assim definida por G.N. Lewis e M. Randall citado por GLASSTONE (1976), grandeza que depende unicamente do estado do seu sistema, pode -se escrever:

$\Delta G_{r}^{0}=\Delta H_{r}^{0}-T \Delta S_{r}^{0}$

onde:

$\Delta H_{r}^{0}=\Sigma \Delta H_{f}^{0}$ produtos $-\Sigma H_{f}^{0}$ reagentes $\left.\cdots \ldots \ldots \ldots \ldots \ldots \ldots \ldots \ldots \ldots, 48\right)$

$\Delta S_{r}^{0}=\Sigma S_{\text {produtos }}^{0}-\Sigma S_{\text {reagentes }}^{0}$ 
$H_{f}^{0}=$ entalpia no estado padrão

$S^{0}=$ entropia no estado padräo

A constante $k^{\circ}$ é conhecida tambēm como constante de equilibrio de pares iônicos.

As explanações teōricas e deduções

das equacões detalhadas poderão ser amplamente vistas nos trabaIhos de BETT et aiii (1975), DENBIGH (1971), CASTELLAN (1975).

2.1.3. Hidrōlise

Os sais e algmas substäncias dissolvemi-se em solventes polares como a ägua e podem ter fortes interacões soluto - solvente podendo até aparecer cristais grandes.

A àgua tem efeitos extremamente importantes na reação qữmica que è a hidrōlise. Segundo a definicão de HARVEY (1967) hidrōlise significa meramente a clivagem ou separacăo de um composto em dois diferentes produtos pela reacão da água, de acordo com a equacão molecular geral:

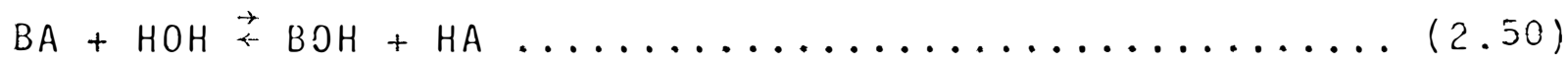

onde:

$B \cdot=$ uma base

$A=u m \bar{a} c i d o$ 
Alguns conceitos de termodinãmica e leis das ações das massas serão usadas a seguir para evolução dos fundamentos a serem apresentados.

\subsection{1. Hidrölise de sais}

Os sais podem ser classificados em quatro grupos principais segundo VOGEL (1960 página 34):

I - provenientes de ācidos e bases fortes

II - provenientes de ácidos fracos e bases fortes

III - provenientes de ácidos fortes e bases fracas

IV - provenientes de ācidos e bases fracas

Quando os sais são dissolvidos em àgua, es tabelece-se um equilíbrio entre os íons do sal e os da àgua,e a solucão resultante pode ser neutra, àcida ou alcalina, depen dendo do grupo que pertencer o sal.

Uma solução aquosa de um sal do grupo I, os ânions não se combinam com os îns de hidrogênio e nem os cátions com a oxidrila da āgua, pois os ácidos e bases provenientes são eletrōlitos fortes. 0 equilíbrio entre os ions $\mathrm{H}^{+}$ e $\mathrm{OH}^{-}$da àgua

$\mathrm{H}_{2} \mathrm{O} \stackrel{+}{*} \mathrm{H}^{+}+\mathrm{OH}^{-}$

não se altera e a solução permanece neutra. 
0 sal proveniente do grupo II, tipo MA, de um äcido fraco $H A$ e de base forte $B O H$, o sal se dissocia total mente em solucão aquosa.

$M A \stackrel{\leftarrow}{\leftarrow} M^{+}+A^{-}$

Inicialmente haverà somente uma pequena concentracão dos ions $\mathrm{H}^{+}$e $\mathrm{OH}^{-}$, provenientes da escassa ioniza cão da ägua. 0 àcido fraco HA, estā pouco ionizado com a concentracão dos íons $A^{-}$emi equilíbrio com os ions $H^{+}$, por conseguinte, muito pequena. 0 equilïbrio é mantido, porque a concen tracão inicial do Ton $A^{-}$diminue combinando com o ion $\mathrm{H}^{+}$.

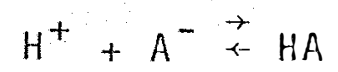

Os ĩons de $\mathrm{H}^{+}$necessārios a esta reàcão, sō é proveniente da dissociação da āgua e simultaneamente produz a hidroxila correspondente. Como os ions $H^{+}$formam HA (äci do fracol em consequẽncia a concentracão da $\mathrm{OH}^{-}$aumenta e a so lucão adquire um caráter alcalino.

A reacão mencionada, entre o ion (ou ions) de um sal e os ĩons da ãgua são chamados de hidrōlise. Á equacão de forma geral pode ser escrita:

$\mathrm{MA}+\mathrm{H}_{2} \mathrm{O} \stackrel{+}{\leftarrow} \mathrm{MOH}+\mathrm{HA}$ 
Da equacão anterior, pode-se definir a hidrōlise como sendo uma reação de um sal com āgua, dando umăcido e uma base.

Na hidrōlise de sais do grupo III, a concentração inicial do cätion $\mathrm{M}^{+}$se reduz pela combinacão com os ions de hidroxila da àgua para formar MOH pouco ionizado, até alcancar o equiliorio.

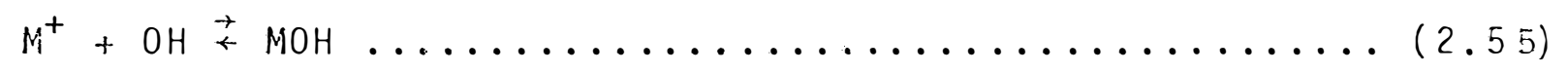

Neste caso a concentracão do ion $\mathrm{H}^{+}$aumenta, e a solucão adqui re un carater àcido. Desta forma podemos apresentar:

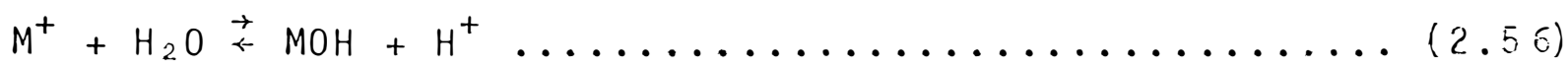

Os sais do grupo IV, tem simultanamente as reacões seguintes:

$\mathrm{M}^{+}+\mathrm{H}_{2} \mathrm{O} \stackrel{\rightarrow}{\mathrm{MOH}}+\mathrm{H}^{+}$ 


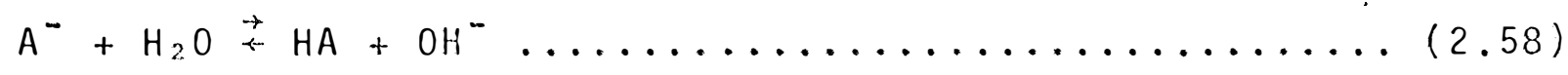

como podemos observar nas equacões 2.57 e 2.58 que o carater àcido ou bảsico da solucão dependerá dos valores relativos das constantes de dissociacão do ācido e da base. Se forem iguais, a solucão serā neutra.

a. Constantes de hidrōlise

As constantes são calculadas aplicando a lei da acão das massas, classificando de acordo com os grupos.

- Grupo I - àcidos e bases fortes

A reacão da solucão é neutra, portanto não hā constante de hidrōlise.

- Grupo II - àcido fraco com base forte

Consideremos o sal em equilíbrio:

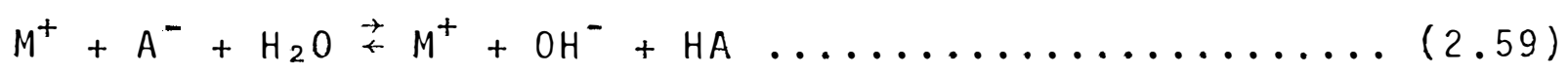

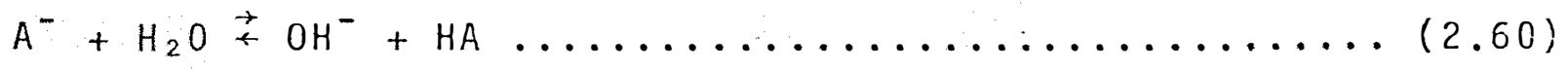


Aplicando a lei da ação das massas

$\frac{a_{O H} \times a_{H A}}{a_{A^{-}}}=\frac{[O H][H A]}{\left[A^{-}\right]}=$constante $=k_{h} \ldots \ldots \ldots \ldots \ldots(2.6 i)$

onde:

$\mathrm{a}=$ atividades dos ĩons

[]$=$ concentrações

$\mathrm{Na}$ equacão 2.61 a igualdade entre as atividades e concentracões poderão ser escritas para solucões diluîdas, quando a atividade e concentracöes são iguais (LINDSAY 1979). Conforme VOGEL (1960 pägina 37) admite-se que na solucão diluĩda, a atividade da āgua não dissociada pode-se tomar como constante, e nas solucões diluî́das a forca ioñica é peque na e o fator de atividade de ambos ions $\mathrm{OH}^{-}$e $\mathrm{A}^{-}$são iguais.

- Grupo III - àcido forte e base fraca

A equação de equilíbrio, se representa

por:

$\mathrm{M}^{+}+\mathrm{H}_{2} \mathrm{O} \stackrel{\rightarrow}{\rightarrow O H}+\mathrm{H}^{+}$

Anarogamente, apiicando a lei da ação das massas temos:

$K_{h}=\frac{\left[H^{+}\right][\mathrm{MOH}]}{\left[\mathrm{M}^{+}\right]}$ 
- Grupo IV - ācido fraco e base fraca

A equacão de equilíbrio se representa:

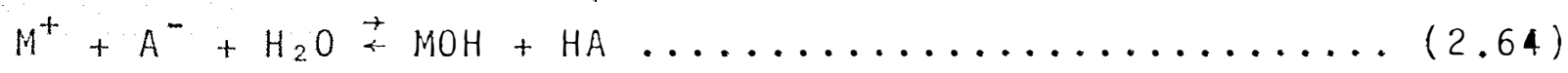

Aplicando a lei das ações das massas, temos :

$K h=\frac{[\mathrm{MOH}][\mathrm{HA}]}{\left[\mathrm{M}^{+}\right]\left[\mathrm{A}^{-}\right]}$

E oportuno salientar que as constantes de hidröitise podem ser calculadas também pela relacão entre constantes de ànions $k_{a}$, constantes de base e constante do grau de ionização.

\section{b. Grau de ionização e de hidrōlise}

Consideremos um sal ou eletrōrito binārio $B A$ que forma os ions $B^{+}$e $A^{-}$em uma solucão na qual a concentraç̃o de BA é C. Suponha que uma fração a de BA se ionize, de modo que a concentração de BA não-ionizada é C(1 - $\alpha)$ e a concentração de cada ion formado $\mathrm{B}^{+}$e $\mathrm{A}^{-}$e $\alpha \mathrm{C}$, logo:

$\mathrm{BA} \stackrel{\rightarrow}{\rightarrow} \mathrm{B}^{+}+\mathrm{A}^{-}$

$C(1-\alpha) \rightleftarrows \alpha C+$ 
Aplicando a lei do equiliorio temos:

$K=\frac{\left[B^{+}\right]\left[A^{-}\right]}{[B A]}$

Substituindo as concentracões da equacão 2.67 na 2.68 temos

$K=\frac{\alpha C \cdot \alpha C}{C(1-\alpha)}$

ou

$K=\frac{\alpha^{2} C}{(T-\alpha)}$

Essa equacão, segundo DENARO (1971), ë co nhecida como lei da diluicăo de 0stwald. Se na equacão 2.66 houver a hidrōlise a constante passarā a ser constante de hidrölise. Podemos representar da seguinte forma:

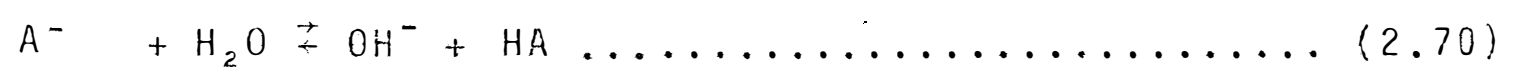

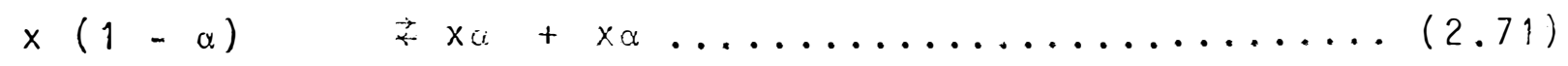

no equilibrio, temos:

$K_{h}=\frac{x a}{x}\left(\frac{x a}{1-\alpha}\right)$

ou 
$K_{h}=\frac{\alpha^{2} x}{(1-\alpha)}$

onde

$x=$ fracão molar (ou concentração)

c. Conversões $K_{h}, K_{w}, K_{a}$

Consideremos a equacão:

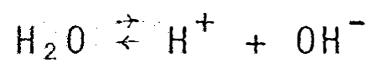

$\mathrm{e}$

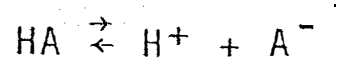

da equação $2.73,2.74$ e 2.70 , no equilitbrio temos:

$K_{w}=\left[\mathrm{H}^{+}\right] \times\left[\mathrm{OH}^{-}\right]$

$K_{a}=\frac{\left[\mathrm{H}^{+}\right] \times\left[\mathrm{A}^{-}\right]}{[\mathrm{HA}]}$

$K_{h}=\frac{[\mathrm{OH}] \times[\mathrm{HA}]}{\left[\mathrm{A}^{-}\right]}$

$\frac{K_{w}}{K_{a}}=\frac{\left[\mathrm{H}^{+}\right]\left[\mathrm{OH}^{-}\right]}{\left[\mathrm{H}^{+}\right]\left[\mathrm{A}^{-}\right] /[\mathrm{HA}]}=\frac{\left[\mathrm{OH}^{-}\right][\mathrm{HA}]}{\left[\mathrm{A}^{-}\right]}=K_{h}$

portanto

$k_{h}=\frac{k_{w}}{k_{a}}$ 
$\mathrm{ou}$

$p K_{h}=p K_{W}-p K_{a}$

Aplicando os mesmos conceitos para a cons tante de base $k_{b}$ temos:

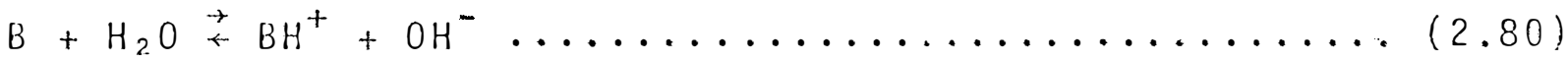

onde no equilibrio, temos:

$K_{b}=\frac{\left[\mathrm{BH}^{+}\right]\left[\mathrm{OH}^{-}\right]}{[\mathrm{B}]}$

e

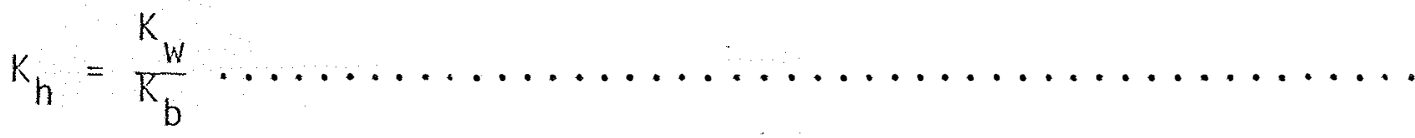

Das equacões anteriores, pode-se deduzir

que :

$K_{w}=K_{a} \cdot K_{b}$

Isto mostra que quando são conjugados um àcido e uma base num mesmo solvente, devem apresentar uma razão inversa um em relação ao outro.

Para um sal de base fraca e àcido forte,

temos:

$\left[H^{+}\right]=\frac{c K_{W}}{K_{b}}$ 
2. ̈́. Hidratação

Consideremos a reação abaixo como exempio.

$\mathrm{Na}_{(\mathrm{g})}^{+}+\mathrm{Cl}_{(\mathrm{g})}^{-} \stackrel{\rightarrow}{\leftarrow} \mathrm{Na}_{(\mathrm{ag})}^{+}+\mathrm{Cl}_{(\mathrm{ag})}^{-}$

A variacão da entalpia na reaçăo da equa ção 2.85, de acordo com a definicão HARVEY e PORTER (1967), é chamada de entalpia de Hidratação e podemos escrever de acordo com a lei de Hess:

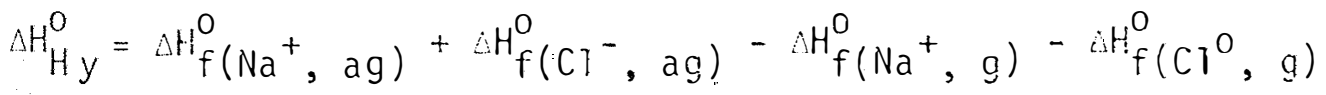

sendo que os dois $\bar{u} 1$ timos termos podemos obter da seguinte for ma :

$\left.\Delta H_{f(N a}^{0}, g\right)=\Delta H_{S u b(N a, S)}^{O}+\Delta H_{i o n}^{O}\left(N^{+}, g\right)$

e

$\Delta H_{f\left(C T^{-}, g\right)}^{0}=1 / 2 \Delta H_{d i s s}^{0}\left(C_{2}, g\right)-\Delta H_{i o n}\left(C_{1} T^{-}, g\right) \cdots \ldots(2.88)$

Raramente, a entalpia de soluções são numericamente grandes, comparadas com outras entalpias, e tem se melhanca com a cristalizacão e depende do raio iōnico e da car ga. 
Năo é possível definir estritamente com bases termodinämicas, as funçöes termodinämicas dos îns, pois deve haver outros numerosos fatores que as influem. Portanto os valores obtidos são uma apr ximacão para aprendermos os pro blemas de hidratação.

Os trabalhos de Noyes (1962) citado por HARVEY e PORTER ( 1967 página 327) mostram estrita correlacão do tamanho do raio iōnico e sua carga $z_{i}^{2} / r$ ( $r$ é o raio do íon) com a entalpia, conforme podemos verificar na Figura 1.

Para discussão do presente trabalho somen te será consideraço o tamanho do raio iōnico. 


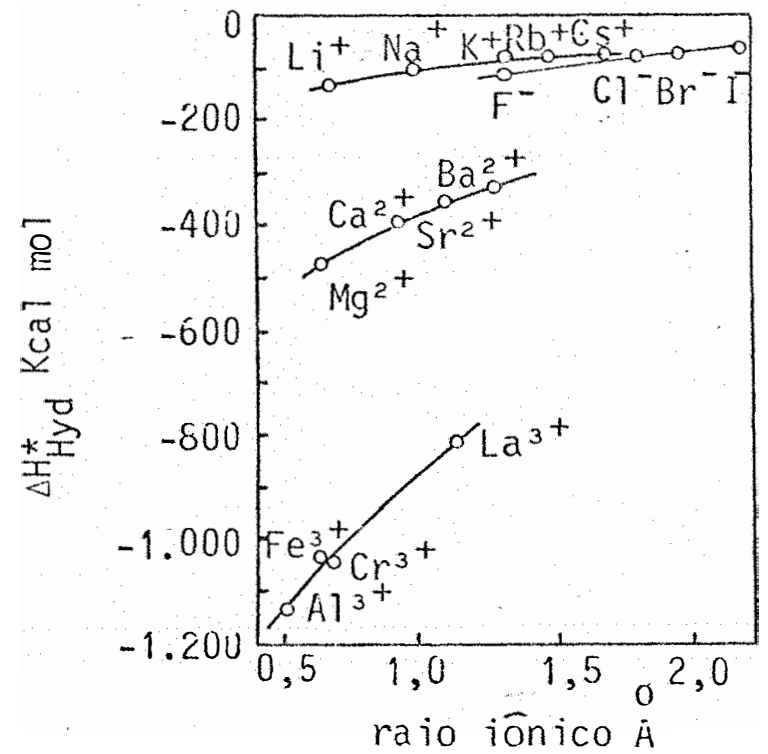

Figura 1 - Entalpia de hidratcção absoluta $\left(\Delta_{h y}\right)$ em função do raio iónico (HARVEY e PORTER, 1967, pg. 327). 
2.3. Modelos matemáticos para movimento da āgua nos solos

A àgua mové-se sempre que existirem diferenças de potencial total $\psi$ da āgua nas diferentes partes dentro do sistema. Este movimento dá-se no sentido do decréscimo do potencial $\Psi$, isto $\bar{e}$, do potencial maior para o menor.

equação matemātica que descreve este movimento em forma de den sidade de fluxo, apesar de suas limitacões, é a equação de Dar cy.

$q=-K \nabla \Psi^{\prime \prime}$

onde:

$q \bar{e}$ a densidade de fluxo de àgua $\left(\mathrm{cm}^{3} / \mathrm{cm}^{2} \mathrm{~s}\right)$

K condutividade hidrāulica do solo (cm/s)

$\nabla \psi \bar{e}$ o gradiente de potencial ( $\mathrm{cm} / \mathrm{cm}$ )

A equação 2.89 mostra que a densidade de fluxo é uri volume $Q$ de āgua que passa por unidade de tempo pela unidade de ārea da seccão transversal ao sentido do fluxo. Portanto, podemos escrever:

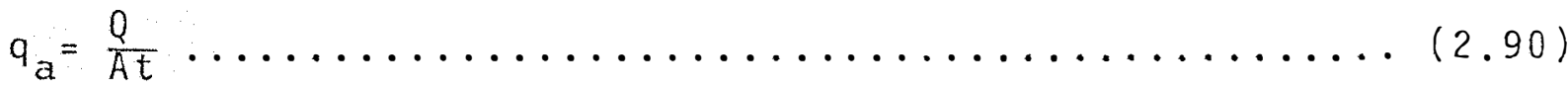
onde:

A àrea da secção transversal $\left(\mathrm{cm}^{2}\right)$

$t$ tempo (s) 
Pela análise dimensional, ela representa uma velocidade. Entretanto, ela não é uma velocidade que a água se move pelo solo. A velocidade real $v$ da água no solo é o volume de água a que passa por unidade de tempo pela área disponível ao fluxo, isto é, pela seç̧ão transversal dos poros. para um solo saturado, esta secção transversal dos poros é o produto de área efetiva A pela porosidade do solo. Desta forma, equacionando temos:

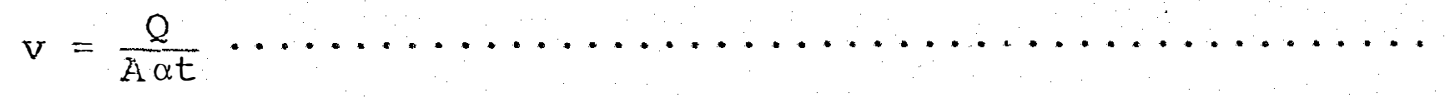

substituindo a equação 2.90 em 2.91 verifica-se que

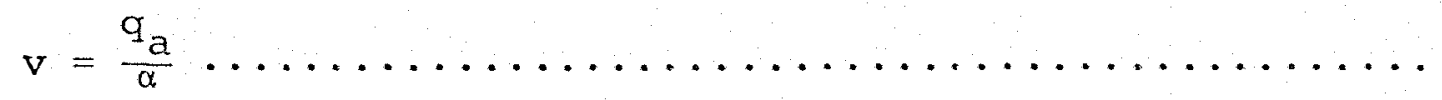

O gradienté de potencial $\nabla \Psi$ é definido no sistema cartesiano nas três dimensões $x, y$ e $z$ pela equação $\operatorname{grad} \psi^{\prime}=\quad=\frac{\partial \psi}{\partial x}+\frac{\partial \Psi}{\partial y}+\frac{\partial \psi}{\partial z} \cdots \ldots \ldots \ldots \ldots \ldots \ldots \ldots \ldots \ldots$

E fácil de verificar que ela representa a variação do potencial $\psi$ ao longo da direção x, y ou z.

O coeficiente de proporcionalidade $k$ é $a$ condutividade hidráulica e pode ser definido pela relação entre o fluxo e o gradiente, cujo o sinal menos indica unicamen... te o sentido do fluxo que é inverso do gradiente.

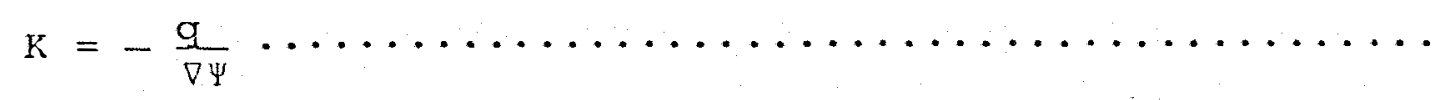




\subsubsection{Deslocamento miscível}

Existem vārios modelos matemäticos

qุue tentam descrever o deslocamento miscivel, em que a solucão des locadora é colocada de maneira continua dentro do solo ou em intervalos de tempos. Nos experimentos normalmente interessa o comportamento de um soluto contido na solução deslocadora ou na solução deslocada, tendo ou não este soluto reaçöes com o solo e transformações quîmicas e ou biolögicas, resultando em processos de perdas e ganhos.

De modo genérico, o soluto dentro de úm meio poroso qualquer, pode-se movimentar por difusão e por flu xo de massa, além de estar sujeito a outros processos de perdas e ganhos como sorção e ou transformações químicas e biológicas .

A difusão é déscrita pela equação deFick:

$q_{D}=-D \nabla(C \theta)$

onde:

$q_{D}=$ fluxo do soluto por difusãonosolo (g soluto/cmen ${ }^{2}$. s)

$D=$ coeficiente de difusão do soluto no solo $\left(\mathrm{cm}^{2} / \mathrm{s}\right)$

$\dot{\nabla}(C \Theta)=$ grádiente de concentração do soluto ( $\left(\mathrm{Cm}^{3} / \mathrm{solc}_{1}\right)$ 
o movimento do soluto ocorre devido a diferenca de concentraçäo entre os dois pontos na solucäo do so10. Desse modo, se a difusão ocorrer e a umidade do solo permanecer constante, a equacão 2.94 pode ser reescrita em um movimento unidirecimal:

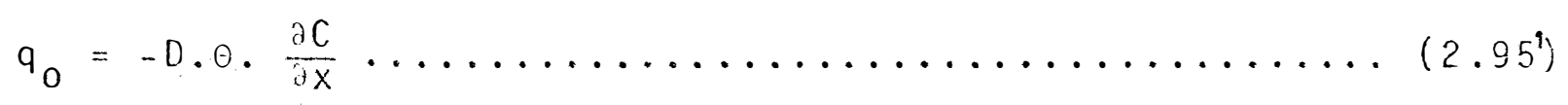

onde:

$\Theta=$ umidade do solo ( $\mathrm{cm}^{3}$ àgua $/ \mathrm{cm}^{3}$ solo)

$C=$ concentração do soluto ( $\mathrm{g}$ soluto $/ \mathrm{cm}^{3}$ soluto)

Por outro lado, se a umidade não for cons tante, o soluto poderá movimentar devido ao fluxo de massa, 10 go:

$q_{m}=q^{\prime}$.

onde:

$q_{m}=$ fluxo do soluto no solo devido ao fluxo de massa (g soluto/ $\mathrm{cm}^{2}$ solos. s)

$q^{\prime}=$ fluxo de massa da soluçăo no solo, equação 2.39. $\left(\mathrm{cm}^{3}\right.$ de solução/ $\mathrm{cm}^{2}$ solo s) 
0 fluxo total do soluto no solo $q_{T}$ (g soluto/ $\mathrm{cm}^{2}$ solo. s) pode ser estimado pela soma dos fluxos devi do a difusão $\left(q_{D}\right)$ e fluxo de massa $\left(q_{m}\right)$ :

$q_{T}=q_{D}+q_{m}$

ou

$q_{T}=-D \cdot \theta \cdot \frac{\partial C}{\partial x}+q^{\prime}$

Aplicando a equacão da continuidade podese obter a variação da concentracão do soluto em funcão do tem po em um elemento de volume do solo.

$\frac{\partial(C \theta)}{\partial t}=\frac{\partial q_{T}}{\partial x}$

ou substituindo a equação 2.96 em 2.97:

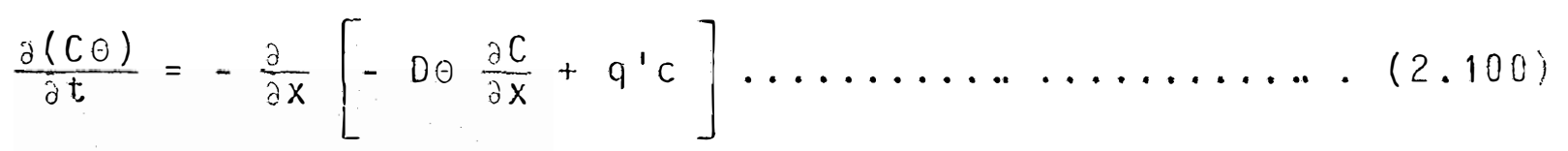

Normalmente, o estudo de deslocamentomiscivel é realizado com solo em condicões de equilíbrio dinâmico saturado ou não, onde a umidade $\Theta$ e tambēm o fluxo de massa de solucão do soluto q' no solo se mantém constantes durante o ex perimento. Isto é feito devido ao grande nūmero de variāveis jā em estudo, como difusão, fluxo de massa, adsorcão, dessor - 
cẫo, troca iōnica, insolubilizacão, solubilizacão, precipitacão etc que dificultaria demais a solucão matemātica.

$$
\text { A equação } 2.100 \text { pode ser reescrita se as }
$$

condicões de fluxo da solucão e umidade for constante, da seguinte forma:

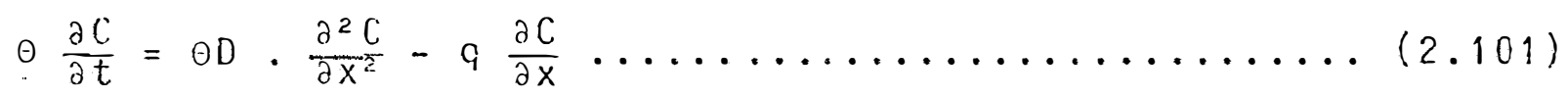
ou

$\frac{\partial C}{\partial t}=D \frac{\partial^{2} C}{\partial x^{2}}-\frac{q}{\theta} \frac{\partial C}{\partial x}$

0 fluxo de massa da solucão do soluto no solo ( $\mathrm{q}, \mathrm{cm}^{3}$ de solucão $/ \mathrm{cm}^{2}$ de solo. s) dividido pela ärea disponĩvel ao fluxo $\left(\mathrm{cm}^{2}\right)$, corresponde à velocidade da solucão do soluto e do prōprio soluto nos poros do solo na direcão do movimento ( $\mathrm{v}, \mathrm{cm} / \mathrm{s}$ ) (NIELSEN et alii a972, p. 37 ; KIRKHAM e P WERS, 197\%, p. 400; NIELSEN e BIGGAR, 1962).

$v=\frac{q}{\Theta}$

Não havendo reacão entre o soluto e o so1o, a velocidade de deslocamente do soluto nos poros do solo ( $v, \mathrm{~cm} / \mathrm{s})$ é a prōpria velocidade da āgua nos poros $\left(\mathrm{v}_{\mathrm{H}_{2} \mathrm{O}}, \mathrm{cm} / \mathrm{s}\right)$.

$$
\mathrm{v}_{\mathrm{H}_{2} \mathrm{O}}=\mathrm{v}
$$


A equaçăo 2.101 pode ser reescrita, en termos de velocidade do soluto nos poros do solo:

$$
\frac{\partial C}{\partial t}=D \frac{\partial^{2} C}{\partial x^{2}}-v \frac{\partial C}{\partial x}
$$

$$
0 \text { segundo termo à direita da equacão }
$$

2.105) corresponde ao fluxo de massa, dando a posicão da frente ("front") da solução deslocada que se move pelo solo, enquanto que o primeiro termo a direita, corresponde a difusão, dancio na realidade a dispersão do soluto ou a espessura de transicão (BIGGAR e NILSEN, 1976).

No presente trabalno è desprezivel o primeiro termo a direita em relação ao fluxo de massa devido ão tipo de experimento conduzicio em coluna de solo com efluxo livre.

\subsubsection{Aplicaçöes}

As referẽncias remontam a LAPIDUS e AMUND SON (1952) como um dos primeiros a estudar a movimentacão dos solutos em colunas de cromatografia e troca iónica, apresentan do um modelo matemātico envorvendo fluxo de massa, difusão e adsorção (KASTEN et alii 1952).

Subsequentemente, NIELSEN e BIGGAR (1961, $196 \check{c}$, 1962b, 1962c) efetuaram vārios experimentos e desenvol- 
veram os modelos matemäticos tratando sobre deslocamento misci vel com colunas de solo e esferas de vidro (NIELSEN e BICGAR 1961, 1962) em condicõos cie equilî́brio dinämico saturado e não saturado, com diferentes velocidades de infiltração de āgua. Apresentaram resultados de movimentação de $\mathrm{Cl}^{-}$, concluindo que as curvas de eluicão dependem da velocidade da āgua e da difu são do soluto, podendo também ser afetados pela adsorcão e tro cas ünicas.

AVINIMELECH et alii (1970), estudaram o deslocamento do cătion $\mathrm{K}^{+}$, por uma solucão saturada de $\mathrm{CaSO}_{4}$, em coluna de solos e apresentaram um modelo matemático, para descrever esse movimento.

JURY (1982) desenvolveu um modelo matemätico para transporte de solucão atravēs do solo, ignorancio a influéncia da dispersão do soluto. Considerando que a distri buição do soluto assume um processo físico com a contribuicão da densidade de fluxo, propós uma equação matemätica para predizer as concentracões nas diferentes profundidades do solo:

$C_{(Z, I)}=\int_{0}^{\infty} C_{I N}\left(I-I^{\prime}\right) \frac{L}{Z} f_{L}\left(\frac{I^{\prime} L}{Z}\right) d I^{\prime} \ldots \ldots \ldots(2.106)$

onde

$C_{(Z, I)}=$ concentrações a profundidade $Z$, com quantidade I de àgua aplicada ao solo.

$c_{(I N)}=$ concentração inicial

$f_{L} \quad=$ densidade de fluxo 
A resolucão da equacăo 2.106 necessita de uma sērie de condicŏes de contorno, muitas vezes de dificil so lucão. A resolução proposta, foi utilizando distribuicão lognorimal estatistica da seguinte forma:

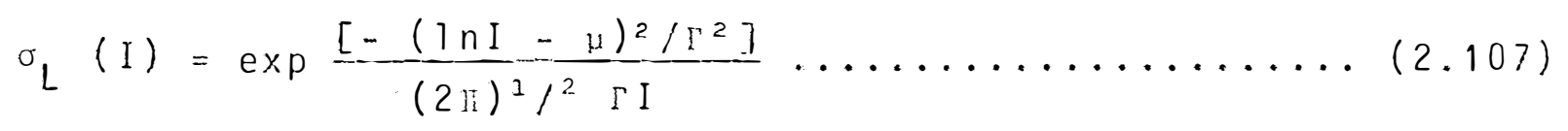

onde:

$\mu$ é a distribuição de $\ln$ I

$\Gamma^{2} \bar{e}$ a variança

Substituindo a equação 2.107 em 2.106 e considerando a aplicação uniforme da àgua e com as seguintes condiçoes de contorno:

$$
\begin{array}{ll}
C_{\text {IN }}=0 & I<0 \\
C_{\text {IN }}=C_{0} & \text { I }>0
\end{array}
$$

chegou-se a seguinte equaça:

$C_{(Z, I)}=\frac{C_{0}}{2}\left(1+\operatorname{erf}: \frac{[\ln (I L / Z)-\mu]}{(2)^{2} /^{2} \Gamma}\right) \ldots \ldots \ldots \ldots(2.108)$

$$
\text { Aplicando a equação } 2.108 \text { JURY et alii }
$$

(1982) estudou o transporte do $\mathrm{Br}^{-}$nas condicões de campo, colocando extratores. Os resultados experimentais encontrados es täo bastante prōximos dos calculados. 
Os ensaios realizados foram com anions, e sem caracteristicas físicas e quimicas dos solos, das quais fo ran dificeis de serem avaliados a aplicabilidade da equação.

Um outro modelo foi desenvolvido utilizan do cālculo numërico por BRESLER e R.J. HANkS (1969) para estimar as concentrações de sais com um fluxo simultāneo de àgua e condiçöes de inundação e umedecimento, o modelo proposto, vi sa estimar a concentração de $\mathrm{NaCl}$ ao longo da coluna de solo.E um método que necessita do auxilio de um computador para cálcu 10, caso contrārio torna-se moroso. Um outro método por proces so iterativo foi proposto por PINDER e COOPER (1970) para cälculo do "front" do sal.

A translocaçăo de metais pesados em uma ärea florestal foi realizado "in situ" tratando o local do experimento com lamas de esgotos, por um periodo de 15 meses por SIDLE e KARDOS (1977).

Os resultados mostraram que a mobilidade dos metais estão na seguinte ordem nos primeiros $120 \mathrm{~cm}$ de pro fundidade:

$\mathrm{Cd}>\mathrm{Zn}>\mathrm{Cu}$

Nas anālises de outros elementos tais como $\mathrm{Cr}, \mathrm{Pb}, \mathrm{C}_{0}$ e $\mathrm{N}_{i}$ verificou-se um incremento até os $7,5 \mathrm{~cm}$ de profundidade. 
AMOOZEGAR-FARD ot aliz (1984) apresentou um modelo matemätico aproximado para prever os movimentos dos metais poluentes utilizando a teoria desenvolvida por LAPIDUSAMUNOSON (1952). Os estudos estäo correlacionados a um elemento metālico com as composicöes granulomētricas e químicas do solo, portanto, numa equacão específica para cada caso de metal e por solo.

Os estudos realizados por ALESSII et ali: (1980) em colunas de solos 1 ixiviados com solutos provenientes da fermentacão de resĩduos urbanos ( 1 ixo), mostram que apōs quatro vezes o seu volume de poros, a concentracão $C / C_{0}$ do efluxo é aproximadamente igual a 1. Entretanto, existem outras correlacões para que $C / C_{0}=1$ sejam sempre com volume de lixiviaça constante, para qualquer tipo de solo ou metais poluentes. São discutidos vários fatores, tais como a CTC, complexacões e reações químicas. Na maioria dos solos, para o Cd atin gir a concentração inicial no efluxo é necessärio lixiviar de 4 a 12 vezes o volume de poroṣ.

SIDLE et alii (1977) também estudou a translocacão dos metais pesados tratados com lamas de esgoto em uma área florestal por 168 e 196 dias, aplicando a equacão de Freundlich, tendo encontrado resultados razoáveis até a pro fundidade de $15 \mathrm{~cm}$. Para translocacão até $120 \mathrm{~cm}$, indicam outros processos envolvidos como quelacão dos compostos durante a translocação. 
BRESSLEF e HANKS (1969) desenvolveu um modelo teōrico pelo mētodo de cá culo numérico, formando a equaç̃̃o

$\left[d Q / d_{t}\right]_{x}=\left[-D_{p}(d C / d x)+\bar{v} \theta C+s\right]_{x}$

onde:

$Q$ = quantidade de soluto transferido por unidade de ārea

$t=$ tempo

$D_{p}=$ coeficiente de dispersão Efetiva do soluto

$C=$ concentração do soluto

$x=$ a distāncia no sentido do fluxo

$\bar{v}=$ velocidade mëdia da solução

$\Theta \quad=$ umidade em volume

s = quantidade do soluto adsorvido

Para o diesenvolvimento da equação 2.109 o autor desprezou o termo $D_{p}(d C / d x)$ e s chegando-se a equacão $\sum_{i=1}^{K}[C \ominus]_{i}^{j} \Delta x-\sum_{i=1}^{K}[C \Theta]_{i}^{j-1} \Delta x=[q C]_{i=0^{\prime}}^{1-1 / 2}-[q C]_{i=K}^{1-1 / 2} \Delta t^{1-1 / 2}$

Esta equação foi aplicada para uma solucão de $\mathrm{NaCl}$ e demonstrou ser razoável os resultados entre o calculado e experimental. Porém è discutivel em casos onde a adsorcäo esteja presente, pois os termos foram desprezados para o desenvolvimento da equação (2.110) 
2.4. Considerações teōricas sobre adsorçäo

A adsorcão é entendida pera maioria dos quimicos, como foi observada em 1.773 por C.W. Scheele e F. Fontana 1.777 e outros conforme GLASSTONE, (1946 p. 1.075) ao fenómeno de adsorção de um găs em sōlido como carvão poroso. As sim, o solvente é encarado simplesmiente como veículo do soluto. Por esta razão, os primeiros pesquisadores determinavam a massa adsorvida atravēs da variacão a composicăo da solucão. Designado por $C_{i}$ a concentracão inicial do soluto (g/l) e por $C_{f}$ a concentracão final, a massa adsorvida $x(g)$ era calculada co mo:

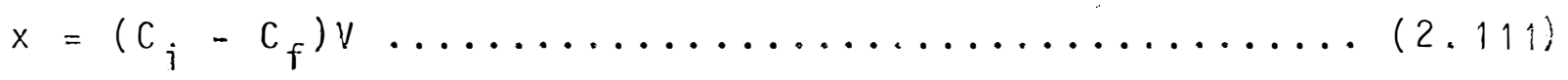
ou

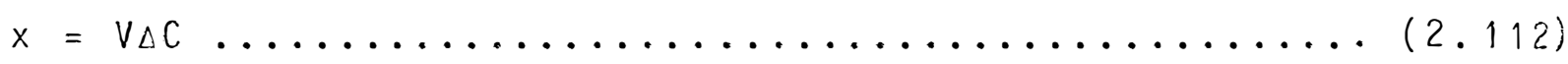

Entretanto as evoluçöes das tēcnicas expe rimentais posteriores exigiram melhor exposicão do fundamento teórico, uma vez que estas não mais satisfaziam os dados experimentais. Assim, apareceram vārias propostas das quais, trata remos a seguir, as mais conhecidas. 


\subsubsection{Estudo geral da isoterma de adsorção}

Os cälculos da massa de acorcio com a equa cão c. 111 apresentam valores corretos para baixas concentracöes de equilíbrio, desde que não haja adsorção do solvente. A medida que foram exploradas faixas mais longas de concentracão verificou-se que as isotermas resultantes não estavam de acordo com a hipötese gratuita de adsorção exclusiva do soluto. A utilização de sollicões com concentraç̃es crescentes de soluto, mostrou a existēncia de comportamentos de sistemas que não poderiam ser descritos em termos de equacão de Fremalich ou Lang muir.

A isoterma para adsorcão de soluções aquo sas de àcido acētico apresenta o aspecto mostrado na Figura $2(a)$, quando analisamos o sistema em toda faixa de fracões molares, utilizando carvão como adsorvente. Existe um māximo e um minimo na isoterma, ao invēs de um patamar levemente ascendente ou não da equacão de Langmuir. Nas solucões aquosas de àlcool etîlico mostram um comportamento ainda mais estranhāvel numa primeira añilise. A Figura 2(b) (ālcool etîlico) evidencia a existência de um māximo e um trecho de adsorcão negativa. Esses resultados parecem insōlitos unicamente porque a adsorcão de solutos não é entendida devidamente. Neste caso, é impossível o paralelo que se tenta estabelecer com a adsorcão de gases puros. Na isoterma de adsorcão de gases, tem na ordenada 
a quantidade de massa ou volume adsorvido, porēm na adsorcão do soluto, o que se mede experimentalmente è a variacão da con centração da solucão, resultanté do fenömeno de adsorcäo, cuja grandeza que figura na ordenada $\bar{e} n_{0} \Delta x / m$.

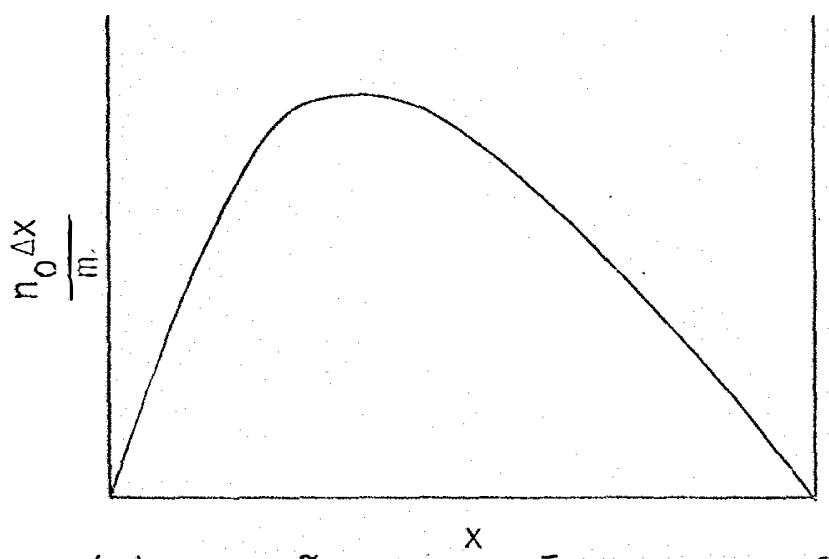

(a) adsorção acido acētico en carvão

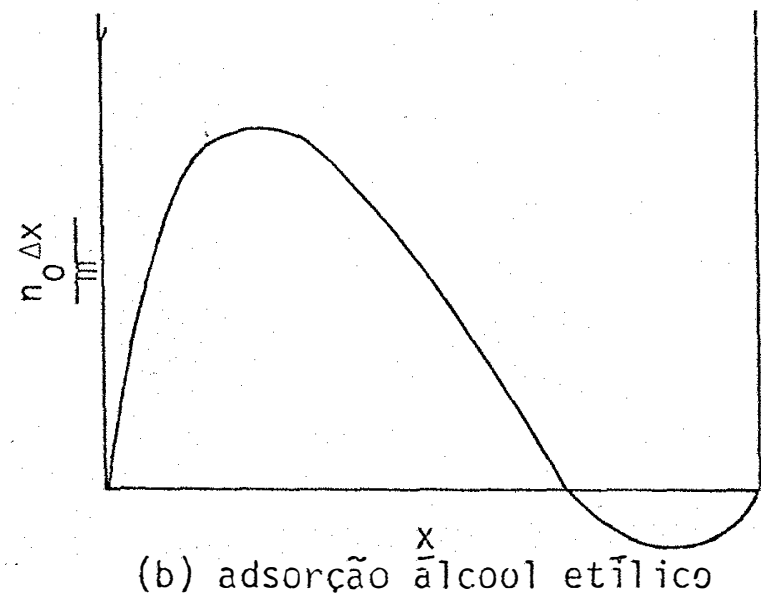

Figura 2 - Isotermas de adsorcăo que apresentam máximos e mīni mos. 
Como serä visto, mesmo que não exista a adsorcão do solvente, o paralelo é totalmente desprovido de sentido, excetuando-se aos sistemas que limitam às pequenas concentracões.

0 significado de isotermas do tipo indica do na Figura 2(b) pode ser entendido se considerarmos a possibilidade de adsorcão do solvente. Na primeira parte da faixa de fraçöes molares, um componente é adsorvido preferencialmente en relacão ao outro. Isto significa que, no equilibrio, êle estā presente na camada adsorvida em maior proporcão do que na fase macica (ou volumētrica). Por outro lado, na faixa de fracões molares igual a 1 , existe adsorção negativa de outro componente considerado, indicando a adsorcão preferencial do outro componente (o solvente). Para liquidos completamente misci veis, a ordenada da isoterma deve ser zero em ambas as extremi dades da faixa completa de fracões molares $(x=0, x=1)$, pois não é possĩvel a variação da composicão nesses dois pontos.

Tratando-se de līquidos completamente mis civeis as designações soluto e solvente não tem mais razão de ser, sendo preferível designar os componentes numericamente de 1 e 2.

Para constituir uma base formal para a teoria da adsorcão dos componentes de uma solucão é imprescindível o estabelecimento de dois conceitos: 


\section{a. adsorcão preferencial ou seletiva}

E obtida das pröprias determinacōes experimentais das variacões de composicão da solucão. E uma medida do empobrecimento ou diminuicão da fase volumētrica (solucão), em relacão a um componente, decorrente do enriquecimento da fa se superficial em relacão ao mesmo componente, por unidade de àrea ou massa do adsorvente. Corresponde a conceito de excesso superficial que figura no tratamento de Gibbs da Termodināmica das superfícies (MOORE, 1962 p. 865).

b. adsorcão absoluta ou solucão de um componente individual

E a quantidade desse componente adsorvida por unidade de ārea ou massa de adsorvente. E portanto, uma "concentração superficial".

o primeiro conceito é utilizado em aplica ções prāticas. O segundo conduz, todavia, a um melhor entendimento do fenōmeno de adsorcão.

As isotermas experimentais correspondem à adsorcão preferencial ou seletiva. Para evitar a ambiguidade, foi sugerida a denominacão isoterma da variacão da concentra cão. Apesar da precisão deste nome, o uso subsequente consagrou o emprego da denominacão isoterma composta.

As isotermas que levam em conta a adsorcão absoluta são denominadas isotermas individuais.

Para estabelecer a relacão entre as adsor cões segundo os dois conceitos, é necessārio efetuar um balan- 
co de material. Quando a massa m de sōlido é colocada em conta to com no moles de solucão, a fracão molar do componente 1 decresce de uma quantidade $s x$. Essa alteração decorre da adsor cäo pelo sōlido de $n_{1}^{j}$ moles do componente 1 e $n_{2}^{j}$ moles do componente 2, por unidade de massa do adsorvente. No equilibrio, permanecem na fase volumëtrica (fase macica ou solucão) n moles do componente 1 e $n_{2}$ moles do componente 2 , resultando numa fração molar x para o componente 1.

seja $x_{0}$ a fração molar do componente 1 , no inĩcio da experiência. Segue-se que:

$n_{0}=n_{1}+n_{2}+n_{1}^{j}+n_{2}^{j} n_{1}$

$x_{0}=\frac{n_{1}+n_{1}^{j} m}{n_{0}}, x=\frac{n_{1}}{n_{1}+n_{2}}$ e $1-x=\frac{n_{2}}{n_{1}+n_{2}} \ldots \ldots$

e

$\Delta x=\left(x_{0}-x\right)$

substituindo, 2.114 em 2.115 , resulta

$\left.\Delta x=\frac{n_{2}}{\left(n_{1} n_{1}-n_{1}\right.} n_{2}^{j}\right)^{j}$

ou rearranjando a equacão 2.116 , temos

$\frac{n_{0} \Delta x}{m}=n_{1}^{j}(1-x)-x n_{2}^{j}$ ou $\frac{n_{0} \Delta x}{m}=n_{1}^{j} x_{1}-n_{2}^{j} x_{2} \ldots \ldots(2.117)$ 
onde:

$x_{1}$ e $x_{2}$ são as fracöes molares dos componentes 1 e 2 na fase volumetrica.

A isoterma composta é por vezes expressa em temos de $x_{1}^{j}-x_{1}$ onde $x_{1}^{j} \bar{e}$ a fracão molar do componente 1 na fase superficial (camada adsorvia). Essa forma enfatiza a adsorcão preferencial de um componente e pode ser facilmente relacionada equaça anterior:

$x_{1}^{j}-x_{1}=\frac{n_{1}^{j}}{n_{1}^{j}+n_{2}^{j}}-x_{1}=\frac{1}{n^{j}} \frac{n_{0} \Delta x}{m}$

onde:

$n^{j}$ ē o nümero total de moles na camada adsorvida por umidade de massa do sōlido.

Uma equação anāioga a equacão $2.11 \hat{8}$ pode ser obtida em termos de massas e fracões de massa:

$\frac{w_{0} \Delta C}{m}=w_{1}^{j}(1-v)-w_{2}^{j} C$

onde:
$w_{0}$
é a massa inicial do lĩquido colocado em contato com uma massa m do adsorvente
C a fração da massa no equilíbrio 
$w_{1}^{j}$ e $w_{2}^{j}$ massas dos dois componentes adsorvidos por umidade de massa do adsorvente

A equação 2.119 é especialmente ūtil quan do a massa molecular de um componente não é conhecida.

E interessante, em determinados problemas, conhecer a correlacão entre $n_{0} \Delta x / m$ e $w_{0} \Delta C / m$. Esta correlacão $\bar{e}$ facilmente obtida expressando as fracões molares em termos das fracões de massas moleculares e colocando os nūmeros de moles adsorvidos em termos das massas adsorvidas e das massas molecu lares. Obtēm-se:

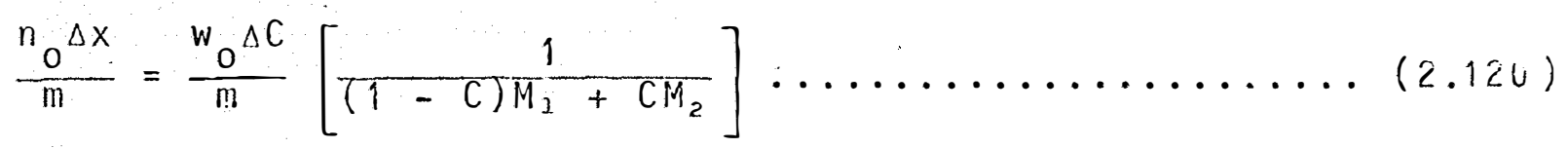

onde:

$M_{1}$ e $M_{2}$ são as massas moleculares dos componentes 1 e 2

0 emprego das formas volumētricas de expressar a composicão das soluções (g/l ou moles/l) não é recomendada a não ser para as soluções aquosas extremamente diluídas. Ainda neste caso, a conversão nas formas ponderais de expressão é bastante trabalhosa, enquanto não induza a imprecisões sensiveis dos resultados. Para soluções diluídas com solventes orgānicos, o emprego è menos satisfatōrio, pois a massa 
molecular mais elevada de tais solventes, faz com que, para uma dada molaridade, se tenha fracão molar do soluto muito maior do que a que se teria com solucões aquosas.

Partindo-se de formas postuladas para as isotermas individuais, è possĩvel calcular as isotermas compos tas resultantes. Ostwold e Izaguirre, conforme trabalho de KIPLING (1960), realizaram estas sinteses, onde são mostradas na Figura 3 seis exemplos de tais sinteses. A adsorcão "negativa", só pode ocorrer se houver adsorção do solvente. Contudo, ē bom frisar que a adsorção do solvente é condição necessāria mas não suficiente para existēncia da adsorcão "negativa". 


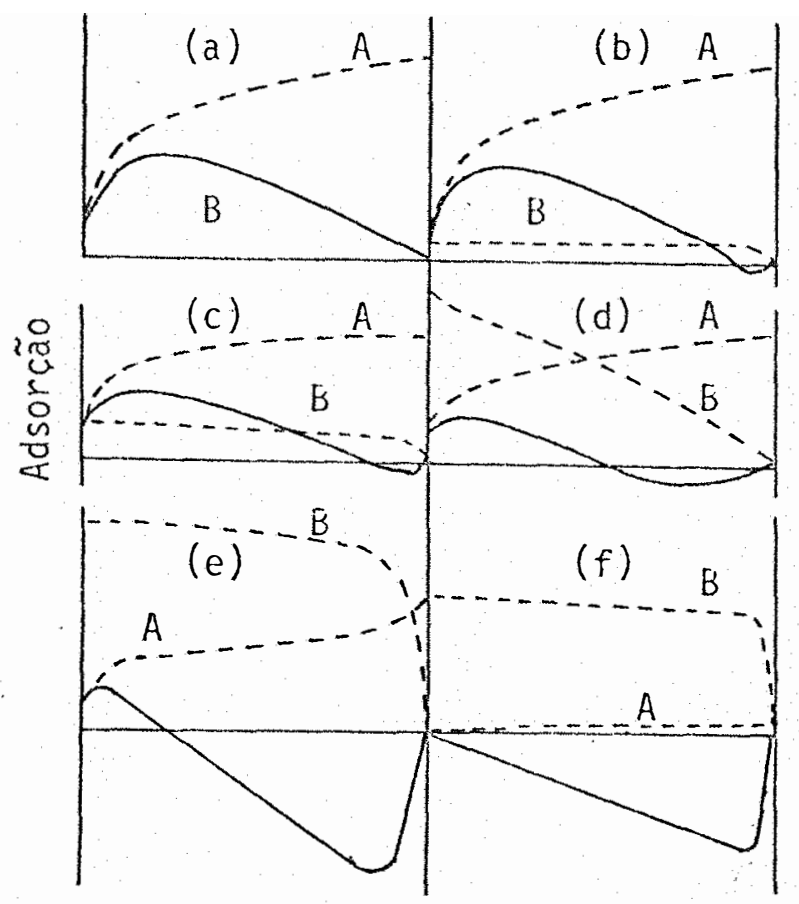

Concentração

Figura 3 - Isotermas de adsorção compostas e individuais Linhas cheias - Isoterma composta

Linhas interrompidas - Isoterma individual

A - soluto

B - solvente 
Por outro lado, podemos ver que pode exis tir um máximo na isoterma composita, mesmo quando inexiste adsorçăo de solvente $\left(n_{z}^{j}=0\right.$ para toda a faixa de fracöes mola res). Nestas condiçoes a equacão 2.117 forma-se:

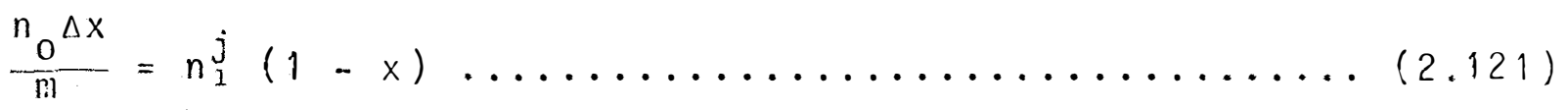

e o valor decrescente de $(1-x)$ ocasiona um decréscimo linear no valor de $n_{0} \Delta x / m$ se $n_{I}^{j}$ for constante, a partir de um dado vâ lor da fracão molar (por exemplo pela formacão de uma monocama da completa).

Na prática, o principal interesse reside na operacão inversa dessas sinteses. A experiência fornece iso termas compostas e o problema está em desdobrā-las em isoter mas individuais.

Para a discussão dos resultados experimen tais do presente trabalho é suficiente a consideracão de siste mas em que a solucão è obtida pera dissolucão de um sōlido lou sal), apresentando, portanto baixos limites de solubilidade em termos de fracão molar (ou meq). 
2.4.2. Adsorcäo dos solutos obtidos pela dissolução de um sölido

No estudo abrangido pela designaçà acima, os aspectos mais importantes para o perfeito entendimento do fenômeno são:

- o aspecto da isoterma,

- o "grau" de adsorcão do solvente,

- o significado do patamar encontrado em muitos sistemas,

- a possibilidade da existéncia de multicamadas,

- a possibilidade de existēncia de adsorcão quĩmica,

- a adsorcão de um seguncio soluto presente na solucão, e

- a adsorção de solutos iônicos.

0 aspecto mais frequente da isoterma com. posta para tais tipos de sistemas è o mostrado na Figura 4. A equacão de Freundlich normalmente ë aplicāvel a baixas concentracões do soluto. A equação de Langmuir, no estudo das adsorcões dos liqquicios completamente miscíveis é questionāvel, ve rificou-se ser sólida para adsorção de soluções contendo solutos sōlidos. Não existe, todavia, uma justificação amplamente vālida para a aplicabilidade da equacão de langmuir em tais sistemas. Um tratamento cinētico foi proposto, cuja validade estā assentada na inexistència da competicão do soluto e do solvente pela superfície do adsorvente. 
.56 .

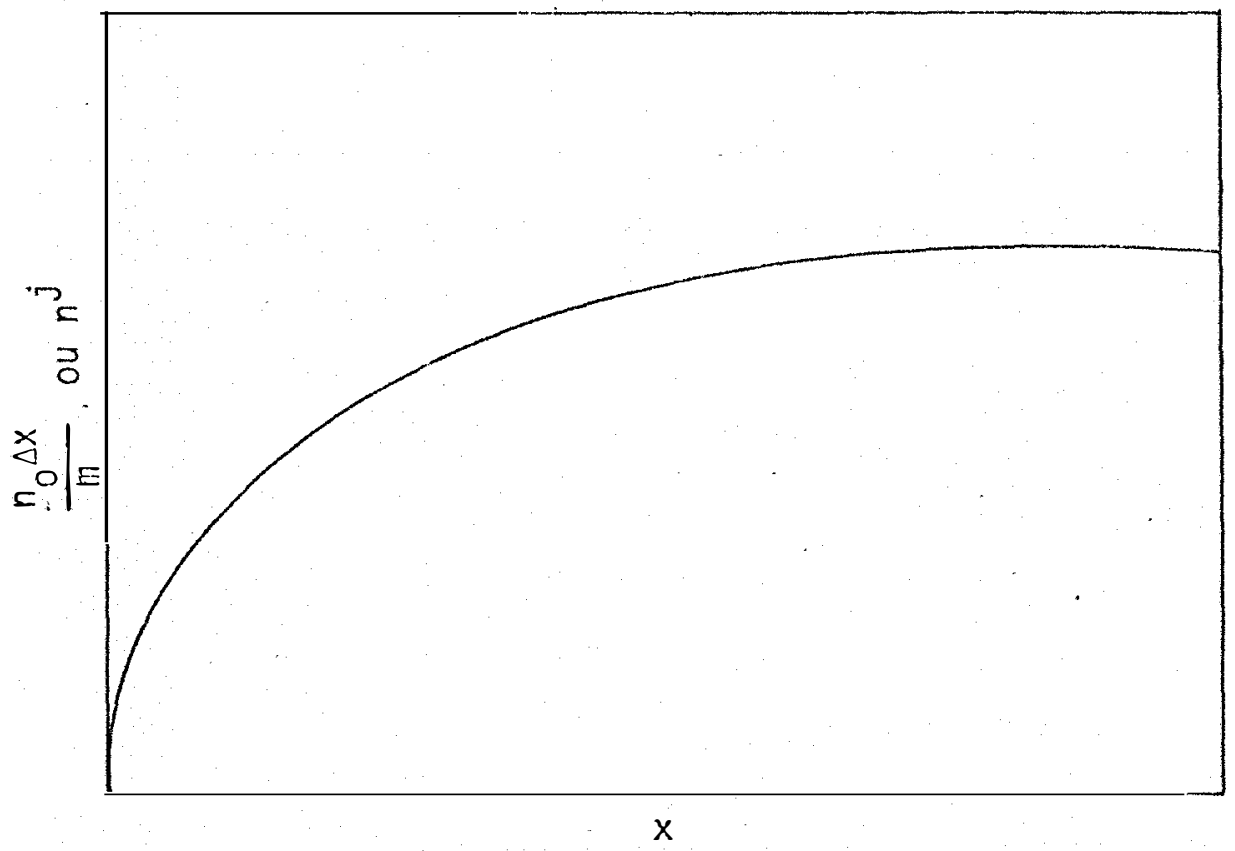

Figura 4 - Aspecto tîpico da isoterma de adsorção de soluções obtidas pela dissolucão de solutos sōlidos. 
Evidentemente, ē desprovido de sentido pa ra muitos sistemas.

FRANGISKOS et alii (1961) considerou que uma methor adaptaça aos dados experimentais seria conseguida por uma equação de très constantes e propós:

$x / m=k-(k-a) e^{B C}$

sendo

$K$, a e B constantes

e

base do logaritmo natural

A constante $K$ fornece o valor da assintota. Além disso, $x / m$ pode ser diferente de zero na origem, desde que a seja diferente de zero, prevendo, portanto, o caso da coexistēncia de adsorcão física e adsorcão química. Em geral, uma tal equação deve ser melhor adaptāvel aos dados experimen. tais, do que uma equaça com duas constantes.

Resta verificar, na proposta acima se $\bar{E}$ possivel obter um significado para tal equação, jä que fara as equações de Freundlich e Langmuir não foi de todo atingido esse objetivo.

A adsorcão do solvente pode ocorrer como mostra a equacão 2.11.7. Se admitirmos que a fase adsorvida seja constituída por uma monocamada compacta, na qual simplesmen 
te ocorre o desalojamento das espécies adsorvidas, uma pelas outras, $n_{1}^{j}$ e $n_{2}^{j}$ logo, poderemos relacionar:

$$
\frac{n_{1}^{j}}{\left(n_{1}^{j}\right)_{m}}+\frac{n_{2}^{j}}{\left(n_{2}^{j}\right)_{m}}=1
$$

onde:

$\left(n_{1}^{j}\right)_{m}$ e $\left(n_{2}^{j}\right)$ representam os nümeros de moles dos componentes 1 e 2 necessārios a formação de uma monocamada completa sobre a unidade de massa do adsorvente.

$$
\text { o valor de }\left(n_{1}^{j}\right)_{m} \text { pode ser calculado a par }
$$
tir de uma orientação admitida para moléculas, com comprimentos de ligacão e àngulos de ligação provenientes de outras determinações. Não hā nenhuma maneira exata de estabelecer esta orientação e o grau de confiança de um arranjo postulado depen de das evidéncias circunstanciais que o suportam. Frequentemen te a adsorção do solvente não é considerada neste tipo de isotermas. Na Figura 5 é possível verificar que a isoterma compos ta é praticamente coincidente com a isoterma individual para adsorção de ācido lāurico dissolvido em tetracloreto de carbono, apesar da considerável adsorção do solvente (KIPLING e WRIGHT, 1962). Isto decorre facilmente da equação 2.114, tendo em conta que até o limite de solubilidade, a fracão molar do soluto é extremamente pequena, justificando que se escreva:

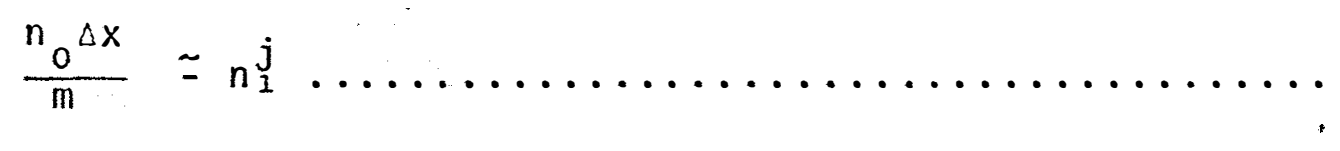


cuja aproximasão que deixa de ter sentido, quando a solubilida de do soluto no solvente é extremamente alta.

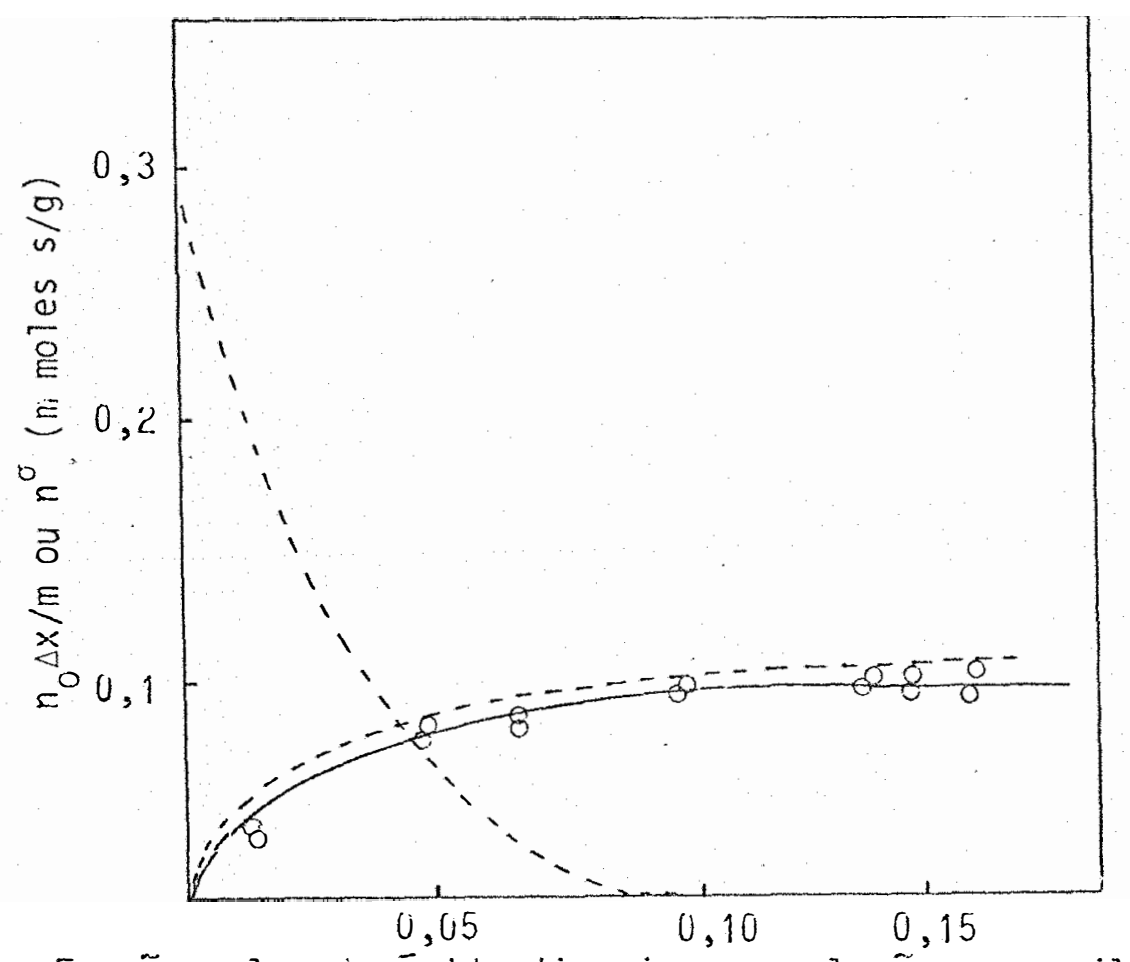

Fração molar cio ácido dimerico na solução en: equilíbrio

Figura 5 - Isotermas individuais e compostas para adsorçăo de soluções de ácido láurico em tetracloreto de carbono.

Linhas interrompidas - isotermas individuais

Linhas cheias - isotermas compostas

(KIPLING e WRIGHT, 1962) 


\subsubsection{Equação de Freundlich}

$$
\text { observou-se que os dados experimentais }
$$
ajustavan-se a isoterma de Freuncitich, expressa da seguinte for ma:

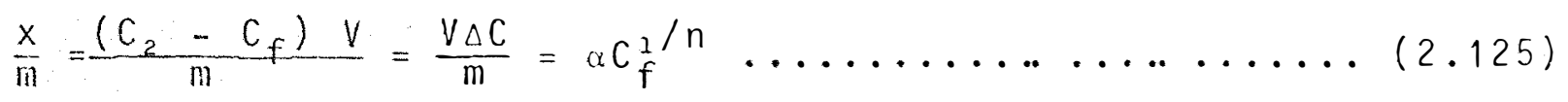

\section{onde}

$$
\begin{aligned}
& m \quad=\text { massa do adsorvente }(\text { g ou } 1) \\
& \text { a e } 1 / n=\text { constantes sendo } n>1 \\
& c_{f} \quad=\text { concentracão final no equilíibrio }
\end{aligned}
$$

A equação acima não foi Freundlich o seu introdutor, conforme relatos de FERRERONI (1972), embora leve seu rome, Kuster e Boedecker jä utilizavam equaçöes da mesmä forma.

\section{A concentracão final (ou de equilíbrio)} foi utilizada por Freundlich substituindo por pressão na adsorcão de gases em sōlidos e a massa determinada gravimetricamente. Ao tempo de Freundlich não havia fundamento teōrico para aplicacão da equacão, quer para gases ou para solucões, o que determinou certo atraso no conhecimento de ambos os tipos de adsorcão. A equação mostrou ser adequada em faixas limitadas de pressão ou concentração. 
A dedução da equação 2.125 pode ser feita mediante um tratamento semi-rigoroso combinando a expressão da energia livre de Helmholtz para a superficie, com a equação de adsorção de Gibbs. Este tratamento foi realizado por Henry.

Seja $\Gamma_{0}$ a energia livre superficial (por unidade de āreal para superfīcie em contacto com o solvente pu ro e r la energia livre da superficie coberta com uma monocamada completa do soluto. A fracão da superfície coberta represen tamos por $\theta$, logo a energia livre da superficie será:

$\Gamma=\Gamma_{0}(1-\theta)+\Gamma_{2} \theta=\Gamma_{0}-\left(\Gamma_{0}-\Gamma_{2}\right) \theta$

A fração $\Theta$ pode ser expressa em termos das quantidades adsorvidas, por unidade de massa do adsorvente, para cobertura parcial e para cobertura completa, portanto

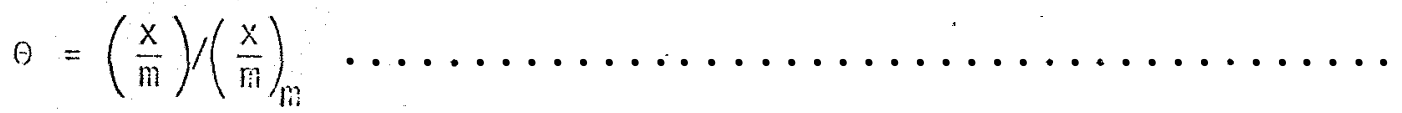

onde:

$\left(\frac{x}{m}\right)_{m}$ è a quantidade adsorvida quando se forma a monocamada com
pleta. 
Substituindo a equação 2.127 em 2.126 temos:

$\Gamma=\Gamma_{0}-\frac{\left(\Gamma_{0}-\Gamma_{1}\right)(x / m)}{(x / m)_{m}}$

Para solucões diluidas, $(x / m)$ pode ser igualado ao excesso superficial de Gibbs $r$, de tal modo que:

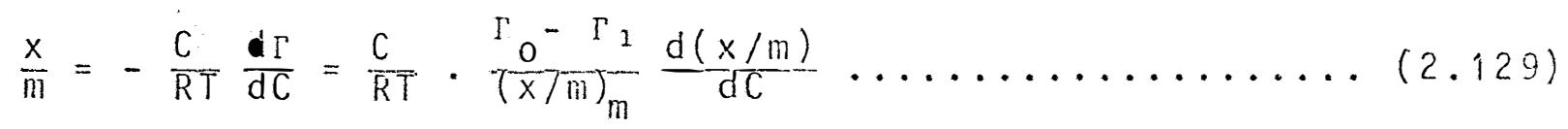
Integrando a equação 2.129 , obtem-se:

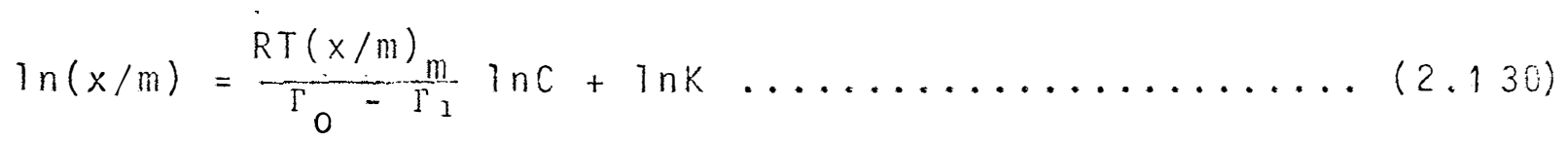
Como são constantes os termos:

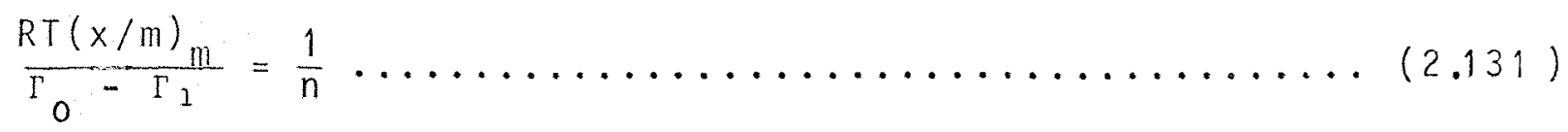
e substituindo a "equação 2.131 na 2.130 , chega-se na forma usual da equação de Freundlich.

2.4.4. Equạcăo de Langmuir.

As equacões baseadas na teoria cinética. apresentavam maior faixa de aplicabilidade e serviam para ambos os tipos de adsorção. 
Langmuir tinha a forma:

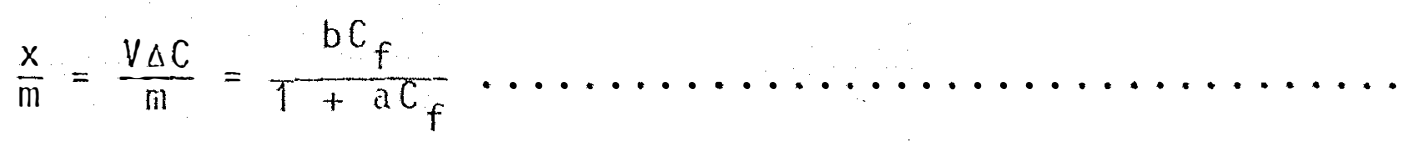

onde:

$a$ e b são constantes

$C_{f}$ a concentração final da solucão no equilïbrio

As isotermas de adsorção indicavam a massa adsorvida por unidade de massa, em função da concentração de equilibrio. As formas ponderais de expressar a composicão de solucões foram sempre preferidas em relacão às formas volumétricas, o grau de adsorcão era de preferéncia indicada por

$n_{0} \Delta x / m$

onde:

$\mathrm{n}_{0}=$ nümero inicial de moles da solucão $\Delta x=$ variação da fração molar do soluto

ou

$$
w_{0} \Delta x / m
$$


onde:

$w_{0}=$ massa inicial da solucão

$\Delta C=\operatorname{variacão~da~fração~da~massa~do~soluto~}$

BORZANI et alii (1974) apresentou um mode 10 modificado, baseado na teoria cinética.

Para discussão do presente trabalho serã adotada a forma da equacão 2.132 , pela facilidade de obtenção direta dos valores e tambēm na forma linear, para obtenção da adsorcão mäxima atravēs da equacão.

A sua forma linear è a seguinte

$C_{f} /(x / m)=1 / K b+\frac{1}{b} C_{f}$

onde:

$C_{f}=$ concentração final da solução de equilíbrio

$K=$ constante de afinidade entre adsorvente e adsorvato

$b=$ adsorção mäxima

2.4.5. Applicações

Estudo da capacidade de troca do cádmio adsorvido em solo areno-argiloso e limoso, na forma de $\mathrm{CdCl}_{2}$, com os cations $\mathrm{Al}^{+}, \mathrm{Ca}^{2}{ }^{+}$e $\mathrm{Na}^{+}$todos na forma de cloretos, em 
quatro concentrações de $24,43,84$ e 170 нeq $\mathrm{Cd} / 1$, foram efetuados por LAGERHERFF e BROWER (1972). Nas suas pesquisas, è notōria a competicão de todos os cātions com o cādmio, que com o aumento de sua concentração decresce a adsorcão do $\mathrm{Cd}^{2}{ }^{+}$. Tam bēm è notado que no tratamento com o $\mathrm{Na}^{+}$, para alcalinizacão do solo, não hä preciptação do $\mathrm{Cd}^{2}{ }^{+}$, e sua competicão é notada quando a concentração do $\mathrm{Cd}^{2}{ }^{+} \bar{e}$ abaixo de 43 ueq Cd/l. E discu tida baseada na teoria da ação das massas e valēncia-concentra cão, com a teoria de Gapon e de Eriksson. Entretanto a equação apresentada abaixo:

$C d / A T=K_{1}\left(\sqrt{C d_{0}} / \sqrt[3]{A T_{0}}\right)$

$C d / C a=K_{2}\left(\sqrt{c_{0}} / \sqrt{c_{a}}\right)$

onde:

$\mathrm{Ca}, \mathrm{Al}, \mathrm{Ca}$ são na fase adsorvida

$C d_{0}, A l_{0}, C a_{0}$ são na fase da solucão em equilíbrio

$K_{1}$ e $K_{2} \quad$ constantes

não é satisfatória para os resultados obtidos no seu trabalho.

KUO e BAKER (1980) estudaram sorção de cádmio, zinco e cobre em solos āridos, fazendo a sorçăo indivi dual de cada elemento e conjuntamente com os trēs elementosNão foi rotada grande diferença na sorcão $C_{u}$ em presença de outros 
dois elementos $Z$ n e $C d$, assim como na sorcão de $Z$ n em presenca de Cu e Cd. Na sorcão de Cd com Cu e Zn a diferenca se faz pre sente, havendo a sorcão individual nitida em pH 4 a 5 . Isto significa que hā competicão do Zn ou Cu com o Cd: Nota-se também que em pH maiores do que neutralidade, as caracteristicas fĩsicas e químicas dos solos influem na sorcão. No trabalho tambēm são discutidas as presencas de outros elementos inerentes ao solo como Al, Mn e Fe que saem junto na extração do Cu, Al e Cd, que por sinal em pH menor que 6, são grandes as quantida des extraidas em relacão a pH maiores que 7. Quanto a influência da característica do solo, parece que a CTC ë o que demons tra ter maior fator de correlacão com a sorção.

SOON (1981) estudou o mecanismo de retencăo e relaxacão do cádmio em dois tipos de solos, argiloso e areno-argiloso tratados anaerobicamente com lamas de esgoto e fertilizados quimicamente com $P$ em solucão de equilibrio contendo $\mathrm{Ca}\left(\mathrm{NO}_{3}\right)_{2}$ e cādrio. O autor utilizou a equacião Freundlich

$x=K C^{n}$

onde $K$ e $n$ são constantes e $x$ e $C$ são as concentracões adsor vidas e do equilíbrio, colocando os resultados obtidos em isoter mas com as modificacões introduzidas por BARROW (1979). O coeficiente $K$ mostra ser um bom indicador na afinidade de sorcão do cādmio. As isotermas mostram também que com o aumento do 
Ca-laria decresce Fe-lama e a afinidade do Cd com o solo é comparāvel com $\mathrm{NH}_{4} \mathrm{NO}_{3}$. O decrēscimo de Al-lama è pouco perceptìvel na afinidade solo-cādmio.

As atividades dos ions $\mathrm{Cd}^{2}$ foram calcula das termodinamicamente por Wagman et alii (1968) para as seguin tes reações:

\begin{tabular}{|c|c|c|c|}
\hline & & $\lg K^{0}$ & \\
\hline $2 \mathrm{HPO}_{\mathrm{i}}^{-}$ & $\stackrel{+}{*} \mathrm{PO}_{4}^{3-}+2 \mathrm{H}^{+}$ & $-12,33 \quad(\times 2)$ & $\ldots \ldots(2.138)$ \\
\hline $3 \mathrm{Cd}^{2+}+2 \mathrm{PO}_{4}^{3-}$ & $\stackrel{*}{*} \mathrm{Cd}_{3}\left(\mathrm{PO}_{4}\right)_{2}$ & 32,61 & $\ldots \ldots(2.139)$ \\
\hline $3 \mathrm{Cd}^{2}+2 \mathrm{HPO}_{4}^{-}$ & $\stackrel{\leftrightarrow}{\leftarrow} \mathrm{Cd}_{3}\left(\mathrm{PO}_{4}\right)_{2}+2 \mathrm{H}^{+}$ & 7,95 & $(2.140)$ \\
\hline
\end{tabular}

A influēncia do pH na sorcão e desorcão poden ser vistas com relatos de GARCIA-MIRAGAIA e PAGE (1978) que com o aumento do pH aumenta a adsorcão de Ca. O efeito do pH podem ser proveniente das seguintes reacões:

- minerais de argila, oxidrilas e matēria orgānica co.possuem cargas superficiais dependentes de pH, que com aumento de pH a sua carga ficarā mais negativa, isto aumenta a sua adsorcão dos càtions metālicos.

- a constante de estabilidade solo-matéria orgānica-complexos metālicos aumenta com o pH, cujo resultado é atribuido ao au mento da ionização do grupo funcional, especialmente - $\mathrm{COOH}$ com o aumento do pH (STEVENSON e ARDARANI 1972 p. 79).

- a adsorcão especiffica, isto é, adsorcão em excesso da carga de superficie de metais pesados sobre superficie de oxidri - 
las aumenta com o pH (FORBES et alii 1976). O processo exato do envolvimento do pH ainda não ē conhecido, mas a hidrōlise frequentemente é envolvido (JAMES et aliz 1975).

0 trabalho mostra que o pH tem o fator principal no controle da adsorcão de $\mathrm{Cd}^{2}{ }^{+}$nos diferentes trata mentos dos solos efetuado pelo pesquisador.

Os estudos realizados por HARTER (1979) na adsorção de cobre e chumbo pelos solos de horizontes Ap e $B$ mostram que a adsorção está correlacionado com a soma das bases contidas nos solos, cuja relação estā na ordem de 84 e $76 \%$ de $\mathrm{Cu}$ e $\mathrm{Pb}$ respectivamente. 0 pesquisador obteve estes dados, utilizando a equação de adsorção de Langmuir. Apresenta a indá uma equação empĩrica de adsorção:

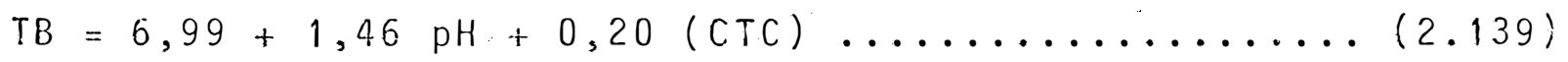

Evidentemente, cujos parāmetros correspondem aos solos por êre analisados, mas não podemos deixar registrado este fato tambëm jā observado pelo presente autor.

As diferenças das composicões minerolōgicas encontradas nos horizontes B, principalmente vermiculita, $\bar{e}$ razão das adsorcõos de Cu e Pb. Outro dado importante verifica do, è a significativa interferéncia da hidrólise com a formação de 


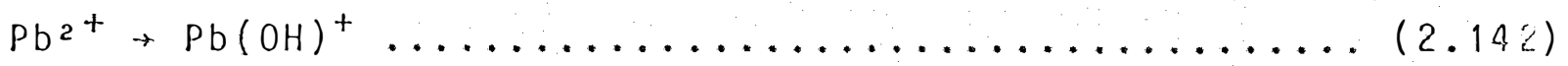

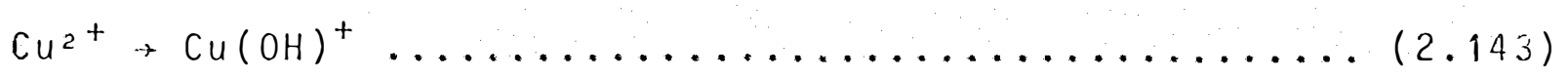

cuja formação acima de $\mathrm{pH}=5,7$ ocorrem em mais de $1 \%$.

Ainda é considerada tambēm, a formaçäo de outros compostos como Pb-fosfato, complexos Pb-Cu que devem formar para precipitacão ou retencão, que não coincidem com a conclusão de Santillian-Medrano e Jurinak (1975). 0 conteúdo de matēria orgãnica parece não ter valor significativo na rela cão de adsorç̃o.

LEVI-MINZI et alii (1976) estudou a adsor säo do cádmio em solos com CTC variando de 16,2 a 32,5 meq/100 g solo, $\mathrm{pH}$ de 7,7 a 8,6, matēria orgānica de 0,5 a $7,8 \%$ e $\mathrm{CaCO}_{3}$ de 0,5 a $25,7 \%$ coletados em Tuscany. Nota-se que o solo possue CTC alto em relacão a maioria dos solos, principalmente a. brasileira. 0 experimento foi objetivando pesquisar a correlação existente na variação da temperatura $\left(5^{\circ} \mathrm{C}\right.$ e $\left.25^{\circ} \mathrm{C}\right)$ e CTC na consiante de $K$ da equação de adsorcão Lamgnuir (constante de afinidade) e a adsorção māxima. os resultados mostram que a temperatura mais alta hā maior sitio de adsorcão e aumenta a constante de afinidade. Mostra ainda que a adsorcão māxima estā diretamente relacionada com CTC e matēria orgānica, $\varepsilon$ a constante de afinidade em maior grau com matéria orgänica e me nor CTC. 0 importante deste trabalho è sugerir que as tempera- 
turas tem influēncia na adsorção do cādmio, provavelmente pela grande afinidade do complexo Cd-adsorvente com maior estabilidade a altas temperaturas.

0 estudo da relacão entre CTC e capacidade de retenção do Cd foram realizadas por NAVROT et aZii (1978), tomando por base que a capacidade de retencão no movimento do $\mathrm{Cd}^{2}$ atravēs do solo seja igual a $\left(\mathrm{Ca}^{2}{ }^{+}+\mathrm{Mg}^{2}{ }^{+}\right)$de acordo com BITTEL e MILLER (1974), cuja relacão seja igual a 1. Assim pro pós a seguinte equação:

$x_{c d}=\frac{V \cdot N_{C d}}{F \cdot C T C+V N_{C d}}$

ou

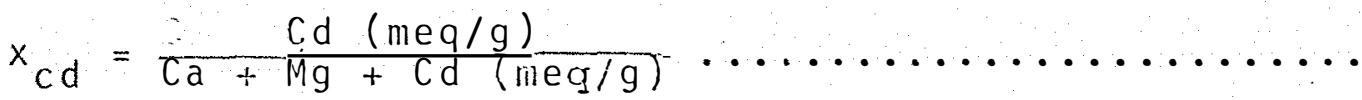

onde:

$x_{c d}$ é a fração iônicana solução de solo de ca

V volume adicionado na solução (ml/g solo)

$\mathrm{N}_{\mathrm{cd}}$ concentracão inicial de Cd (meq/ml)

CTC capacidade troca catiónica do solo (mec/g)

F fração trocāvel de $(\mathrm{Ca}+\mathrm{Mg})$

os resultados experimentais mostram extre mamente precisos com $x_{c d}$ calculados. As conclusões, são de que as adsorcões específicas devem prevalecer no mecanismo as inte racões eletrostáticas e troca iōnica. 


\section{II - MATERIAL E MÉTODOS}

\subsection{Solos}

Os solos usados no presente trabalho foram Terra Roxa Estruturada (TE), Podzólico Vermelho Amarelo-or to (PV-orto) e Glei Húmico $(G H)$. As coletas de amostras de TE foi na ārea do Departamento de Entomologia da Escola Superior de Agricultura "Luiz de Queiroz" da USP, no município de Piracicaba SP em solos cultivados e adubados anteriormente a coleta da amostra, e as amostras de PV-orto e GH foram da Região do Vale do Ribeira no municīpio de Juquià - SP de uma ārea nun ca cultivada anteriormente. Todas as amostras foram retiradas do horizonte $A$. 
As amostras de terra foram secadas a sombra e ao ar e apos a secagem foram destorroadas com mace te de madeira e passadas numa peneira de malha de $2 \mathrm{~mm}$.

As caracterîsticas físicas e quîmicas dos solos acham-se nas Tabelas 1 e 2.

Tabela 1 - Anälise granulométrica de solos Podzölico Vermetho Anarelo-orto, Glei Hümico e Terra Roxa Estruturada.

\begin{tabular}{lccc}
\hline Solo & Areia & Silte & Argila \\
PV-orto & 49,6 & 14,0 & 36,4 \\
GH & 39,6 & 17,0 & 43,4 \\
TE & 39,4 & 10,0 & 50,6 \\
\hline
\end{tabular}



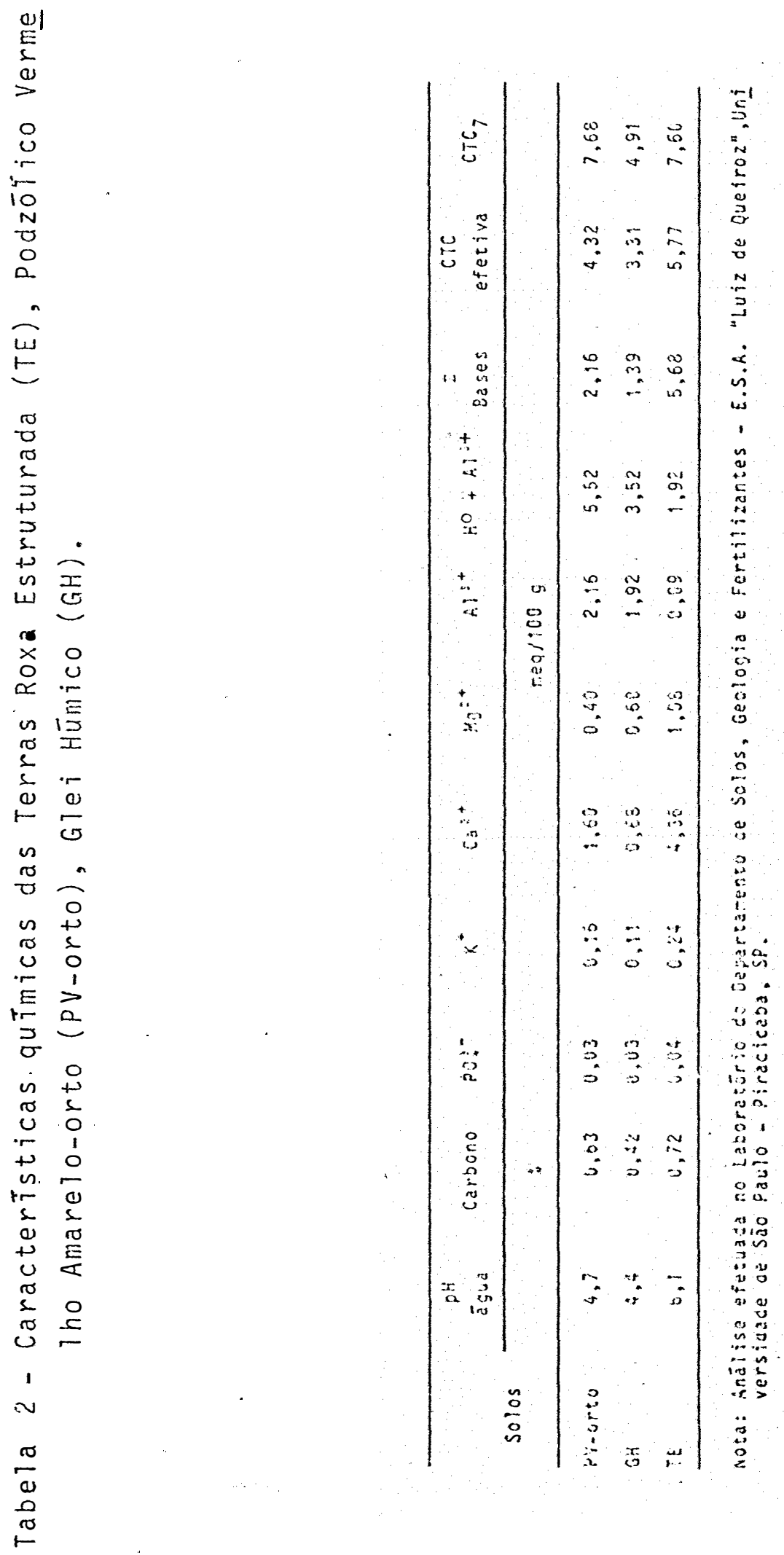
3.2. Experimento de adsorcão de metais pesados

Para os estudos da adsorção dos metais $\left(\mathrm{M}^{2}\right)$, foi adotada a metodologia de JOHN (1972). Em frasco con tendo $0,2 \mathrm{~g}$ de amostra de terra (foram colocados $10 \mathrm{ml}$ de solu ção com 1; 5; 10; 50; 100; 250; 500 e $1000 \mathrm{ppm} \mathrm{de} \mathrm{Cd}^{2}, \mathrm{Cr}^{2} \mathrm{e}$ $\mathrm{Pb}^{2}$. respectivamente, com os seguintes sais: $\mathrm{CdCl}^{2}, \mathrm{CrCl}^{2}$ e $\mathrm{Pb}\left(\mathrm{NO}_{3}\right)_{2}$.

Estas amostras foram colocadas em agita ção continua por 16 horas a uma temperatura de $27^{\circ} \mathrm{C} \pm 2^{\circ} \mathrm{C}$. Logo apōs a agitação foram centrifugadas e a solução sobrenadante foi analisada por espectrómetro mencionado no îtem 3.8 .

A diferença da concentraçäo da solução inicial e final de solução de equilíbrio sobrenadante considerou-se como adsorvido pela amostra de terra.

os dados obtidos foram ajustados na equação de Langmuir na forma linear:

$\frac{c}{x / m}=\frac{1}{K b}+\frac{C}{b}$

onde:

C E a concentração da solucão de equilíbrio, $\mu \mathrm{g} / \mathrm{ml}$;

$x / m \vec{e}$ a quantidade de $M^{2+}$ adsorvida, $\mu g / g$ de terra;

b ē adsorção māxima, $\mu g / g$ terra;

$K$ é constante de afinidade entre o adsorvente e adsorvato, $\mathrm{mll} / \mathrm{mg}$. 
A razăo $C /(x / m)$ foi calculada para cada tratamento com os valores obtidos da concentração $C$ de $\mathrm{M}^{2+}$ em ppm da solução em equilíbrio e $x / m$ da quantidade de metais adsorvido pelo solo $\mu \mathrm{g} / \mathrm{g}$ de terra.

0 coeficiente angular da reta foi calcula dó pelo método dos minnimos quadrados (MIRSHAWKA, 1984) programando-se o computador Prolögica CP 500.

Para ajustar os dados de adsorcăo na equa cão de Freundlich, empregou-se o método do minnimo quadrado (MIRSHAWKA, 1984) programado-se o mesmo computador.

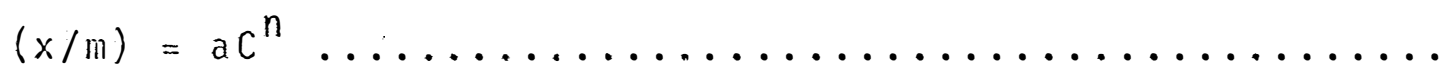

onde:

$x / m \quad j \bar{a}$ definido

a e $n$ constantes

C concentração da solução no equilî́brio $(\mu \mathrm{g} / \mathrm{ml})$

3.3. Experimento de deslocamento de metais pesados

3.3.1. Coluna de ensaios

As colunas foram confeccionadas em tubo de plástico PVC de $5,08 \mathrm{~cm}$ de diāmetro interno por $40 \mathrm{~cm}$ de comprimento, tendo feito furos na lateral de $0,8 \mathrm{~cm}$ a o longo 
da coluna e espacados entre si de $5 \mathrm{~cm}$. Estes furos executados de um lado somente, foram tapados com fita durex. Numa das extremidades foi colocada uma tampa de plástico pvc especialmente torneada com um bico para colocacão de mangueira de borracha latex. A outra extremidade foi colocada uma gase de algodão de fins curativos medicinais para formar uma membrana poro sa (Figura 6) para o recolhimento do efluxo.

A parede do tubo de PVC foi impregnada com cola "DUN DUN" a base de latex para aderéncia de amostras de terra formando uma fina camada aproximada de $0,2 \mathrm{~cm}$. A fina lidade da aplicacão desta camada de terra é a fim de evitar um falso caminhamento ou percolacão atravēs de uma lämina reta de liqquido entre a parede de plástico liso e a coluna de terra en chida (Figura 6). 


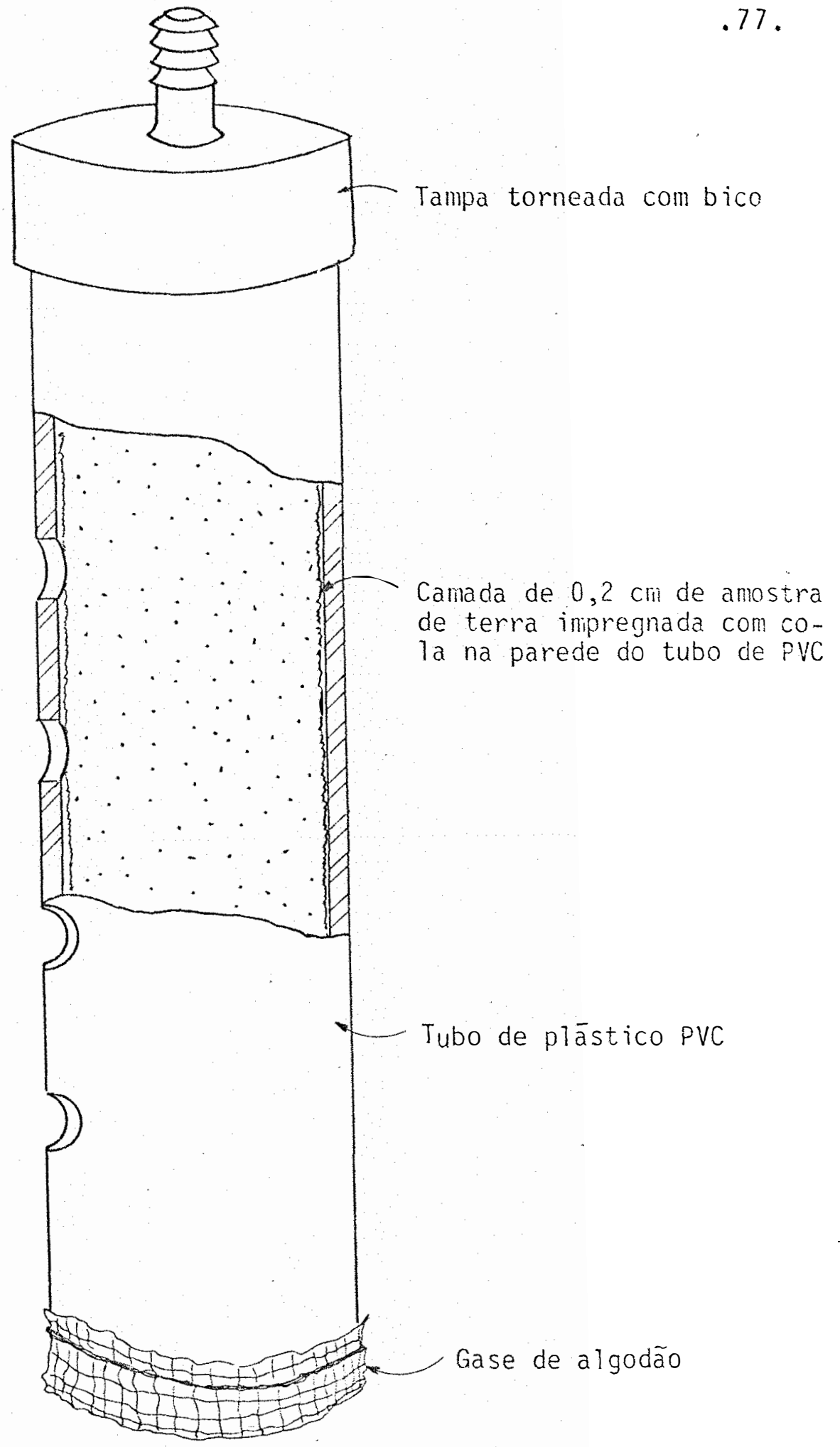

Figura 6 - Detalhe da coluna de solo construido em tubo de plàstico PVC. 
os tubos de plástico foran enchidos com as amostras de terra com um volume contendo aproximadamente $1.000 \mathrm{~g}$ e efetuados em tres vezes. A primeira etapa se compôs enchendo com $1 / 2$ do volume total e socando-se com a pröpria carga contra o fundo do tubo do lado da gase, de uma altura de 8 a 10 cm sobre uma placa de granito, sendo interrompido com 30 golpes. As duas etapas seguintes foram processadas da mesma forma, preenchido com $1 / 4$ do volume total para cada etapa final. Nenhuma quantidade de terra foram adicionadas após tres etapas, para não alterar a compactação devido o número de golpes pré-estabelecidos e os cālculos de volumes de poros com base na massa de terra da coluna.

3.3.2. Cálculo do volume de poros na colunà de terra

Para o cálculo do volume de poros $\left(V_{p}\right)$ da coluna de terra, tomamos as seguintes suposicões:

- massa de terra uniforme ao longo da coluna

- volume de àgua gasto (a) no preenchimento da coluna como sen do igual ao volume de poros $\left(v_{a}=v_{p}\right)$.

Com as suposicões acima, sabendo-se o volume de poros por unidade de massa $\left(v_{p}^{m}\right)$ de um solo pode-se cal cular qualquer volume de poros, desde que se conheça a sua mas sa. Portanto: 
$v_{p}=M_{s} v_{p}^{m}\left(c m^{3}\right)$

$v_{p}^{m}=$ volume de poros por unidade de massa $\left(\mathrm{cm}^{3} / \mathrm{g}\right)$

$M_{s}=$ massa do solo $(\mathrm{g})$

$v_{p}=$ volume de poros da coluna $\left(\mathrm{cm}^{3}\right)$

$\rho_{a}=$ densidade aparente

Para determinação do $V_{p}^{m}$ de cada tipo de solo mediu-se os volumes de água $\left(v_{a}\right)$ para cada coluna de solo en três repeticões, e dividiu-se com as suas respectivas massas. Os valores de $v_{p}^{m}$ de cada tipo de solo encontram-se na Tabela 3 .

Tabela 3 - Volumes de poros ( $\mathrm{V}_{\mathrm{F}}^{\mathrm{m}}$ ) por unidade de massa na coluna de solo e densidades aparentés calculadas.

\begin{tabular}{ccc}
\hline So10 & $V_{p}^{m}$ & $\rho_{a}$ \\
\hline PV-orto & $\mathrm{cm}^{3} / \mathrm{g}$ & $\mathrm{g} / \mathrm{cm}^{3}$ \\
GH & 0,3047 & 1,303 \\
TE & 0,4252 & 1,306 \\
\hline
\end{tabular}


3.3.3. Estudo do deslocamento de cromo, chumbo e câdmio

3.3.3.1. Unidade do experimento.

As unidades do experimento foram efetuadas em grupos de trés colunas para cada tipo de solo, colocados verticalmente, visando em cada unidade de coluna a percora căo de 5,10 e 20 vezes o nümero total de poros atravēs da coluna, utilizando āgua destilada com uma carga hidráulica de $15 \mathrm{~cm}$ ligados por tubos de borracha latex no topo da coluna por una tampa torneada descrita no item 3.3.1.

o efluxo foi protegido da evaporacão envolvendo-se por um saco de plàstico fino o recipiente e a colu na. A tomada da medida do volume percolado foi o efluxo.

Para TE e PV-orto houve dois niveis de tratamento de $\mathrm{pH}$, sendo um tratamento com o pH original de cam po e outra com o pH corrigido $\mathrm{Com} \mathrm{Ca}(\mathrm{OH})_{2}$.

0 esquema da ligacão dessas colunas de so 10 acha-se na Figura ?. 
.81.

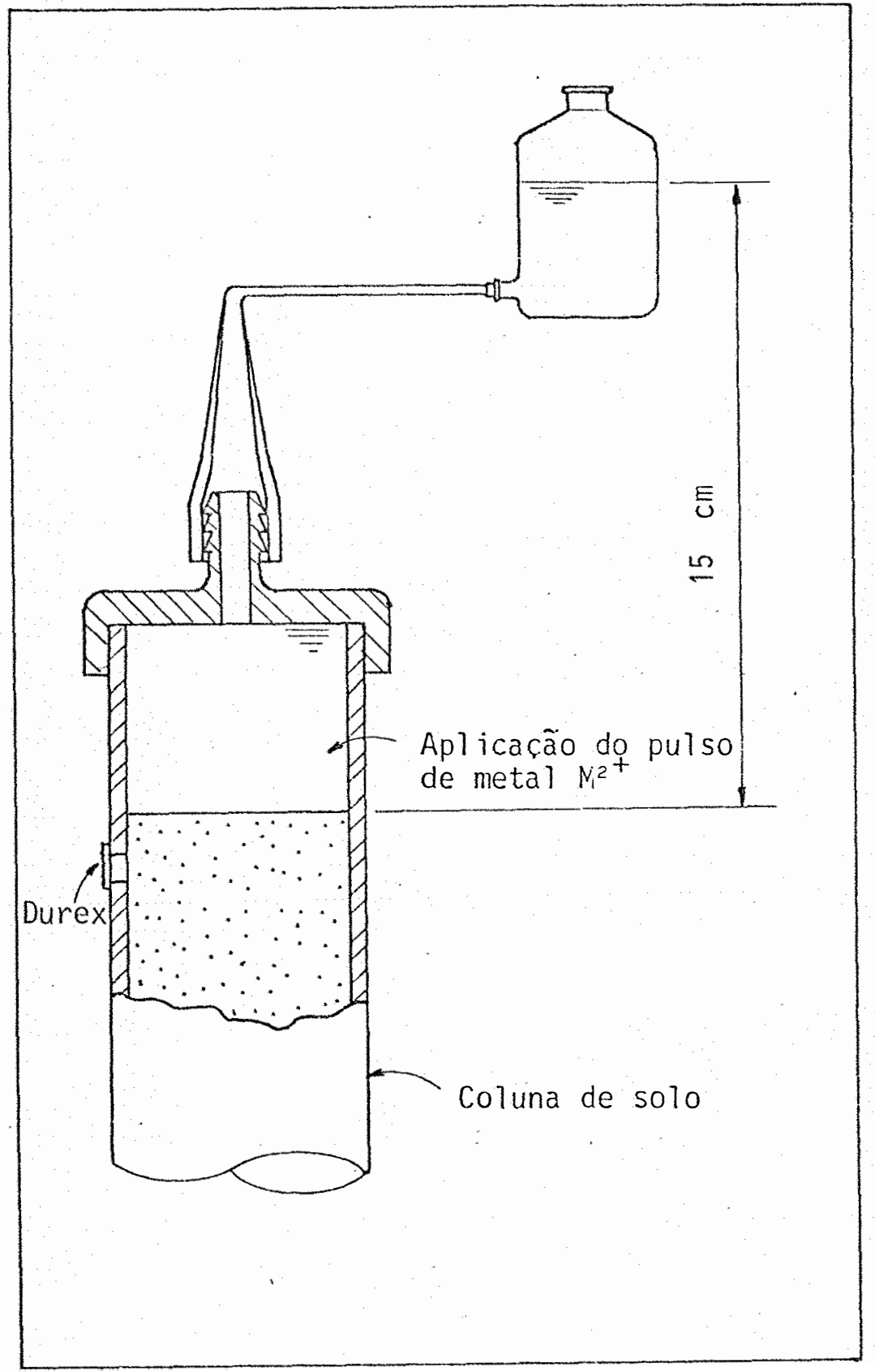

Figura 7 - Esquema de montagem da coluna de solo. 
No topo de cada coluna de solos foram colocados $100 \mathrm{ml}$ de solução de sal na concentração de $20 \mathrm{~g} / \mathrm{l}$ nas unidades de tratamento. Os compostos dos sais utilizados foram os seguintes:

- ritetal $\left(\mathrm{M}^{+}\right)$cromo: $\mathrm{CrCl}_{2}$

- metal $\left(\mathrm{M}^{2}{ }^{+}\right)$chumbo: $\mathrm{Pb}\left(\mathrm{NO}_{3}\right)_{2}$

- metal $\left(\mathrm{M}^{+}\right)$cádmio: $\mathrm{CdCl}_{2}$

Apōs a infiltração da solucão de sal metal $\mathrm{M}^{+}$na coluna de solo, ligou-se imediatamente a àgua des tilada, tendo una carga hidräulica de 15 cm conforme Figura 3.2 .2 e seu efluxo foi recolhido para medida do volume e pH da solução.

A designação $\mathrm{Me}^{+}$indica os cătions metā? cos dos sais utilizados, independentemente das fomas encontra das, hidrolizados, hidratados, complexados ou outra forma, uma vez que a pesquisa ficou voltada a adsorcão e translocacão do elemento.

3.3.3.3. Identificação dos tratamentos na co luna de solo

os critērios para identificacão das colunas foram as seguintes: 


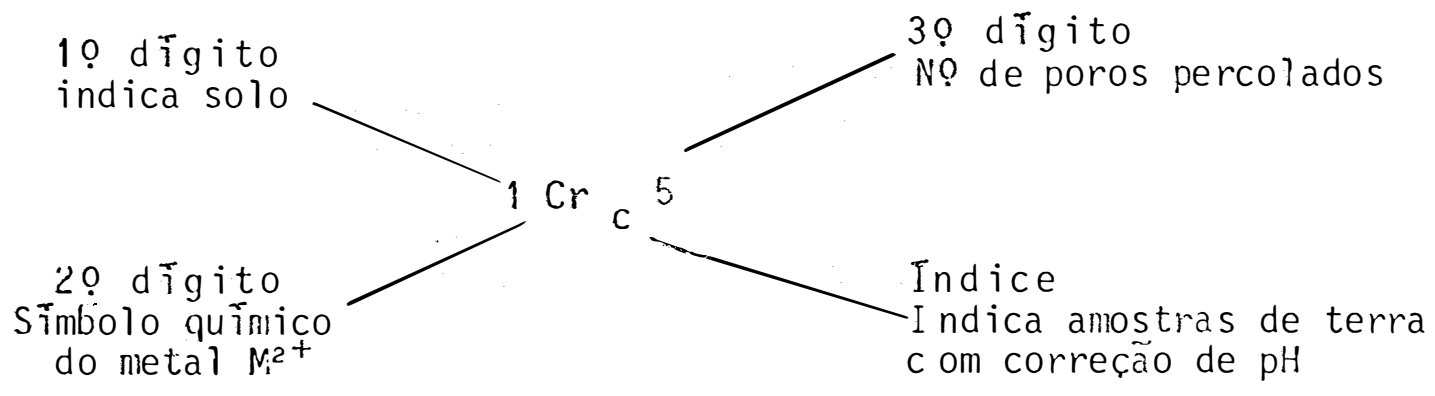

o significado do esquema de numeração e

alfabetos são os seguintes:

- o primeiro dĩgito

A numeracão indicam os solos utilizados:

$1=$ PV-orto

$2=\mathrm{GH}$

$3=T E$

- o segundo digito

Grupo de duas letras são os símboios dos metais $\mathrm{M}^{2}$ aplicado:

$\mathrm{Cr}=\operatorname{metal} \mathrm{M}^{2}+\mathrm{cromo}$

$\mathrm{Pb}=$ metal $\mathrm{M}^{2}+$ chumbo

$C d=\operatorname{metal} \mathrm{M}^{2}+\mathrm{c} \overline{\mathrm{a}} \mathrm{dmio}$

$\because$ o terceiro dígito

Indica o volume de āgua aplicado na colu-

na de solo

$5=$ cinco vezes o nümero de volumes de poros

$10=$ dez vezes o nümero de volumes de poros

20 = vinte vezes o nümero de volumes de poros 


\section{- Indice}

A presenca do sub indice "c" indica solos com correção de pH, cujos dados estão na Tabela 4.

Nas Tabelas de nümero 4 a 6 constam a iden tificacão com os respectivos meta is $\mathrm{M}^{2}+$ com os solos em estudo, seu pH e os volumes de poros.

Das Tabelas de nümero 7 a 12 encontram-se as caracteristicas inerentes a cada coluna, com suas respecti vas massas e seus volumes de āgua aplicado em cada tratamento. 
Tabela 4 - Esquemas dos tratamentos de translocacão dos metais $\mathrm{M}^{2}+$ em PV-orto.

\begin{tabular}{|c|c|c|c|}
\hline $\begin{array}{l}\text { Identificacão } \\
\text { dos } \\
\text { Tratamentos }\end{array}$ & metal & $\mathrm{pH}$ & $\begin{array}{c}\text { No de volumes } \\
\therefore \text { de poros em } \\
\text { estudo }\end{array}$ \\
\hline $1 \mathrm{Cr} 5$ & $\mathrm{Cr}$ & 4,7 & 5 \\
\hline $1 \mathrm{Cr}_{\mathrm{C}} 5$ & $\mathrm{Cr}$ & 6,5 & 5 \\
\hline $1 \mathrm{~Pb} 5$ & $\mathrm{~Pb}$ & 4,7 & 5 \\
\hline $1 \mathrm{~Pb}_{\mathrm{C}} 5$ & $\mathrm{~Pb}$ & 6,5 & 5 \\
\hline $1 \mathrm{~cd} 5$ & $C d$ & 4,7 & 5 \\
\hline $1 \mathrm{Cd}_{\mathrm{C}} 5$ & $\mathrm{Cd}$ & 6,5 & 5 \\
\hline $1 \mathrm{Cr} 10$ & $\mathrm{Cr}$ & 4,7 & 10 \\
\hline $1 \mathrm{Cr}_{\mathrm{c}} 10$ & $\mathrm{Cr}$ & 6,5 & 10 \\
\hline $1 \mathrm{~Pb} \quad 10$ & $\mathrm{~Pb}$ & 4,7 & 10 \\
\hline $1 \mathrm{~Pb}_{\mathrm{C}} 10$ & $\mathrm{~Pb}$ & 6,5 & 10 \\
\hline $1 \operatorname{cd} 1.0$ & $\mathrm{Cd}$ & 4,7 & 10 \\
\hline $1 \mathrm{Cd}_{\mathrm{c}} 10$ & $\mathrm{Cd}$ & 6,5 & 13 \\
\hline $1 \mathrm{Cr} 20$ & $\mathrm{Cr}$ & 4,7 & 20 \\
\hline $1 \mathrm{Cr}_{\mathrm{C}} \ldots 20$ & $\mathrm{Cr}$ & 6,5 & 20 \\
\hline $1 \mathrm{~Pb} 20$ & $\mathrm{~Pb}$ & 4,7 & 20 \\
\hline $1 \mathrm{~Pb}_{\mathrm{c}} 20$ & $\mathrm{~Pb}$ & 6,5 & 20 \\
\hline $1 \mathrm{Cd} 20$ & $C d$ & 4,7 & 20 \\
\hline $1 \mathrm{Cd}_{c} 20$ & $C d$ & 6,5 & 20 \\
\hline
\end{tabular}


Tabela 5 - Esquema dos tratamentos de translocacão de metais $\mathrm{M}^{2}$ em GH.

\begin{tabular}{|c|c|c|c|}
\hline $\begin{array}{c}\text { Ident if icacăo } \\
\text { dos } \\
\text { Tratamentos }\end{array}$ & metal. & $\mathrm{pH}$ & $\begin{array}{c}\text { No de volumes } \\
\text { de poros em } \\
\text { estudo }\end{array}$ \\
\hline $2 \mathrm{Cr} 5$ & $\mathrm{Cr}$ & 4,4 & 5 \\
\hline $2 \mathrm{~Pb} 5$ & $\mathrm{~Pb}$ & 4,4 & 5 \\
\hline $2 \mathrm{~cd} 5$ & $C d$ & 4,4 & 5 \\
\hline $2 \mathrm{Cr} 10$ & $\mathrm{Cr}$ & 4,4 & 10 \\
\hline $2 \mathrm{~Pb} \quad 10$ & $\mathrm{~Pb}$ & 4,4 & 10 \\
\hline $2 \operatorname{cd} 10$ & $\mathrm{Cd}$ & 4,4 & 10 \\
\hline $2 \mathrm{Cr} 20$ & $\mathrm{Cr}$ & 4,7 & 20 \\
\hline $2 \mathrm{~Pb} \quad 20$ & $\mathrm{~Pb}$ & 4,4 & 20 \\
\hline $2 \mathrm{Cd} 20$ & $\mathrm{Cd}$ & 4,4 & 20 \\
\hline
\end{tabular}


Tabela 6 - Esquema dos tratamentos de translocacão de metais $\mathrm{M}^{2}+\mathrm{em} T \mathrm{TE}$.

Identificação dos

Tratamentos metal

$\mathrm{Cr}$

$\mathrm{Cr}$

$\mathrm{Pb}$

$\mathrm{Pb}$

$c d$

$C d$

$\mathrm{Cr}$

$\mathrm{Cr}$

$3 \mathrm{Cr}_{\mathrm{c}} 10$

$3 \mathrm{~Pb} 10$

$3 \mathrm{~Pb}_{\mathrm{c}} 10$

3 cd 10

$3 \mathrm{~cd} 10$

$3 \operatorname{Cr} 20$

$3 \mathrm{Cr}_{\mathrm{c}} 20$

$3 \mathrm{~Pb} 20$

$3 \mathrm{~Pb}_{\mathrm{C}} 20$

3 cd 20

$3 \mathrm{Cd}<\mathrm{OU}$
$\mathrm{Pb}$

$\mathrm{Pb}$

$c d$

$\mathrm{Cd}$

$\mathrm{Cr}$

$\mathrm{Cr}$

$\mathrm{Pb}$

$\mathrm{Pb}$

Cd

cd
No de volumes

$\mathrm{pH}$ de poros em estudo

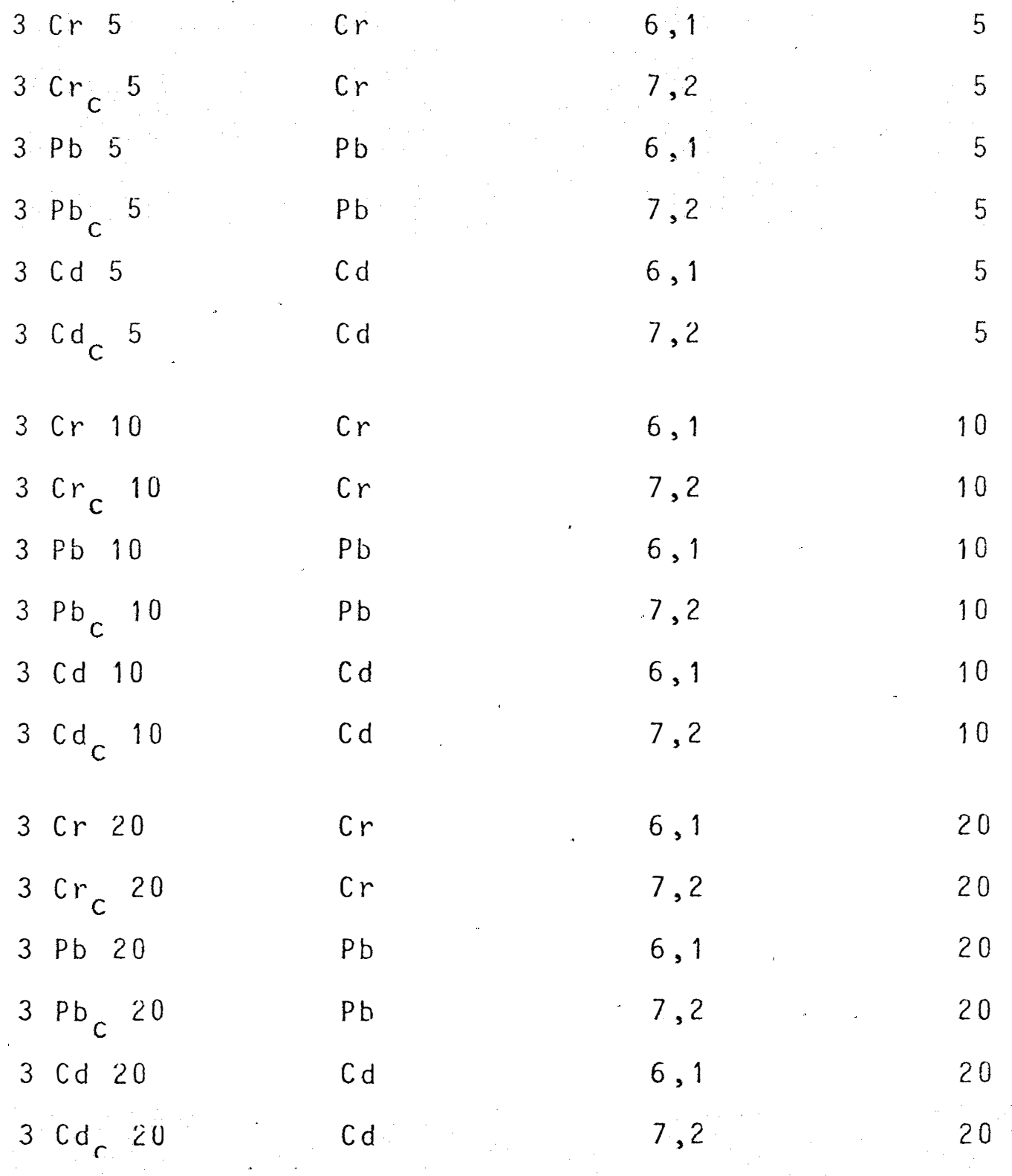




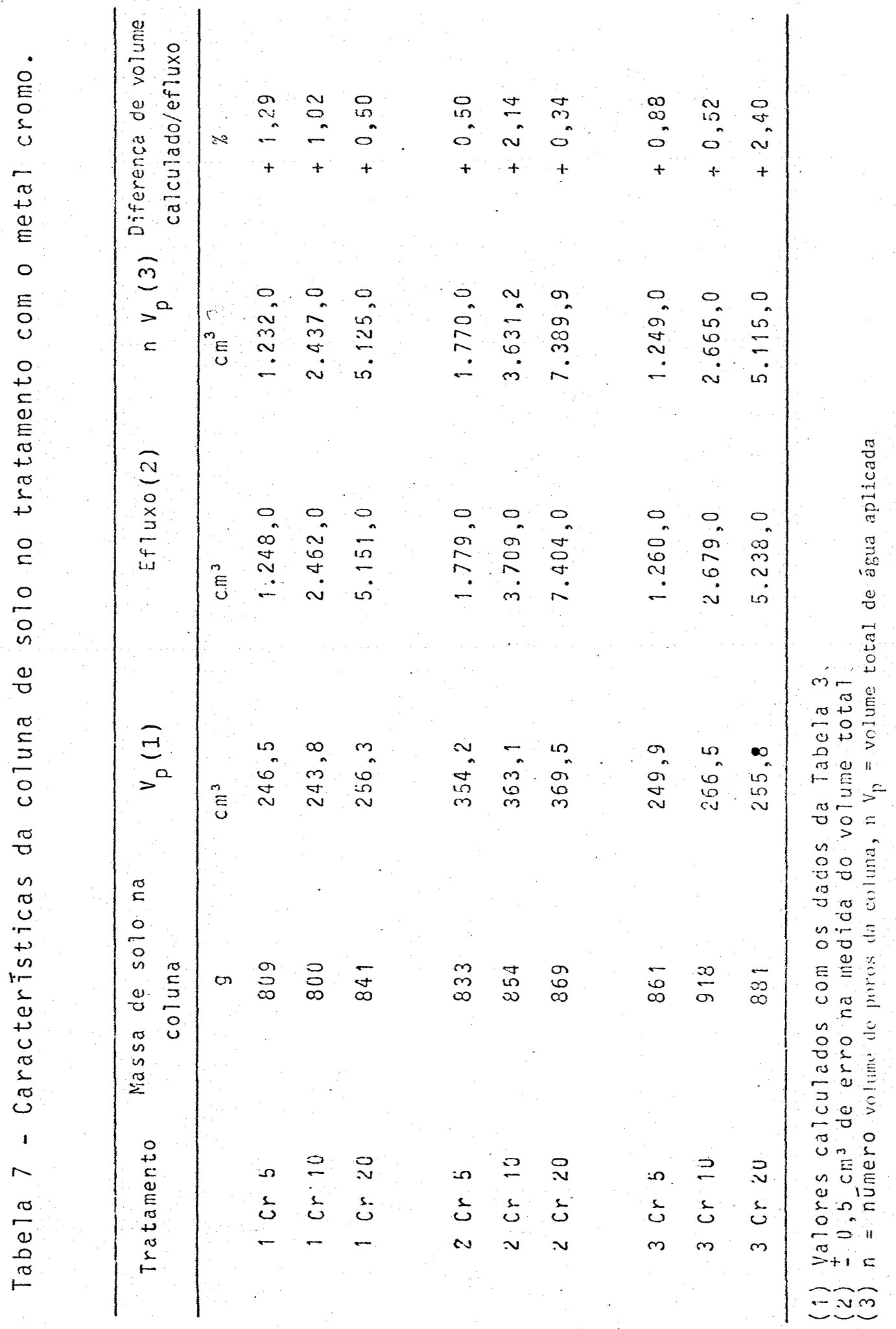




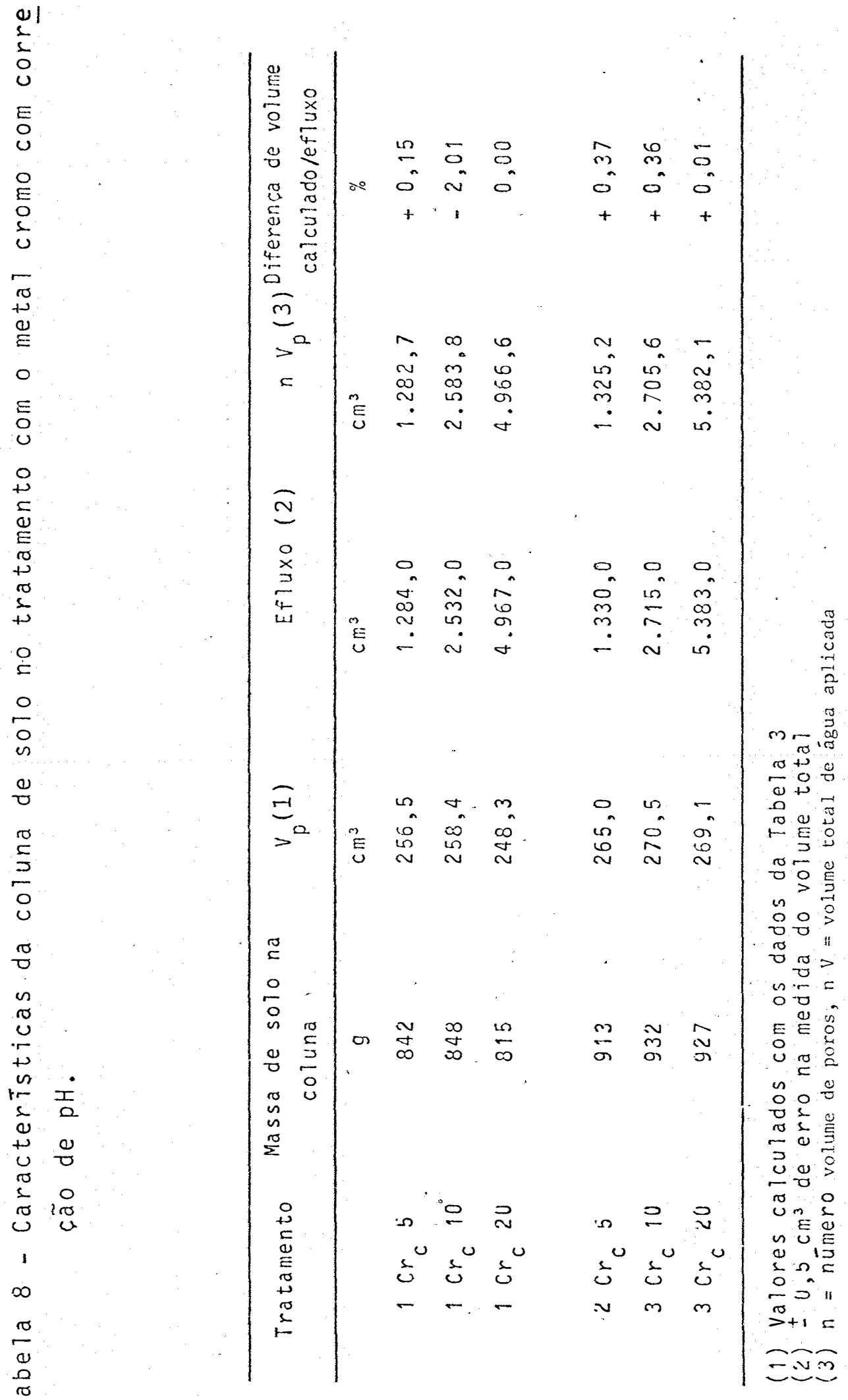




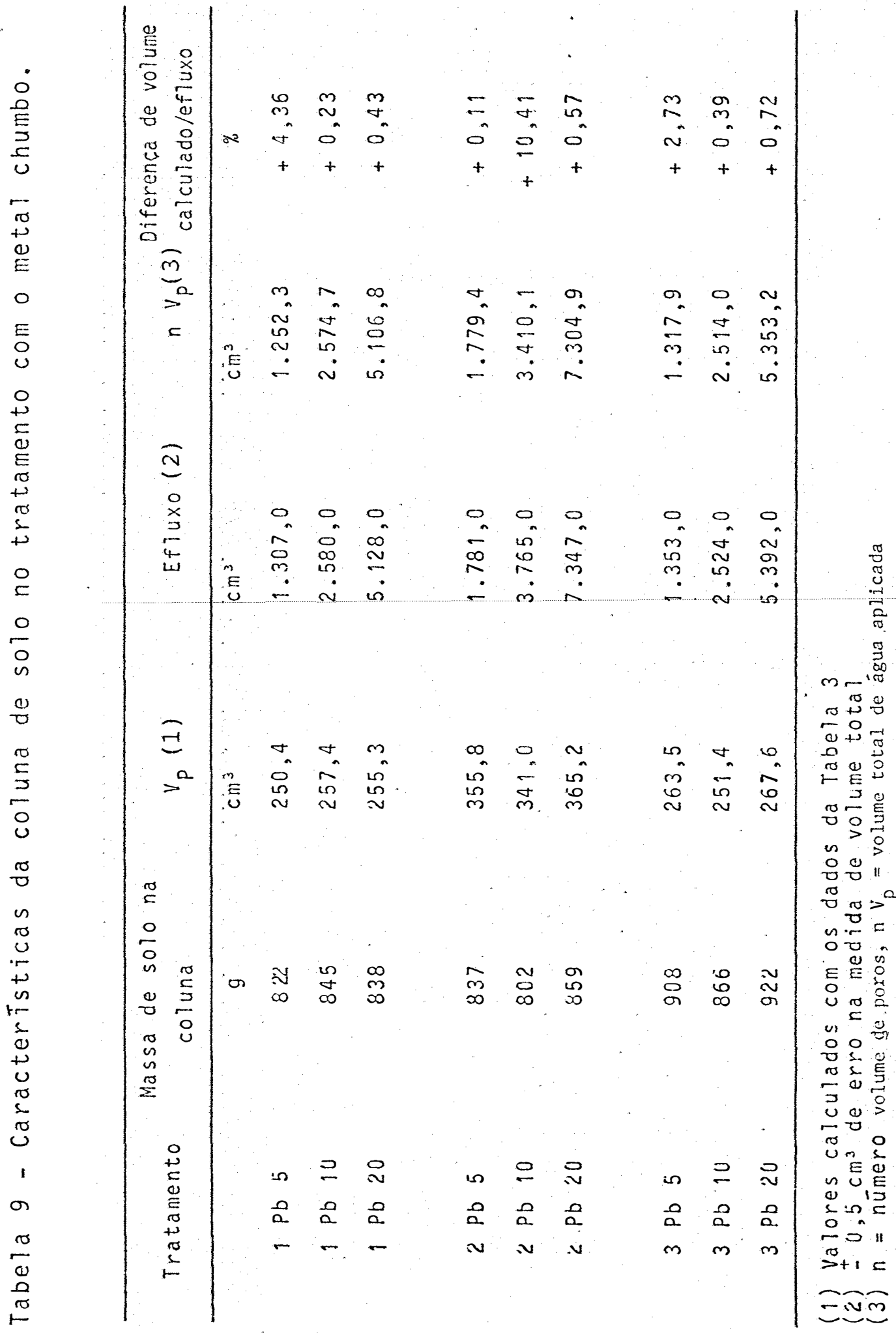




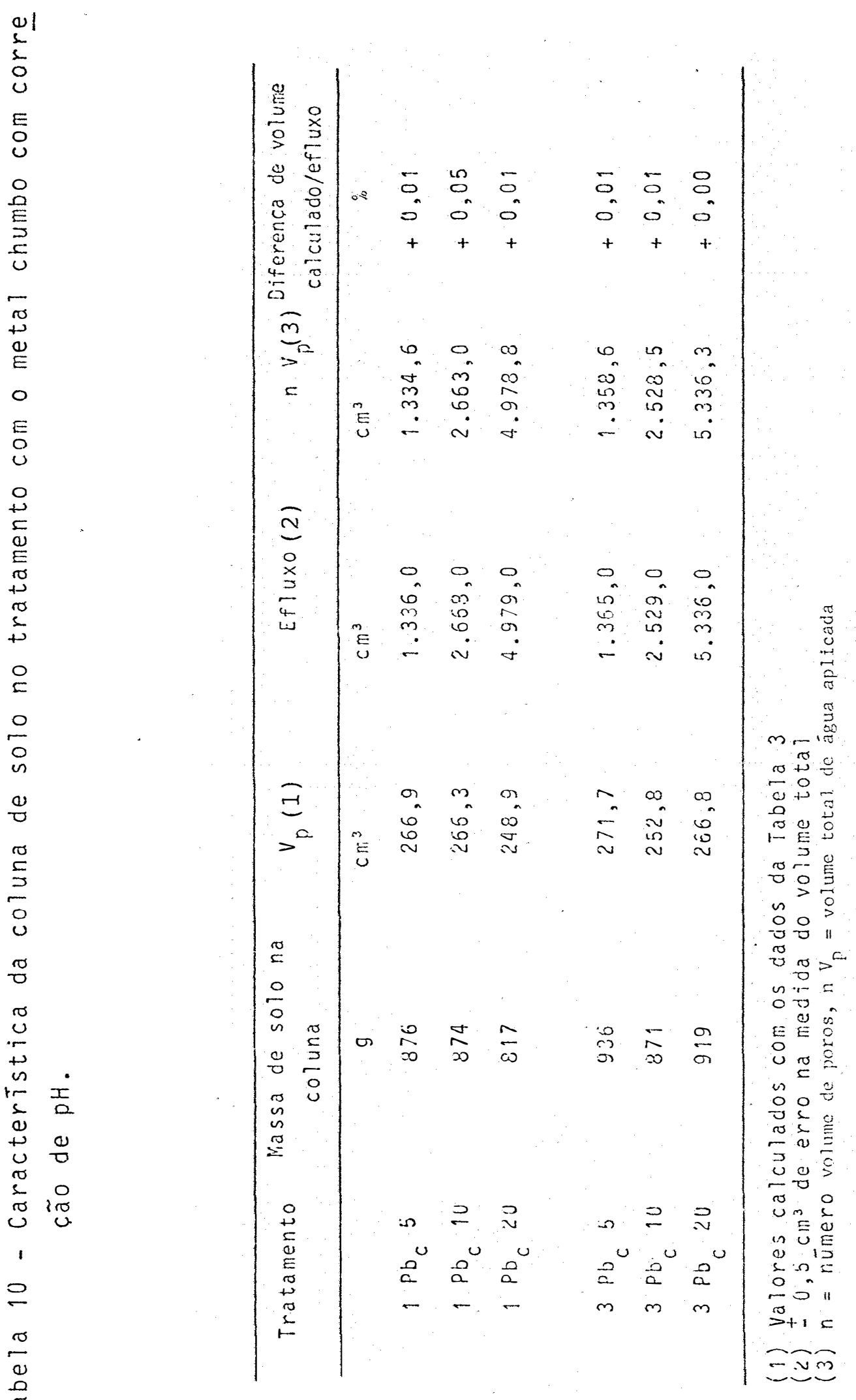




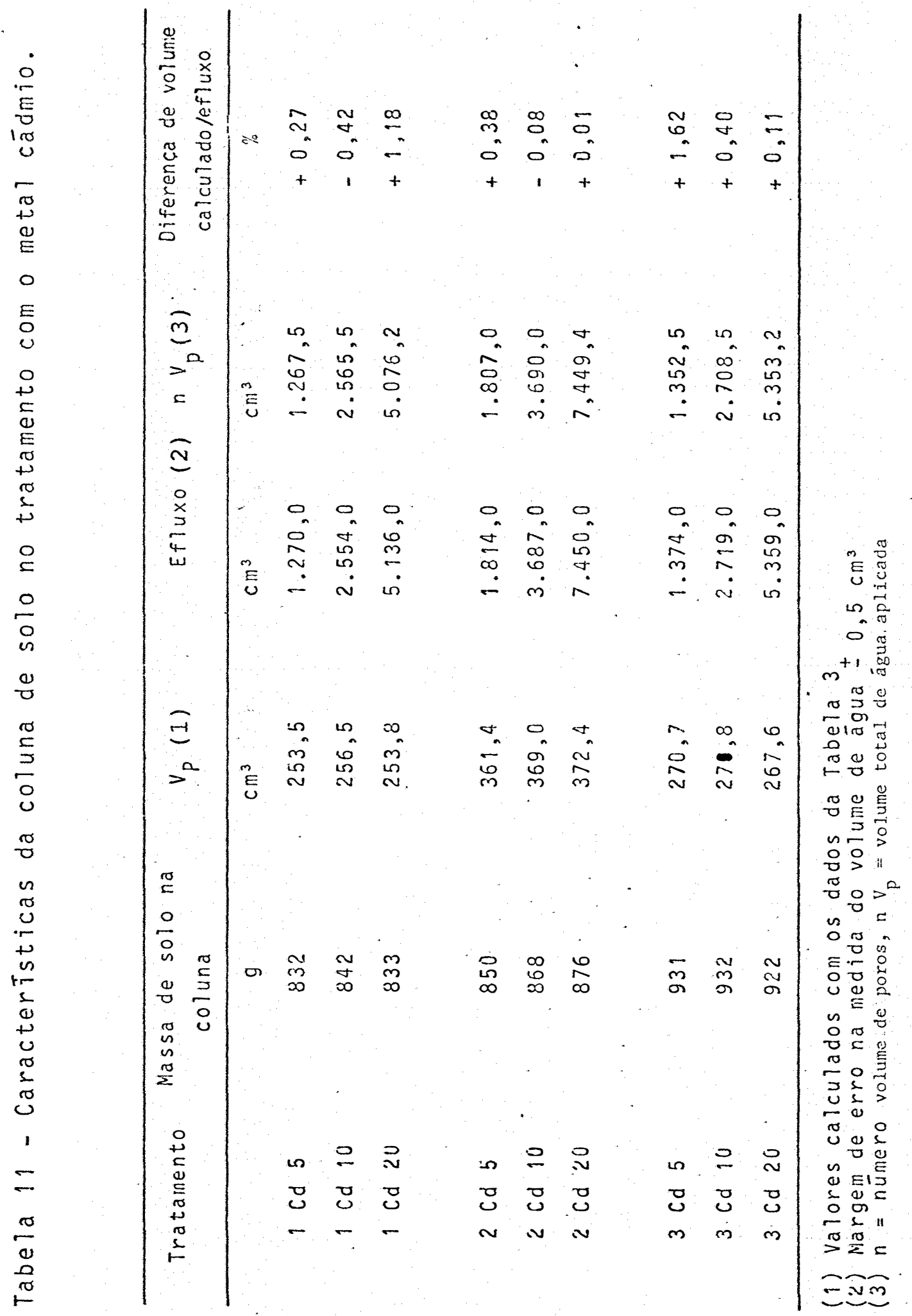




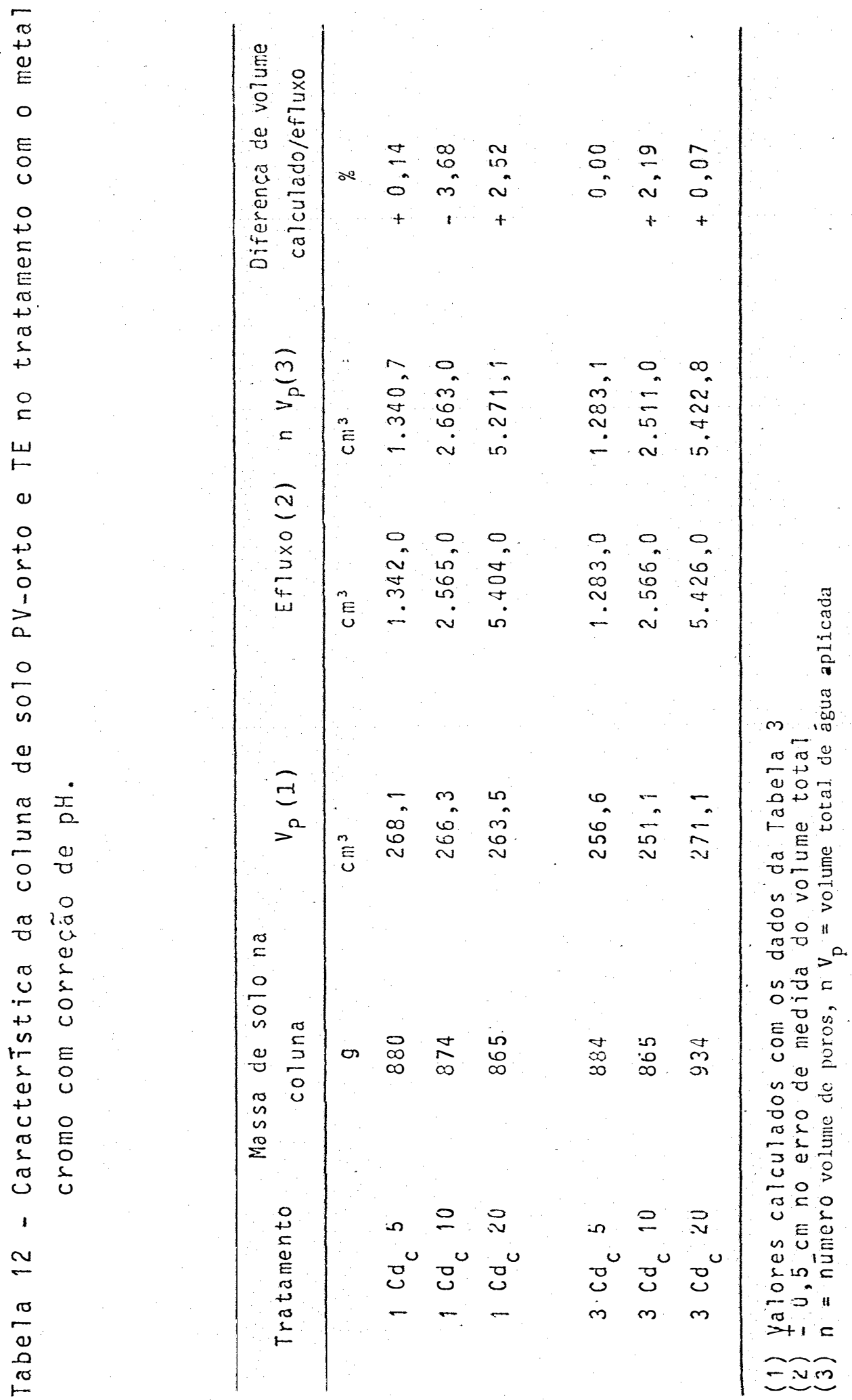




\subsection{Determinacão dos metais pesados $\mathrm{M}^{2+}$ na coluna de so 10}

Apōs completado a percolação do volume de àgua pré-estabelecido, retirou-se imediatamente as amostras de terra úmidas da coluna de solo pelos orifícios descrito no item 3.3.1, na quantidade aproximada de $15 \mathrm{~g}$.

Foram pesados $10 \mathrm{~g}$ da amostra secas ao ar livre e a sombra para anālise de $\mathrm{Cd}^{2}$ e $\mathrm{Pb}^{2}$, tendo adaptado a metodologia de Lagerwerf (1971), colocando-se $20 \mathrm{ml}$ de HCl $1 \mathrm{~N}$ para extração e agitando-se continuamente por uma hora e 24 ho ras de repouso. A solução foi filtrada e lavada até completar o volume de $100 \mathrm{ml}$. Para anālise do $\mathrm{Cr}^{2}$ foi utilizado a metodologia de HESSE (1971).

As anālises das concentraçoes dos metais $\mathrm{M}^{2}{ }^{+}$dos extratos foram efetuados no espectrómetro de emissão atómica induzida por plasma, conjugado ao computador "plasma ATOM - COMP" modelo 975, unidade pertencente a CENA - Centro de Energia Nuclear da Agricultura da Universidade de São Paulo - SP.

3.5. Medida da velocidade do soluto na coluna de solo

A velocidade média da āgua pode ser obtida em termos de densidade de fluxo ( $\mathrm{v}, \mathrm{cm} / \mathrm{s})$ conforme comentado no item 2.3. 
Assim, a equação 2.90 e 2.91 do item 2.3 e a velocidade real nos poros na seccão transversal. E fácil de verificar, que devido as variações de forma, direcão e largura dos poros que a velocidade atual da àgua nos solos é altamente variável de ponto para ponto e não se pode falar em uma ünica velocidade do lịquido, na melhor das hipōteses, em velocidade real mēdia.

Para uma aproximação, introduz-se um fator de correcão $\delta$ (REICHARDT, $1978 \mathrm{p}$. 167) fator de tortuosida de de um meio poroso, pela seguinte relacão:

$\delta=\left(\frac{L}{L_{0}}\right)^{2}$

onde:

$L=$ caminho em linha reta

$L_{0}=$ caminho efetivamente percorrido por uma molécula de āgua

Neste trabalho não foi levado em conta este parāmetro da equacão 3.2 embora v seja diferente de quma vez que este estudo está voltado a adsorcão, retenção e des locamento e suas velocidades relativas entre os solos. Tambēm não foram levados em conta os fluxos de difusão da equação 2.94 e 2.98 , por ser despresível em face ao fluxo de massa.

Desta forma, as velocidades mëdias $\mathrm{da}$ āgua foram tiradas baseando-se na equação 2.90 , no sentido 
unidirecional, isto é, na vertical e portanto, reescrevendo a equaçäo temos:

$q=-K_{(\theta)} \frac{\partial \xi}{\partial z}+1$

onde:

$\xi \quad \bar{e}$ potencial matricial da àgua

$z \quad$ a coordenada vertical

$K_{(\Theta)}$ condutividade hidrāulica em função da unidade $\theta$,

como a coluna de solo em estudo estā saturado, logo

$\frac{\partial \xi}{\partial z}=0$

portanto, a equacão 3.5 , na condiçăo do solo saturado é:

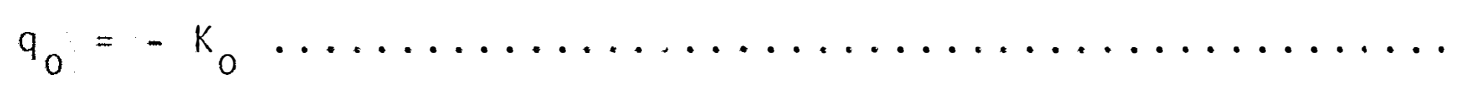

onde:

$q_{0}=$ fluxo de āgua saturado no solo

$k_{0}=$ condutividade hidrāulica em solo saturado

Desse modo, foram feitas medidas simples, tomando-rse a média de 3 repeticões, fazendo-se as leituras di retas de infiltracão nas colunas de solos (NASCIMENTO, 1978). 
A velocidade do soluto foram consideradas iguais a velocidade da āgua, uma vez que o fluxo de massa é predominante a difusão, e as adsorcões havidas são discutidas sem levar em consideracões as equações 2.89 a 2.99 devida a condicões de contorno do experimento conduzido apresentar sem solucão matemātica ou resolucão extremamente difícil.
3.6. Cālculo da quantidade de metais $\mathbf{M}^{+}$retidos na colu na de solo

a. càlculo teōrico

As concentracões de metais $\mathrm{M}^{+}$encontradas nas colunas de solo nos diferentes desniveis, foram ajusta das as curvas pelo método do minnimo quadrado no computador pro logica CP500 e as seguintes curvas foram possiveis de resolu cão:

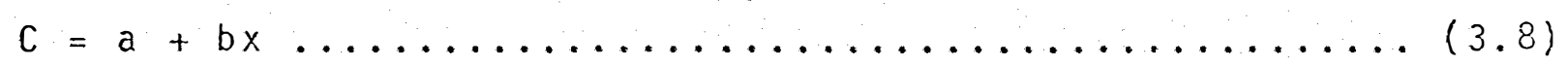

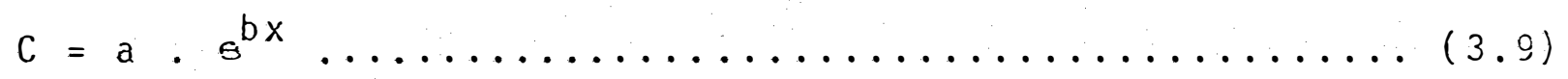

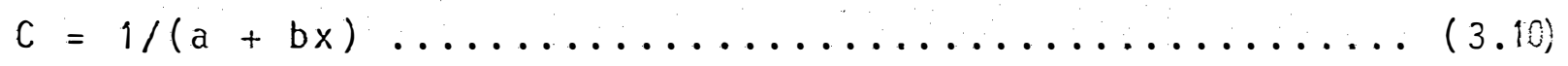

onde:

C é a concentração de metal $\mathrm{M}^{2}+(\mu \mathrm{g} / \mathrm{g}$ solo)

a e b são constantes

$x \quad$ a profundidade da coluna $(\mathrm{cm})$ 
A integração das diferenciais das equacões $3.8,3.9$ e 3.10 darão as respectivas äreas S (DACORSO NETTO P. 197 1.966) e introduzindo um parāmetro nestas equações de tal sorte que forneça somente a massa, é possível o cālculo matemātico no todo ou em parte da coluna.

\section{Portanto, a integral}

$S=\int_{0}^{1} c d x$

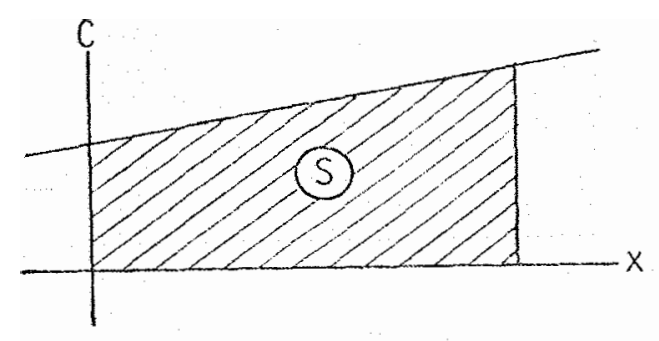

onde:

$C=g M^{2+} / g$ solo

$x=c m$

logo, se multiplicarmos por um fator $k(g$ solo/cm) teremos:

$M_{R}=S K\left(g M^{2}+\right)$

onde:

$M_{R}=M^{2}+$ retiao

$K$ = constante dimensional para cada tipo de solo 
Para o cālculo de $K$ pode-se introduzir os seguintes fatores dimensionais:

$K=\rho_{\text {Solo }} V_{H}$

onde:

solo densidade aparente do solo $\left(\mathrm{g} / \mathrm{cm}^{3}\right)$

$V_{\mu}=$ volume do solo por unidade de comprimento $\left(\mathrm{cm}^{3} / \mathrm{cm}\right)$

Logo:

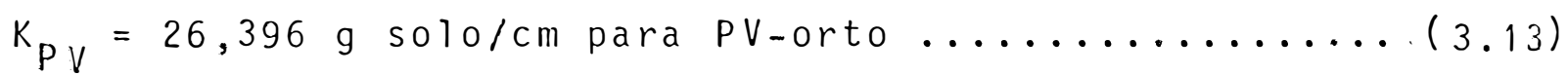

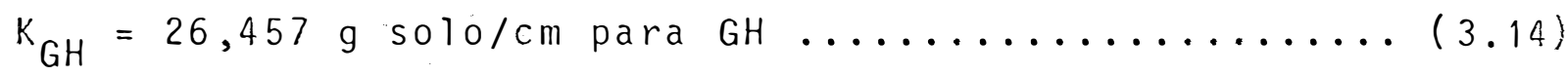

$K_{T E}=29.556 \mathrm{~g} \mathrm{solo/cm} \mathrm{para} \mathrm{TE \ldots \ldots \ldots \ldots \ldots \ldots \ldots \ldots \ldots \ldots \ldots ..15)}$

Para o cálculo dos metais retidos $M_{R}$ subs titue-se na equação 3.11 as equações 3.8 a 3.10 , logo

para:

$\left.(3.8) M_{R}=k \int_{0}^{L} S d x=k\left[a x+\frac{b}{2} x^{2}\right]_{0}^{L} \ldots \ldots \ldots \ldots \ldots \ldots \ldots \ldots \ldots \ldots .16\right)$

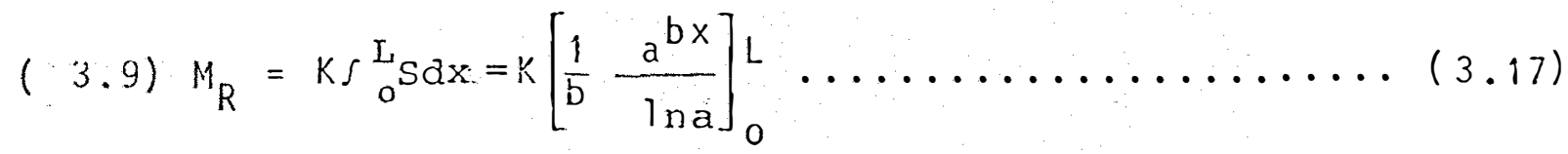

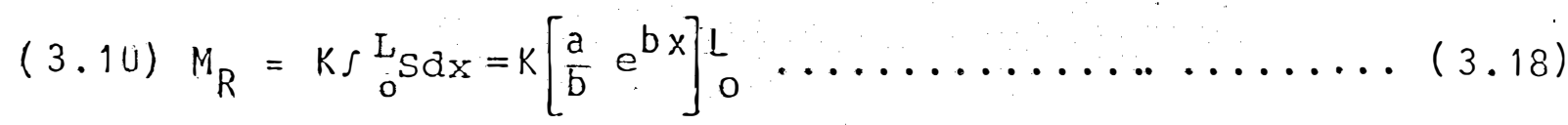


As equač̃os 3.17 e 3.18 são rejeitadas uma vez que os parämetros a e b são negativos conforme Tabela 13 a 18.

Para o cälculo, deve-se substituir na equacăo 3.16 o valor de $k$ da equação 3.13 a 3.15 com os seus respectivos solo e parametros da equação tabulados em 13 a 18.

Matematicamente, somente a equação $3 . \varepsilon$ apresenta resultados reais, e as demais foram rejeitadas por apresentarem resultados discrepantes com a real:

b. Càlculo pelo volume médio

Outro cáicuìo aproximado, $\bar{\epsilon}$ obtendo-se um volume $\Delta V$ a cada incremento na altura ix da colura, de tal for ma que $\Delta x=5 \mathrm{~cm}$ e seja o valor correspondente do local da retirada da amostra. Logo, tendo-se o volume $\Delta V$ e conhecendo a sua densidade (Tabela 3) temos a massa contida neste volume $L V$. Com os resultados da concentracão do metal $M^{+}$obtidos atravës das anālises quĩmicas nos diferentes desníveis $\Delta x$, facilmente obtëm-se as massas retidas de metal $M^{2}$ ou seu sal correspondente na coluna. 
Tabela 13 - Ajustes de curvas obtidas no computador CP500 Prolōgica com os dados da anālise de terra da coluna de PV-orto, GH e TE do metal cromo.

Tratamento. Equação Coeficiente Ajustada Correlaçăo Constante

\begin{tabular}{|c|c|c|c|c|}
\hline & \multirow{2}{*}{ Ajustada } & \multirow{2}{*}{ Correlaçăo } & \\
\hline & & & a & b \\
\hline $1 \mathrm{Cr} 5$ & $\begin{array}{l}y=a \cdot b x^{b x} \\
y=a e^{y}=1 /(a+b x)\end{array}$ & $\begin{array}{l}0,94 \\
0,96 \\
0,83\end{array}$ & $\begin{array}{l}665,96 \\
830,07 \\
6,46 \times 10^{-4}\end{array}$ & $\begin{array}{l}-22,29 \\
-\quad 0,08 \\
\quad 4,24 \times 10^{-4}\end{array}$ \\
\hline $1 \operatorname{Cr~} 10$ & $\begin{array}{l}y=a b^{b} b x \\
y=a x^{b} \\
y=1 /(a+b x)\end{array}$ & $\begin{array}{l}0,73 \\
0,76 \\
0,83\end{array}$ & $\begin{array}{l}494,43 \\
566,52 \\
6,46 \times 10^{-4}\end{array}$ & $\begin{array}{r}-12,54 \\
-\quad 0,05 \\
\quad 4,24 \times 10^{-4}\end{array}$ \\
\hline $1 \mathrm{Cr} \measuredangle U$ & $\begin{array}{l}y=a \\
y=a e^{b x^{b x}} \\
y=1 /(a+b x)\end{array}$ & $\begin{array}{l}0,39 \\
0,32 \\
0,27\end{array}$ & $\begin{array}{l}399,91 \\
403,61 \\
2,38 \times 10^{-4}\end{array}$ & $\begin{array}{l}-7,92 . \\
-\quad 0,03 \\
\quad 1,81 \times 10^{-4}\end{array}$ \\
\hline $2 \mathrm{Cr} 5$ & $\begin{array}{l}y=a b^{y} b x \\
y=a x^{b} \\
y=1 /(a+b x)\end{array}$ & $\begin{array}{l}0,89 \\
0,91 \\
0,78\end{array}$ & $\begin{array}{l}704,14 \\
88 \ddot{2}, 08 \\
-4,11 \times 10^{-4}\end{array}$ & $\begin{array}{l}-21,54 \\
-\quad 0,07 \\
\quad 3,27 \times 10^{-4}\end{array}$ \\
\hline $2 \mathrm{cr} 10$ & $\begin{array}{l}y=a b^{b} b x \\
y=a e^{2} \\
y=1 /(a+b x)\end{array}$ & $\begin{array}{l}0,94 \\
0,94 \\
0,83\end{array}$ & $\begin{array}{l}801,0 \\
1.122,97 \\
-2,84 \times 10^{-3}\end{array}$ & $\begin{array}{l}-29,17 \\
-\quad 0,11 \\
\quad 7,47 \times 10^{-4}\end{array}$ \\
\hline $2 \mathrm{Cr}<0$ & $\begin{array}{l}y=a+b x^{b x} \\
y=a e^{-1 /(a+b x)} \\
y=1\end{array}$ & $\begin{array}{l}0,76 \\
0,81 \\
0,77\end{array}$ & $\begin{array}{l}1.006,79 \\
1.308,27 \\
-4,86 \times 10^{-4}\end{array}$ & $\begin{array}{l}-30,10 \\
-\quad 0,08 \\
\quad 2,67 \times 10^{-4}\end{array}$ \\
\hline $3 \mathrm{Cr} 5$ & $\begin{array}{l}y=a b^{b} b x \\
y=a x^{b} \\
y=1 / a+b x\end{array}$ & $\begin{array}{l}0,59 \\
0,50 \\
0, c 3\end{array}$ & $\begin{array}{l}504,89 \\
407,64 \\
3,77 \times 10^{-3}\end{array}$ & $\begin{array}{l}-17,93 \\
-\quad 0,07 \\
\quad 3,99 \times 10^{-4}\end{array}$ \\
\hline $3 \mathrm{Cr} 10$ & $\begin{array}{l}y=a b^{b} b x \\
y=a x^{2} \\
y=1 /(a+b x)\end{array}$ & $\begin{array}{l}0,38 \\
0,31 \\
0, \hat{\imath} 2\end{array}$ & $\begin{array}{l}238,53 \\
205,34 \\
6,05 \times 10^{-3}\end{array}$ & $\begin{array}{ll}- & 6,35 \\
- & 0,04 \\
& 4,06 \times 10^{-4}\end{array}$ \\
\hline $3 \mathrm{Cr}<0$ & $\begin{array}{l}y=a \\
y=a e^{b} x^{b x} \\
y=1 /(a+b x)\end{array}$ & $\begin{array}{l}0,73 \\
0,73 \\
0,63\end{array}$ & $\begin{array}{l}509,5 \\
55^{2}, 45 \\
-4,03 \times 10^{-4}\end{array}$ & $\begin{array}{l}-19,16 \\
-\quad 0,10 \\
\quad 1,02 \times 10^{-3}\end{array}$ \\
\hline
\end{tabular}


Tabela 14 - Ajuste de curvas obtidas no computador CP500 proló gica com os dados da análise de terra da coluna de PV-ortio e TE com metal $\mathrm{M}^{+}$cromo com $\mathrm{pH}$ corrigido.

Tratamento Equaç̃o Coeficiente Ajustada
Correlação

\begin{tabular}{|c|c|c|c|c|}
\hline $1 \mathrm{Cr}_{\mathrm{c}} 5$ & $\begin{array}{l}y=a+b x \\
y=a e^{b x} \\
y=1 /(a+b x)\end{array}$ & $\begin{array}{l}0,74 \\
0,80 \\
0,68\end{array}$ & $\begin{array}{l}535,86 \\
520,07 \\
1,85 \times 10^{-3} .\end{array}$ & $\begin{array}{l}-20,57 . \\
-0,69 \\
6,53 \times 10^{-4}\end{array}$ \\
\hline $1 \mathrm{Cr}_{\mathrm{C}} 10$ & $\begin{array}{l}y=a+b x \\
y=a e^{b x} \\
y=1 /(a+b x)\end{array}$ & $\begin{array}{l}0,73 \\
0,88 \\
0,84\end{array}$ & $\begin{array}{l}540,29 \\
551,48 \\
\quad 4,03 \times 10^{-4}\end{array}$ & $\begin{array}{l}-20,97 \\
-0,09 \\
7,43 \times 10^{-4}\end{array}$ \\
\hline $1 \mathrm{Cr}_{\mathrm{c}} 20$ & $\begin{array}{l}y=a+b x \\
y=a e^{b x} \\
y=1 /(a+b x)\end{array}$ & $\begin{array}{l}0,63 \\
0,83 \\
0,71\end{array}$ & $\begin{array}{l}475,78 \\
444,46 \\
1,15 \times 10^{-3}\end{array}$ & $\begin{array}{l}-18,61 \\
-0,09 \\
8,05 \times 10^{-4}\end{array}$ \\
\hline $3 \mathrm{Cr}_{\mathrm{C}} 5$ & $\begin{array}{l}y=a+b x \\
y=a e^{b x} \\
y=1 /(a+b x)\end{array}$ & $\begin{array}{l}0,57 \\
0,71 \\
0,58\end{array}$ & $\begin{array}{l}505,82 \\
360,01 \\
5,08 \times 10^{-3}\end{array}$ & $\begin{array}{l}-21,46 \\
-0,12 \\
1,51 \times 10^{-3}\end{array}$ \\
\hline $3 \mathrm{Cr}_{\mathrm{c}} 10$ & $\begin{array}{l}y=a+b x \\
y=a e^{b x} \\
y=1 /(a+b x)\end{array}$ & $\begin{array}{l}0,66 \\
0,78 \\
0,53\end{array}$ & $\begin{array}{l}377,64 \\
399,54 \\
-6,25 \times 10^{-4}\end{array}$ & $\begin{array}{l}-14,59 \\
-0,10 \\
\quad 1,47 \times 10^{-3}\end{array}$ \\
\hline $3 \mathrm{Cr}_{\mathrm{c}} 20$ & $\begin{array}{l}y=a+b x \\
y=a e^{b x} \\
y=1 /(a+b x)\end{array}$ & $\begin{array}{l}0,78 \\
0,76 \\
0,58\end{array}$ & $\begin{array}{l}343,5 \\
352,54 \\
\quad 1,64 \times 10^{-3}\end{array}$ & $\begin{aligned}- & 13,67 \\
- & 0,12 \\
& 1,98 \times 10^{-3}\end{aligned}$ \\
\hline
\end{tabular}


Tabela 15 - Ajuste de curvas obtidas no computador CP500 Prológica com os dados das anālises de terra na coluna de PV-orto, GH e TE com o metal $\mathrm{M}^{2}{ }^{+}$chumibo.

Tratamento Equação Coeficiente Constante Ajustada Correlação

$a b$

1. Pb 5

$y=a b b x^{b x}$
$y=a e^{2}$
$y=1 /(a+b x)$

0,96

0,89

0,70

$1 \mathrm{~Pb} 10$

$\begin{aligned} y & =a b x^{b x} \\ y & =a e^{b}\end{aligned}$

$y=1 /(a+b x)$

0,86

0,94

0,67

$1 \mathrm{~Pb} 20$

$y=a+b x b$

$y=a e$
$y=1 /(a+b x)$

0,83

0,81

0,51

$y=a$
$y=a e^{b} x^{b x}$

0,97

$\angle \mathrm{Pb} 5$

$y=1 /(a+b x)$

$y=a b x^{b x}$

$\angle \mathrm{Pb} 10$

$$
\begin{aligned}
& y=a e^{b x} \\
& y=1 /(a+b x)
\end{aligned}
$$

$2 \mathrm{~Pb} \approx 0$

$$
\begin{aligned}
& y=a \cdot b x^{b x} \\
& y=a e^{b}
\end{aligned}
$$

$y=1 /(a+b x)$

0,99

C,95

0,90

0,91

0,91

0,92

0,77

0,47

$3 \mathrm{~Pb} 5$

$y=a$
$y=a e^{b x}$

$y=1 /(a+b x)$

0,44

0,85

0,68

$y=a b x^{b x}$
$y=a e^{b}$

$\begin{array}{lll}3 \mathrm{~Pb} & 10\end{array}$

$y=1 /(a+b x)$

0,45

0,83

0,82

$y=a b^{b} b x$
$y=a e^{b}$

$3 \mathrm{~Pb} 20$

0,44

0,80

$$
\begin{aligned}
& y=a e^{b x} \\
& y=1 /(a+b x)
\end{aligned}
$$

C, 79

297,32
341,33
1,27

$1,27 \times 10^{-3}$

363,61

513,36

$-9,74 \times 10^{-3}$

179,80

198,26

$8,28 \times 10^{-4}$

303,76

323,24

$2,57 \times 10^{-3}$

331,17

346,27

$2,62 \times 10^{-3}$

253,23

534,02

- C,08

213,03

153,36

C, 20

217,64

164,52

$-0,19$

218,82

127,76

$-0,09$ b
$-7,76$

$-0,05$ $4,04 \times 10^{-4}$

$-13,21$

- 0,11 $1,52 \times 10^{-3}$

$-6,19$

$-0,08$ $1,50 \times 10^{-3}$

$-7,25$

- 0,39 $2,25 \times 10^{-4}$

$-6,79$ 0,63 $1,47 \times 10^{-4}$

$-9,24$

$-0,17$ $0,01 \times 10^{-4}$

- 9,59

$=0,21$ 0,66

$-9,66$

$-0,20$ 0,04

$-9,88$

$-0,21$

. 0,66 
Tabela 16 - Rjusie de curvas obtidas no computador CP500 Prológica cori os dados da anālise de terra na coluna de PV-orto e TE com o metal $\mathrm{M}^{2}$ chumbo com o pH corrigido.

Tratamento

Equação Coeficiente

Ajustada

correlação

$\frac{\text { Constante }}{a}$

\begin{tabular}{|c|c|c|c|c|}
\hline \multirow{3}{*}{$1 \mathrm{~Pb}_{\mathrm{C}} 5$} & $y=a+b x$ & 0,77 & 217,68 & $-9,24$ \\
\hline & $y=a e^{b x}$ & 0,90 & 359,19 & $-0,23$ \\
\hline & $y=1 /(a+b x)$ & 0,70 & $-0,17$ & 0,64 \\
\hline \multirow{3}{*}{$1 \mathrm{~Pb}_{\mathrm{C}} 10$} & $y=a+b x$ & 0,76 & 217,69 & $-9,27$ \\
\hline & $y=a e^{b x}$ & $c, 84$ & 282,72 & $-0,22$ \\
\hline & $y=1 /(a+b x)$ & 0,77 & $-\dot{0}, 11$ & $-0,04$ \\
\hline \multirow{3}{*}{$1 \mathrm{~Pb}_{\mathrm{C}}<0$. } & $y=a+b x$ & $0,7 b$ & 215,55 & $-9,10$ \\
\hline & $y=a e^{D x}$ & 0,62 & 187,53 & $-0,18$ \\
\hline & $y=1 /(a+b x)$ & 0,26 & 0,07 & 0,02 \\
\hline \multirow{3}{*}{$3 \mathrm{~Pb}_{\mathrm{c}} 5$} & $y=a+b x$ & 0,47 & 171,67 & $-7,56$ \\
\hline & $y=a e^{b x}$ & $\bullet, 83$ & 149,08 & $-0,18$ \\
\hline & $y=1 /(a+b x)$ & 0,60 & $-0,10$ & 0,03 \\
\hline \multirow{3}{*}{$3 \mathrm{~Pb}_{\mathrm{C}} 10$} & $y=a+b x$ & 0,50 & 244,57 & $-10,93$ \\
\hline & $y=a e^{b x}$ & 0,86 & 204,41 & $-0,21$ \\
\hline & $y=1 /(a+b x)$ & 0,85 & $-0,12$ & 0,04 \\
\hline \multirow{3}{*}{$3 \mathrm{~Pb}_{\mathrm{c}} 20$} & $y=a+b x$ & 0,42 & 218,16 & $-9,92$ \\
\hline & $y=a e^{b x}$ & 0,56 & 56,66 & $-0,15$ \\
\hline & $y=1 /(a+b x)$ & 0,32 & 0,18 & 0,02 \\
\hline
\end{tabular}


Tabela 17 - Ajuste de curvas obtidas no computador CP500 prológica com os dados das anălises de terra na coluna de PV-orto, $\mathrm{GH}$ e TE com metal $\mathrm{H}^{2}{ }^{+} \mathrm{cädmio.}$

Tratamento

Equacão coeficiente

Ajustada

Correlacão

$\frac{\text { Constante }}{a}$

$1 \mathrm{Cd} 5$

$y=a b x^{b x}$

$y=a e^{b x}$

$y=1 /(a+b x)$

$1 \operatorname{cd} 10$

$y=a+b x$

$y=a e^{b x}$

$y=1 /(a+b x)$

$y=a+5 x^{b x}$

$1 \mathrm{Cd} 20$

$y=a e^{b x}$
$y=1 /(a+b x)$

$2 \operatorname{cd} 5$

$y=a+b x^{b x}$

$y=a e^{b x}$
$y=1 /(a+b x)$

$2 \mathrm{Cd} 10$

$y=a b b x x$
$y=a x^{b x}$

$y=1 /(a+b x)$

$2 \mathrm{Cd} 20$

$y=a$
$y=a e^{b} x^{b x}$

$y=1 /(a+b x)$

$y=a$
$y=a e^{b} x^{b x}$

3 Cá 5

$$
y=1 /(a+b x)
$$

$y=a b b x^{b x}$
$y=a e^{2}$

3 Ca 10

$y=1 /(a+b x)$

$3 \mathrm{~cd} 20$ $y=a b b x^{b x}$
$y=a e^{2}$

$y=1 /(a+b x)$
0,74

0,81

0,77

0,81

0,81

0,75

0,79

0,79

0,77

0,61

0,56

0,50

0,81

0,79

0,76

0,78

0,80

$.0,80$

0,67

0,69

0,69

0,42

0,44

0,45

0,86

0,86

0,80
127,94

128,24

$7,25 \times$

115,37

120,69

$7,37 \times 10^{-3}$

$-3,64$

$-0,05$

$7,02 \times 10^{-4}$

$-2,97$

$-0,04$ $6,87 \times 10^{-4}$

106,92

108, 35

$9,04 \times 10^{-3}$

$-1,37$

$-0,02$ $1,95 \times 10^{-4}$

58,09

57,67

0,02

$-0,70$

$-0,02$ $2,81 \times 10^{-4}$

80,20

81,30

0,01

$-1,07$

$-0,01$ $2,78 \times 10^{-4}$

61,00

61,29

(i, 02

$-0,60$

- 0,01 $2,24 \times 10^{-4}$

123,48

122,06 $8,28 \times 10^{-3}$

$-1,82$ 0,02 $1,73 \times 10^{-4}$

$\begin{array}{rr}115,48 & -1,75 \\ 109,70 & -0,02 \\ 9,58 \times 10^{-3} & 1,54 \times 10^{-4} \\ 143,04 & -3,63 \\ 153,92 \times 10^{-3} & -0,04 \\ 4,89 \times 10 \times 10^{-4}\end{array}$


Tabela 18 - Ajuste de curvas obtidas no computador CP500 Prologica com os dados das anālises de terra na coluna de PV-orto e TE com metal $\mathrm{M}^{2}{ }^{+}$cādmio com $\mathrm{pH}$ corrigi do.

Tratamento

\section{Equação Coeficiente}

Ajustada

Correlaçäo

0,91

$1 \operatorname{cd}_{c} 5 \quad y=a e^{b x}$

$y=1 /(a+b x)$

$y=a+b x$

$1 \operatorname{cd}_{c} 10 \quad y=a e^{b x}$

$y=1 /(a+b x)$

$$
y=a+b x
$$

$1 \mathrm{Ca}_{c} 20 \quad y=a e^{b x}$

$y=1 /(a+b x)$

$$
y=a+b x
$$

$3 \mathrm{Cd}_{\mathrm{c}} 5$

$$
y=a e^{b x}
$$$$
y=1 /(a+b x)
$$

$y=a+b x$

$3 \mathrm{Cd}_{c} 10 \quad y=a e^{b x}$

$y=1 /(a+b x)$

$$
y=a+b x
$$

$3 \mathrm{Ca}_{c} 20 \quad y=a e^{b x}$

$$
y=1 /(a+b x)
$$

0,92

0,91

0,98

0,98

0,96

0,81

0,84

0,86

0,92

0,93

0,81

0,83

0,82

0,76

0,97

0,75

0,40
53,53

54,60

0,02

49,65

49,85

0,02

167,03

$-5,19$

203,43

$-8,29 \times 10^{-4}$

$-0,07$

$1,30 \times 10^{-3}$

$17 \hat{c}, 47$

179,55

$-3,97$

4,93

215,27

457,02

$-7,54$

$-0,15$

- 0,16

$-0,02$ 


\section{IV - RESULTADOS E DISCUSSÃO}

\subsection{Adsorção de metais pesados}

Nas Tabelas 19 a 21 encontram-se os valores calculados a partir dos dados das anālises químicas das so iuções em equilibrio. As Tabelas 22 e 25 foi calculado ajustan do-se a curva pelo mētodo do mïnimo quadrado (MIRSHAHKA, 1984, p. 500) e obtidos as constantes para equação de Freundlich e de Langmuir.

$$
\text { Os resultados encontrados na prova }
$$

branco de $\mathrm{Ni}^{2}$ pocieni ser considerados como existentes em "in na tura" nos solos (LEVI-MINZI et alii 1976, WAKETA e SCHIMITT, 1970) ou para baixas concentracões a sensibilidade do espectrō metro deixa de ter valores significativos. A anālise das Tabe- 
las 19 a 21 mostra que atē os 10 ppm os valores são praticamen te iguais na solucão de equilíbrio aos da prova en branco. Se considerarmos sendo igual a zero a prova em branco, logo a con centração finăl de equilỉbrio não existem $\mathrm{M}^{2}{ }^{+}$atē os $10 \mathrm{ppm}$ de concentracão, portanto, estando totalmente adsorvidos. Por outro lado este resultado dificulta os cālculos de regressão matemática da Tabela 22 e 25 , não espelhando a real situação experimental. Os demais valores, são pertinentes as particuiaridades de cada elemento químico e os tipos de solos dos quais passaremos a discutir. 


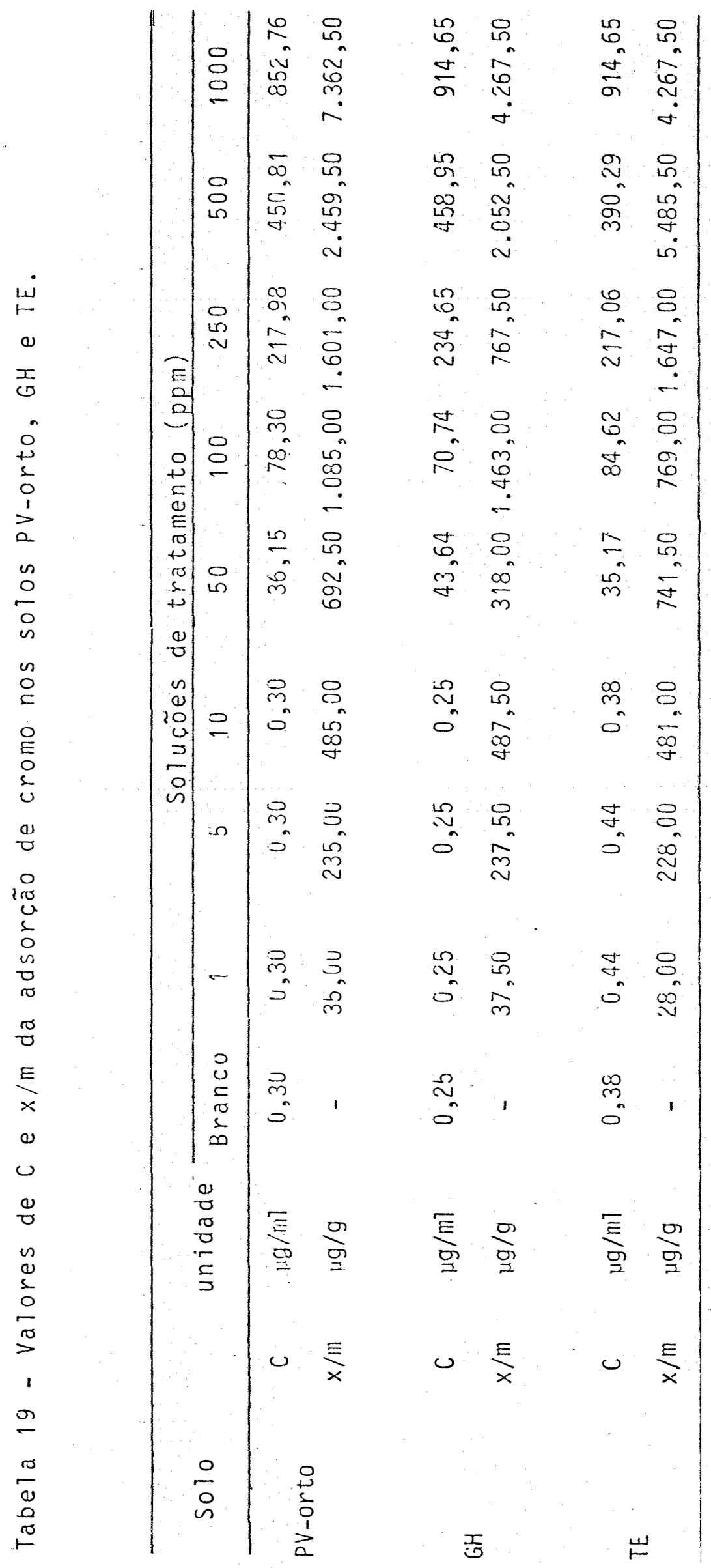




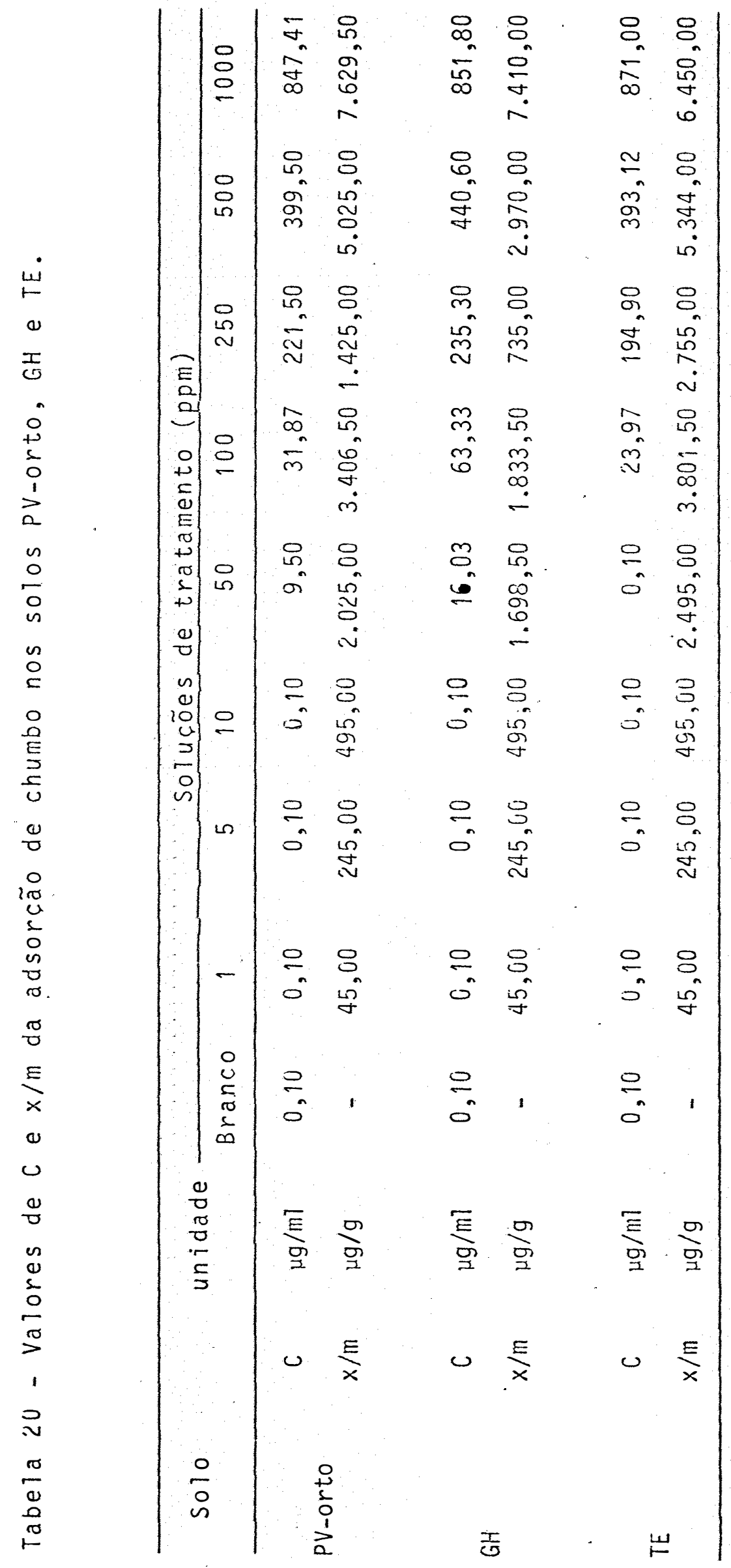




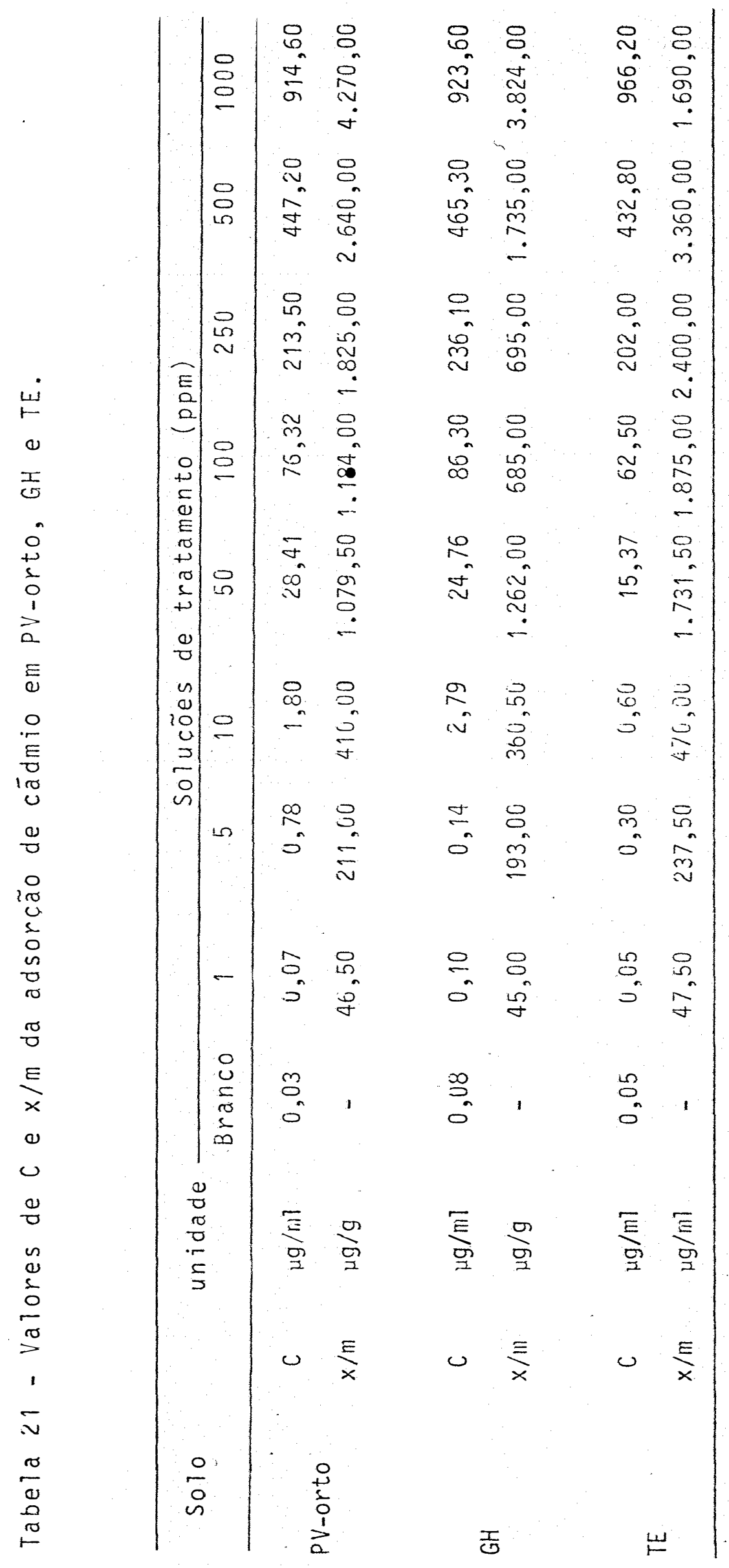




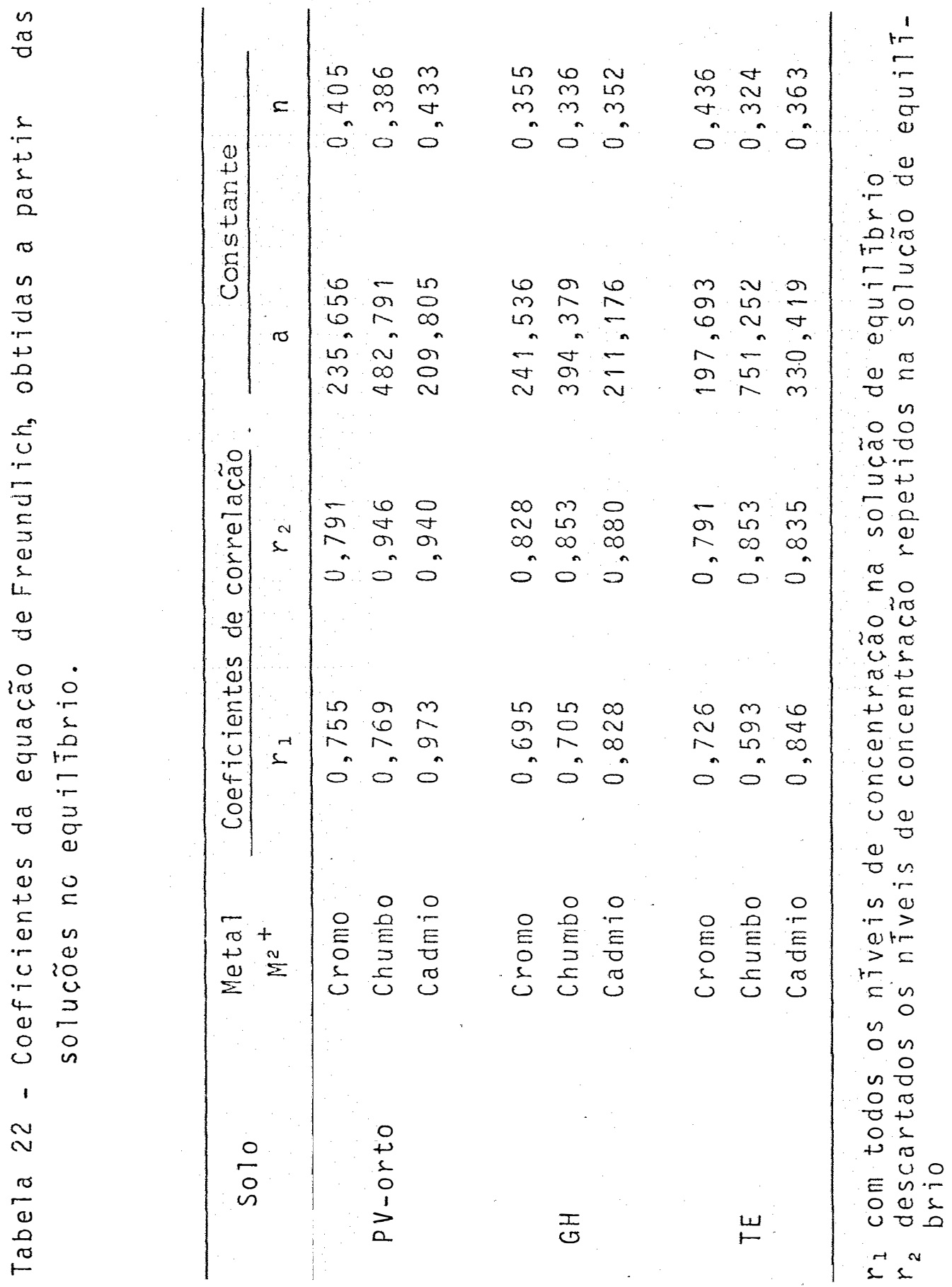




\subsubsection{Adsorcão seletiva por solos}

As caracteristicas químicas dos solos influem na adsorcão, independentemente dos cations $\mathrm{M}^{2}{ }^{+}$. Isto ē facilmente visualizado nas Figuras 8 a 10 e 14 a 16 com a isoterma de adsorção como tambēm na Figura 11 a 13 e 17 a 19 com a equação de Freundlich.

As adsorcões estão na seguinte ordem:

$\mathrm{TE}>\mathrm{PV}$-orto $>\mathrm{GH}$

A anālise granulomētrica apresenta diferencas entre os trés tipos de solos. A TE apresenta um teor de argila bem superior, seguida pelo G H. Todavia, os resultados mostran que não são estes os fatores que diferenciam ou determinam a adsorcão seletiva do solo, uma vez que não é essa ordem encontrada.

A constituicão minerolōgica e quĩmica do solo devem influir com maior preponderãncia pois a vista da Ta bela 1, indicam-nos a ordem de CTC efetiva ser semelhante na seletividade da adsorcão pelo solo. Desta forma, a seguir analisaremos sob este ponto de vista fisico-químico. 


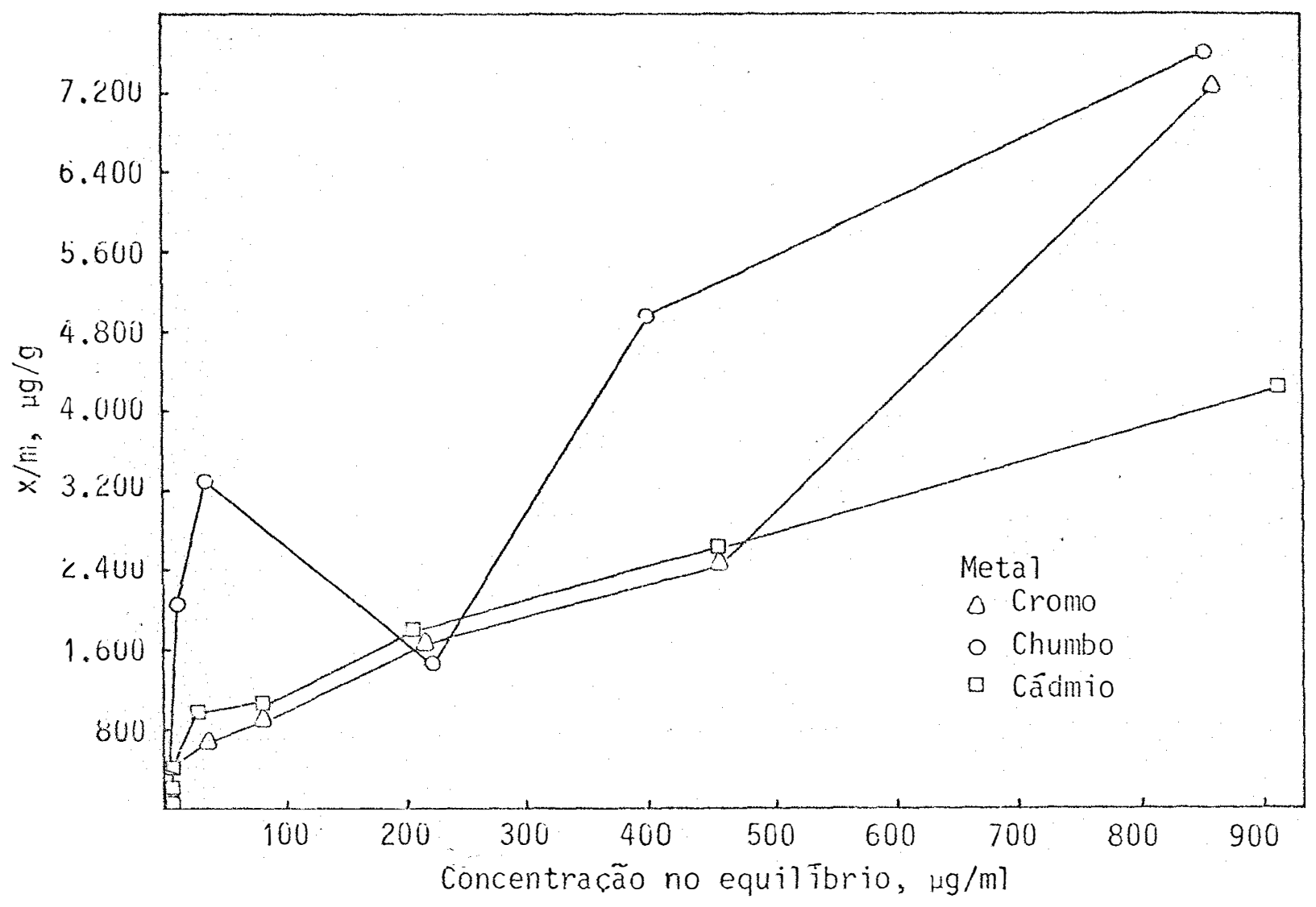

Figura 8 - Isoterma de adsorcão de cromo, chumbo, cãdmio em PV-orto. 


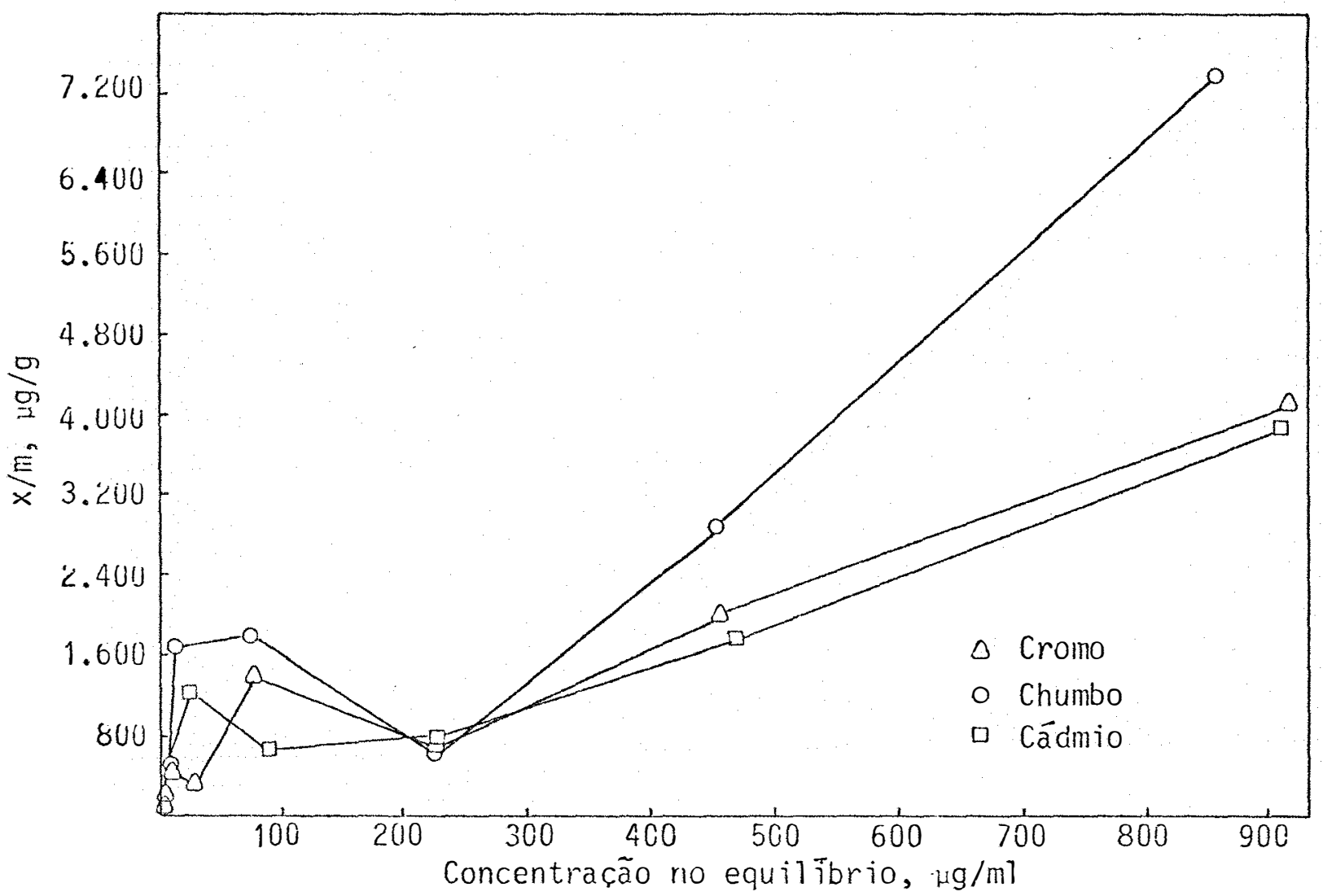

Figura 9 - Isoterma de adsorcão de cromo, chumbo e cádmio em GH. 


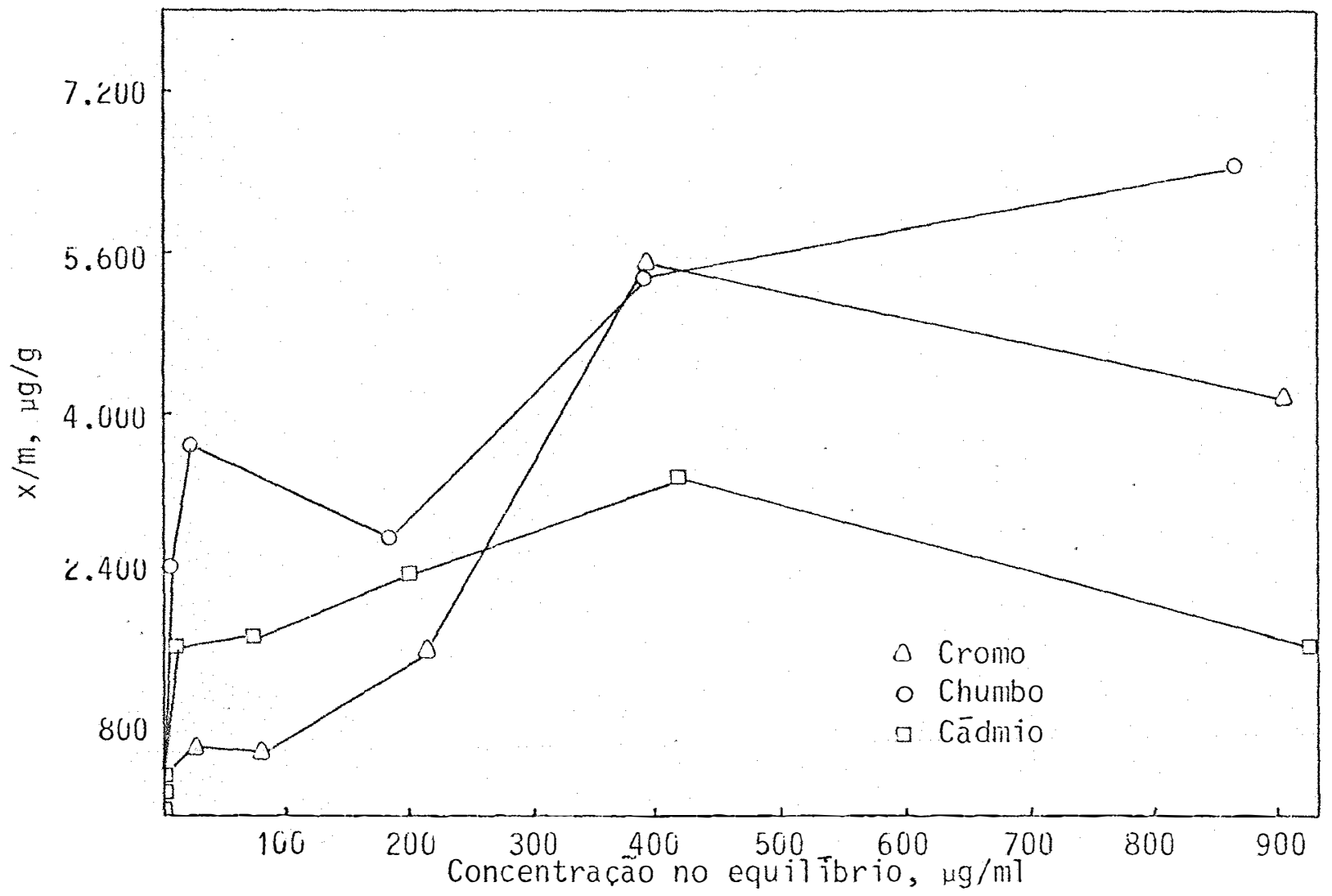

Figura 10 - Isoterma de adsorcão de cromo, chumbo e cádmio em TE. 


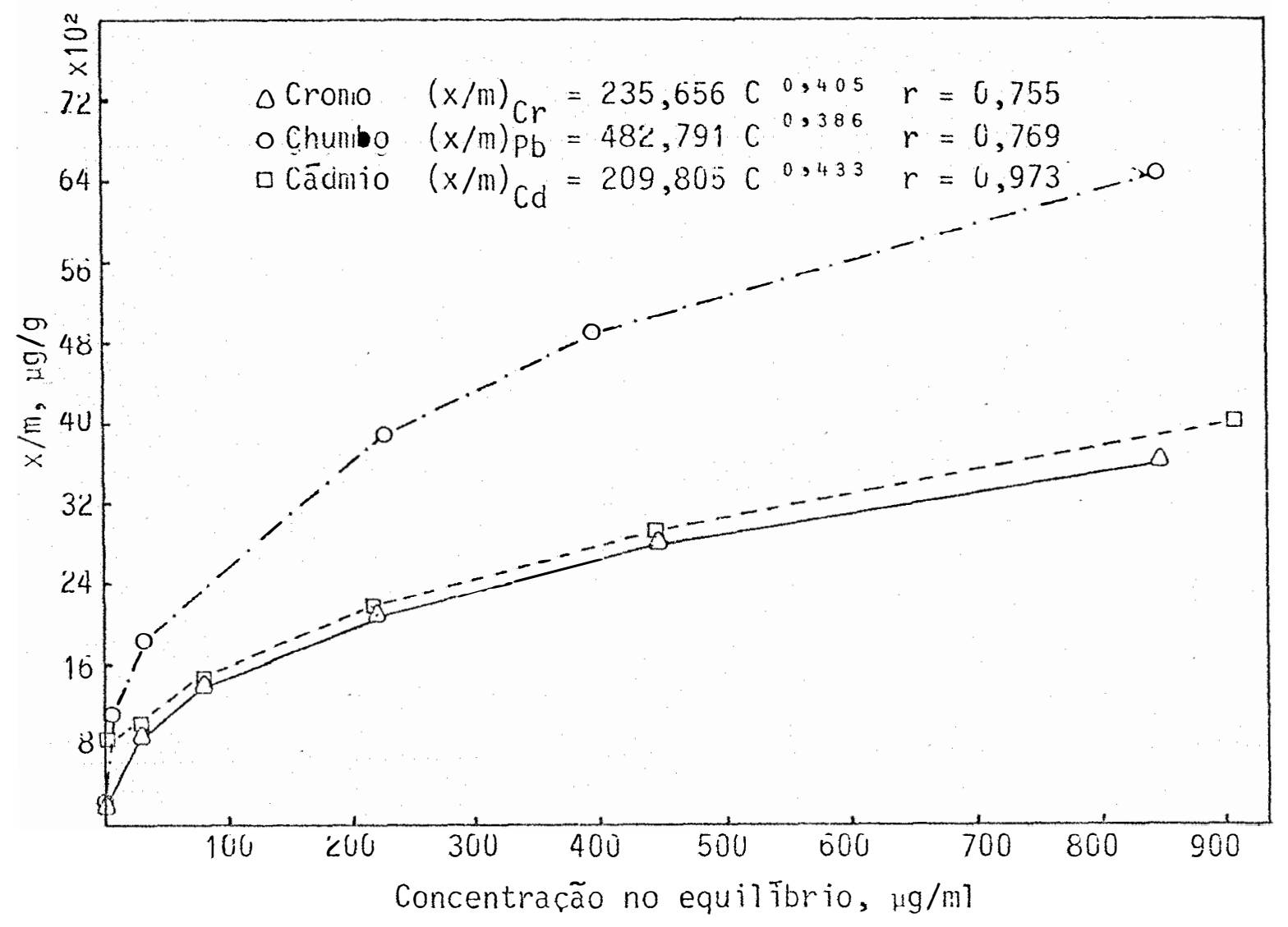

Figura 11 - Isoterma de adsorcão dos metais $\mathrm{H}^{2}+$ de acordo com a Equaçăo de Freundi ich em PV-orto. 


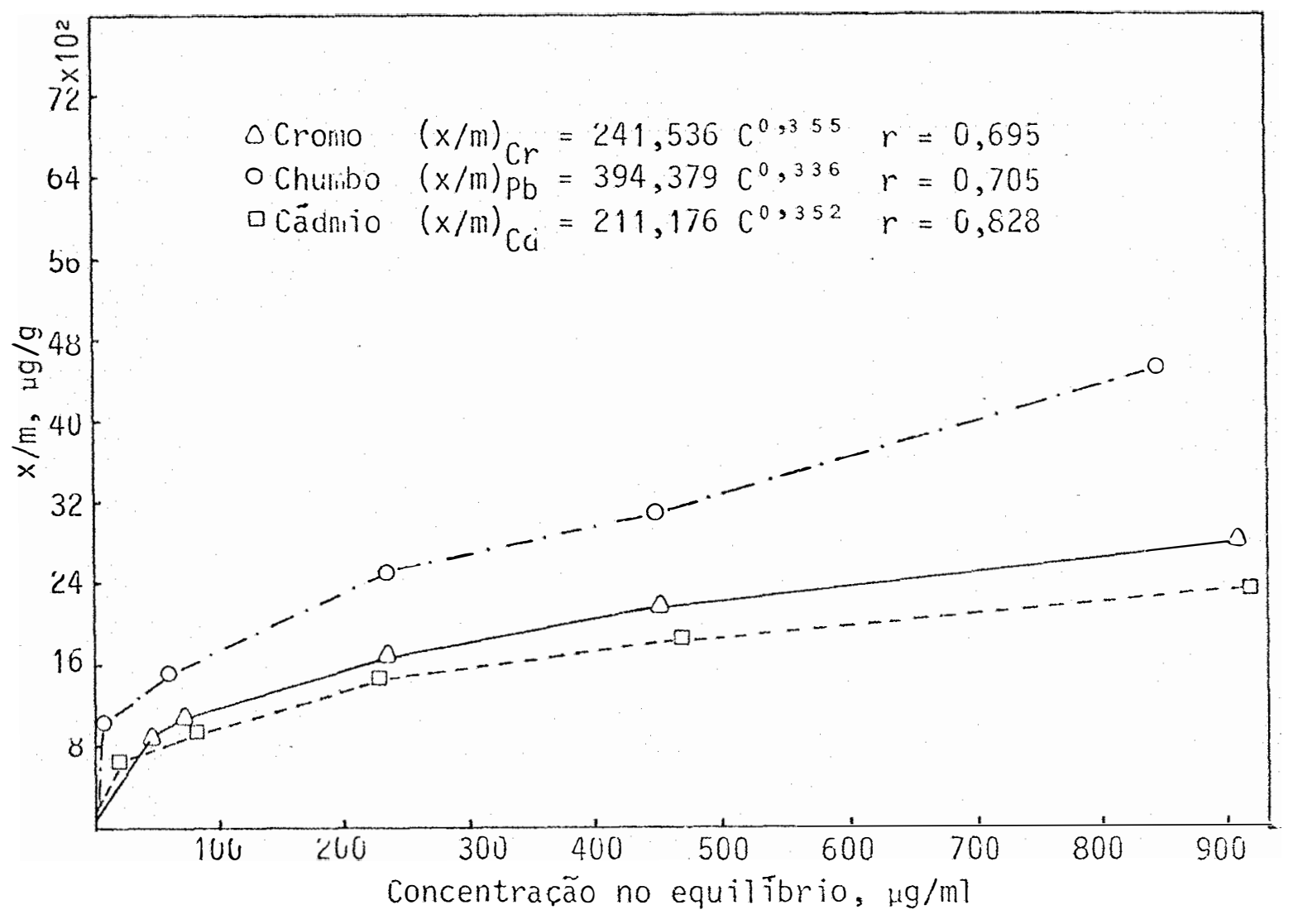

Figura 12 - Isoterma de adsorcão dos metais $\mathrm{M}^{2}$ de acordo com a Equacão de Freundlich em GH. 


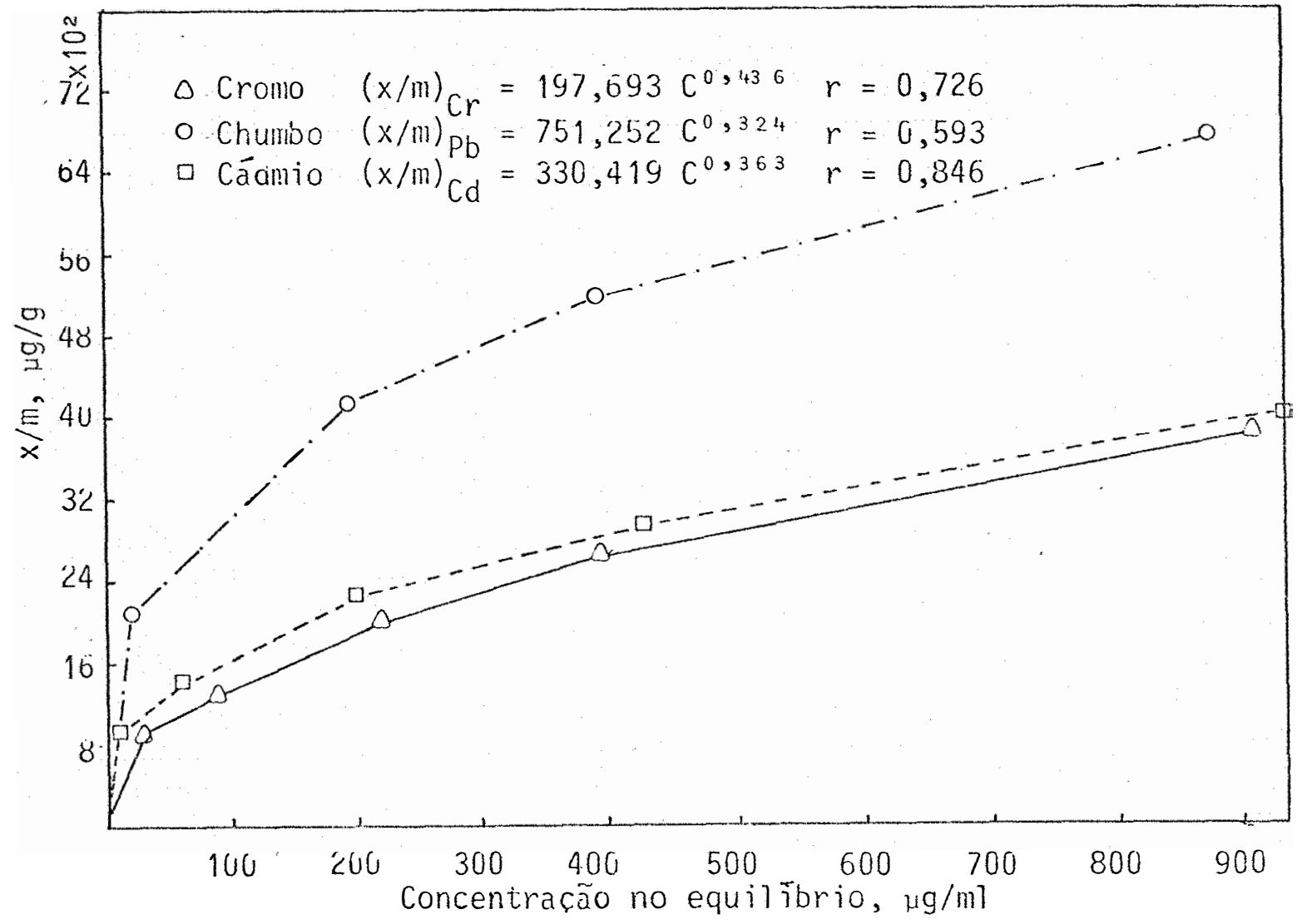

Figura 13 - Isoterma de adșorcão de metal $\mathrm{M}^{2}{ }^{+}$de acordo com à Equação Freundlich em TE. 


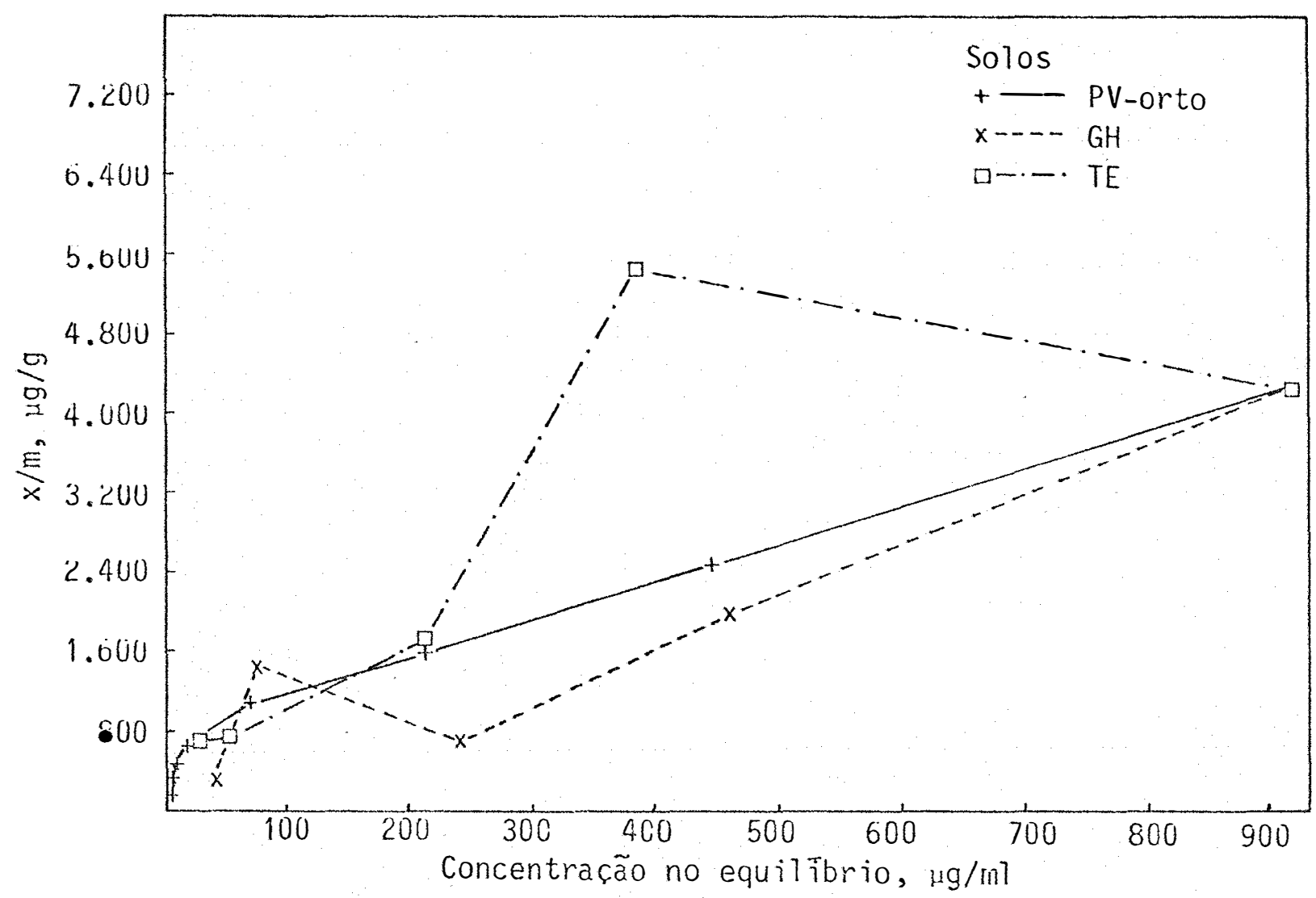

Figura 14 - Isoterma de adsorcão de cromo em PV-orto, GH e TE. 


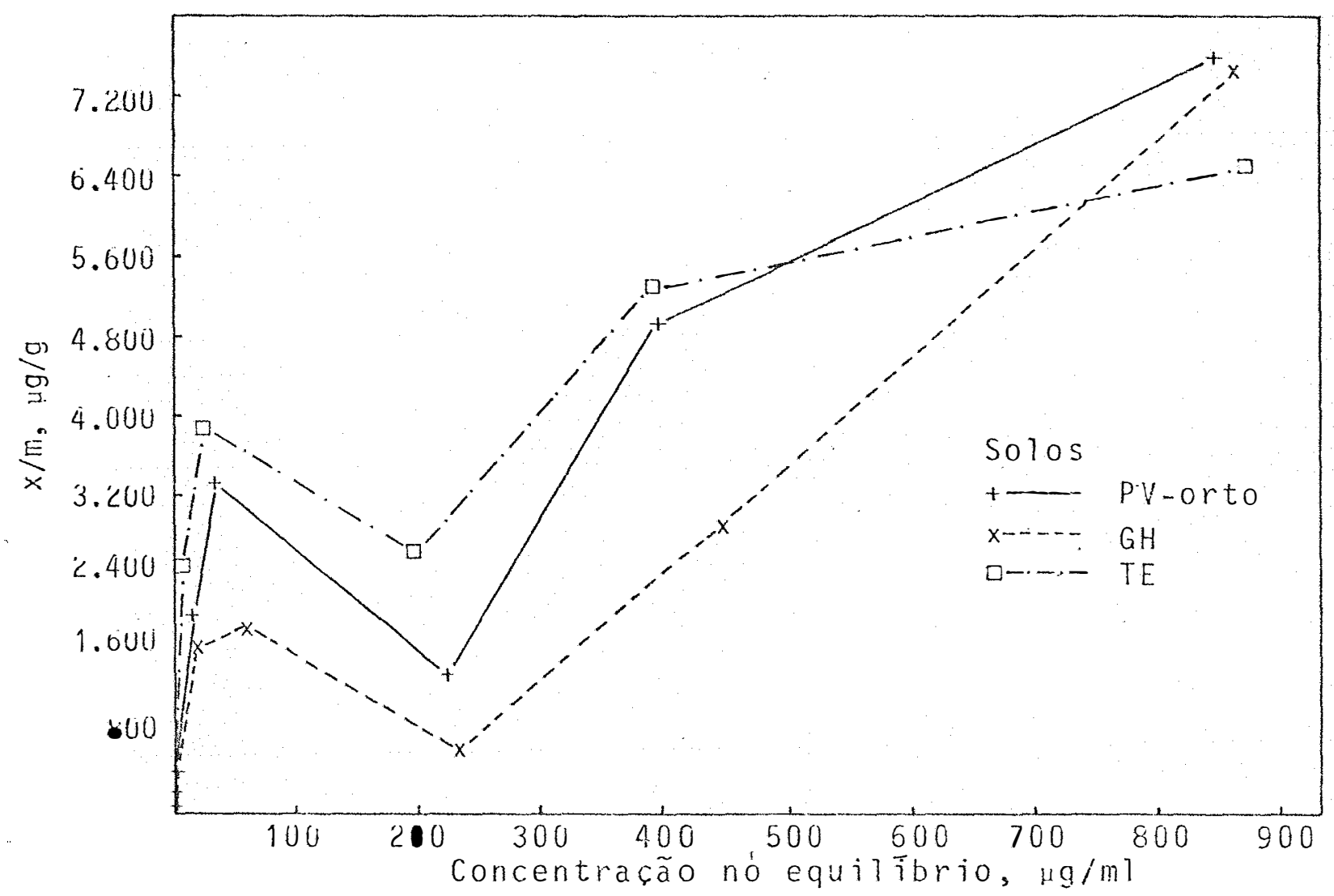

Figura 15 - Isoterma de adsorção de chumbo em PV-orto, GH e TE. 
.122.

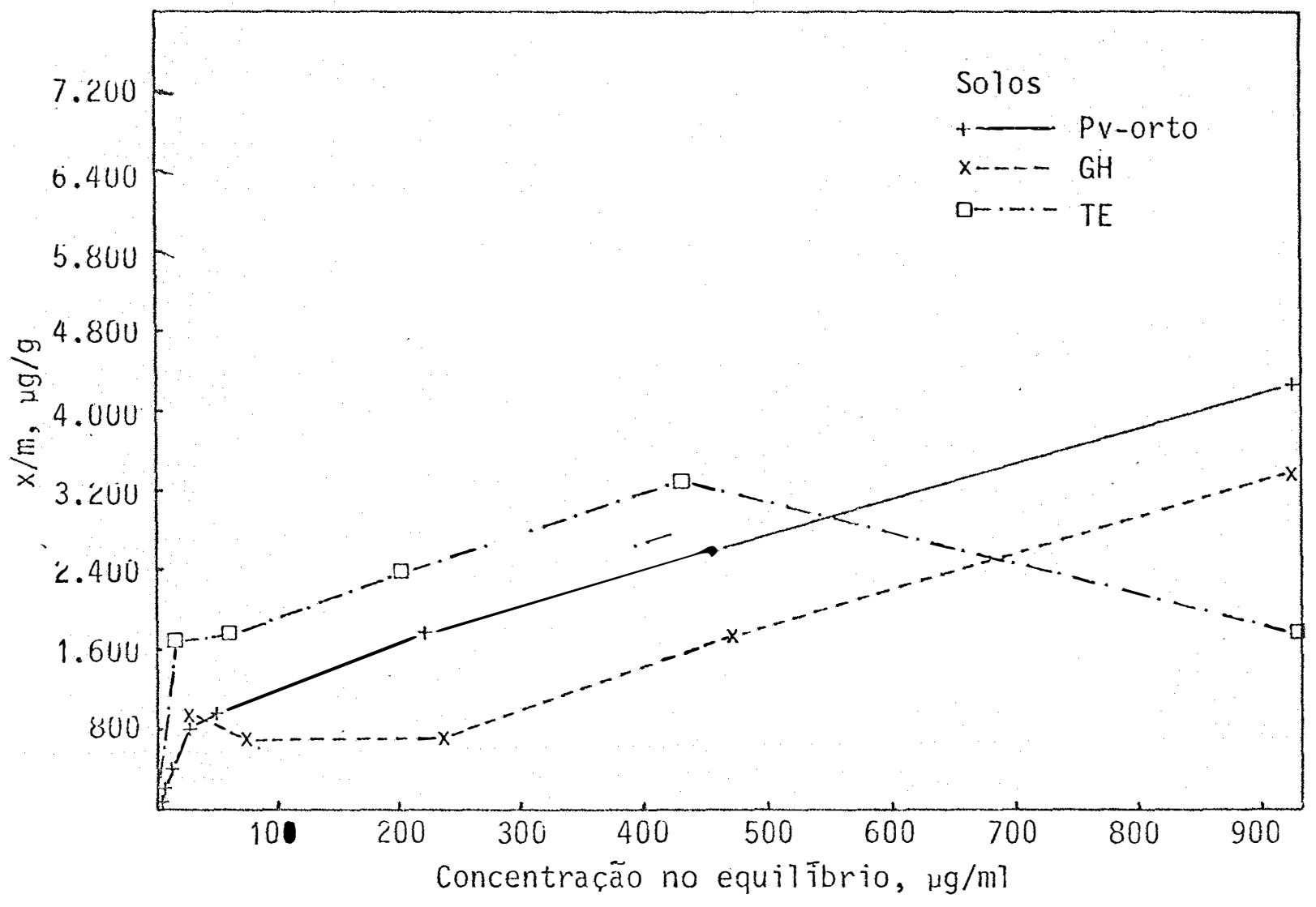

Figura 16- Isoterma de adsorção de cádmio em PV-orto, GH e TE. 


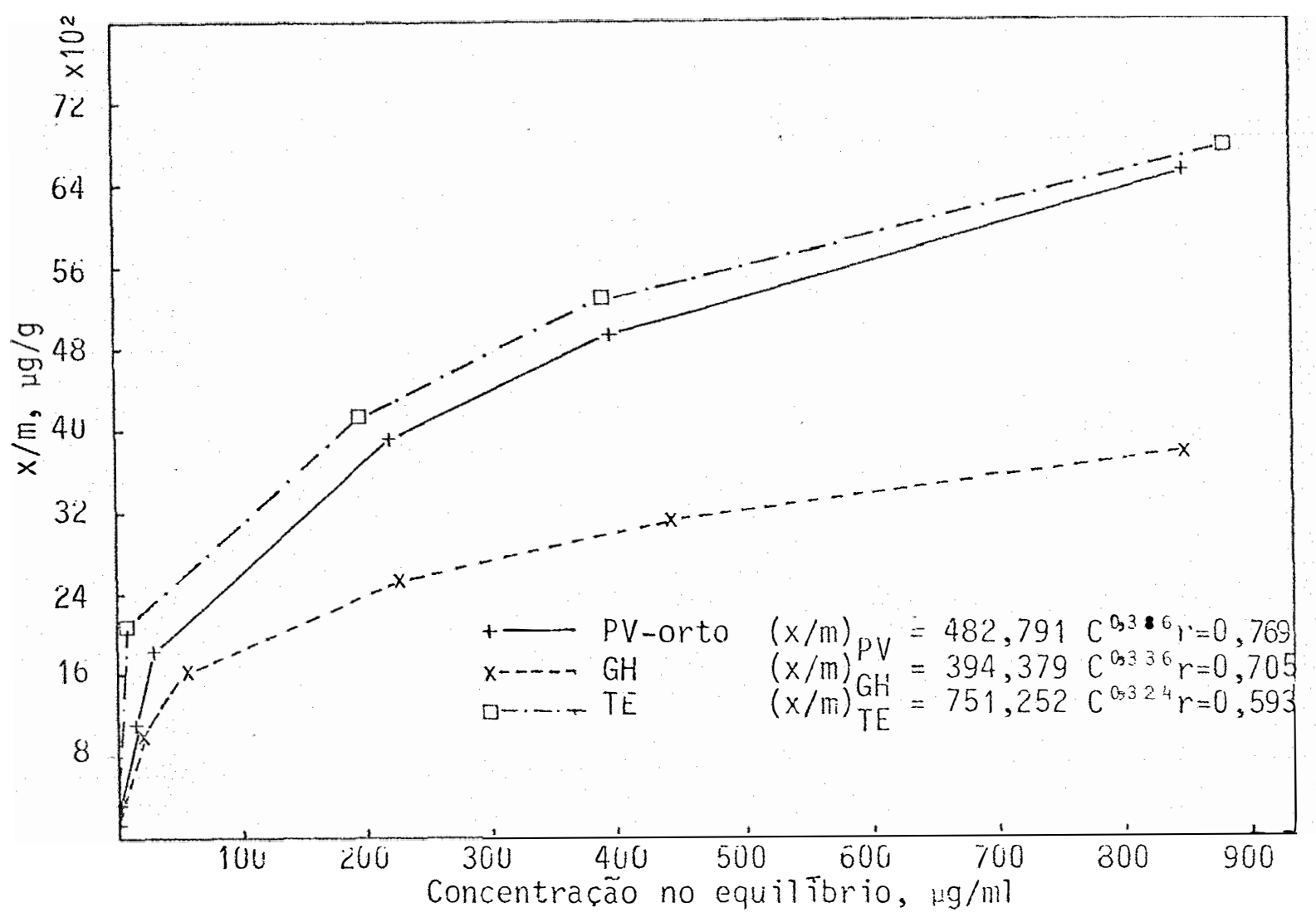

Figura 18 - Isoterma de adsorção de chumbo de acordo com a Equaç̃o de Freundlich em PV-orto, GH e TE. 


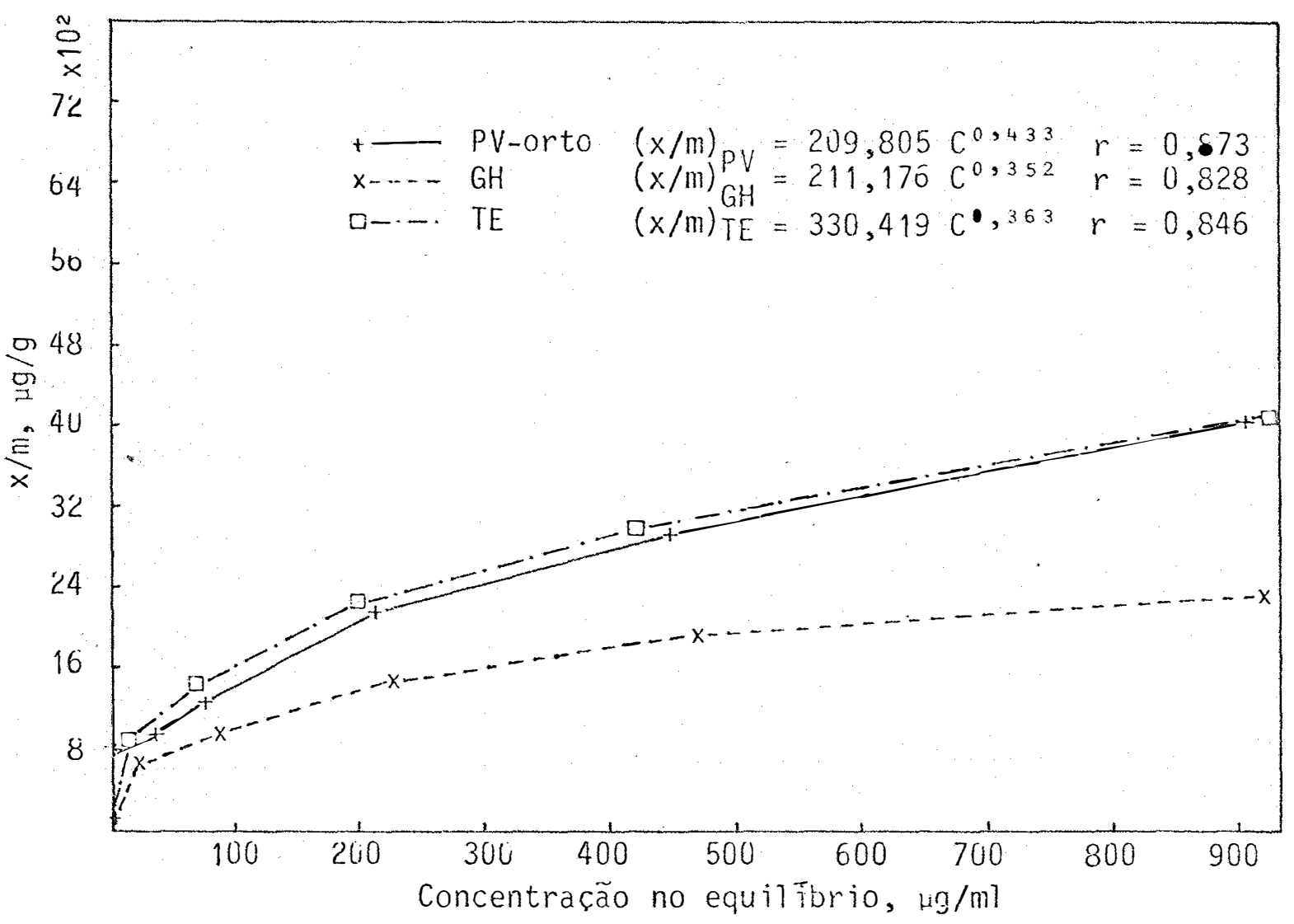

Figura 19 - Isoterma de adșorção de cádmio em PV-orto, GH e TE. Equacão de Freundlich em PV-orto, GH e TE. 


\subsubsection{Adsorcão seletiva por metal $\mathrm{M}^{2}+$}

Os resurtados encontrados na anälise quĩmica da solucão no equilî́brio no experimento de adsorcão (Tabe 1 a 19 a 21 ) mostram que a capacidade adsortiva dos metais $\mathrm{M}^{2}$ são independentes dos tipos de solos. Estas ordens de grandezas podem ser visualizadas nos gräficos da Figura 8 a 10 e 14 a $16 \mathrm{da}$ isoterma de adsorção e Figura 11 a 13 e 17 a 19 da equacão de Freundlich, das quais estäo na seguinte ordem:

a. $\mathrm{mg} / 100 \mathrm{~g}$ terra: $\mathrm{Pb}>\mathrm{Cd} \geqslant \mathrm{Cr}$

b. meq/100 g terra: $\mathrm{Cr}>\mathrm{Cd} \geqslant \mathrm{Pb}$

A razão da inversão da ordem de adsorção no îtem b deve ser a concentracão, pois acham-se na seguinte proporcão aproximada:

$C r: C d: P b \simeq 4: 2: 1$

Isto é irretorquĩvel, uma vez nas mesmas concentracões (ppm), o chumbo è 103,6 mg/meq, cādmio 56,2 mg/ meq e cromo 26,0 rig/meq que guarda a relacão $\simeq 4: 2: 1$.

Por outro lado, da equação 2.33 e 2.34 ob temos as constantes de equilíbrio dos pares iōnicos $K^{0}$ que poderão ser calculados a partir da equaç̃o 2.43. As constantes de equilíbrio $k^{0}$ do cādmio é maior do que o chumbo e cromo (LINDSAY, 1979, p. 318 e 332 ). 
Desta forma, temos:
$\log k^{0}$
$\mathrm{Cd}++2 \mathrm{Cl}^{-}+\underset{*}{+} \mathrm{CdCl}{ }_{2}^{\mathrm{O}}$
$2,60 \ldots \ldots \ldots(4.1)$

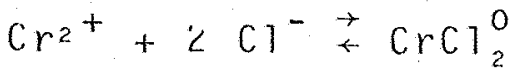
$\mathrm{Pb}^{2+}+2 \mathrm{NO}_{3}^{-} \stackrel{+}{*} \mathrm{~Pb}\left(\mathrm{NO}_{3}\right)_{2}^{\mathrm{O}}$
1,40

Pode-se observar pelos dados da equacão 4.1 e 4.3 , que o cādmio é o que apresenta major associacão em pares iōnicos e deveria ser o que teria menor adsorcão em forma iōnica de $\mathrm{Cd}^{2}$, o que é confirmado essa hipōtese com os resultados experimentais (Tabela 19 a 21 ).

Os pares iōnicos da equacão 4.1 a 4.3 em uma solucão aquosa são hidrolisados de acordo com itiem 2.1.3, uma vez que são.sais provenientes de ācidos fortes e base fraca, com consequente formacão de hidröxidos desses metais $\mathrm{M}^{+}$, o que è confirmado experimentalmente (Tabela 36). As reacões deverão processar da seguinte forma em meio aquoso:

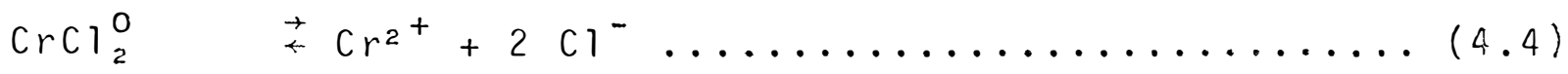

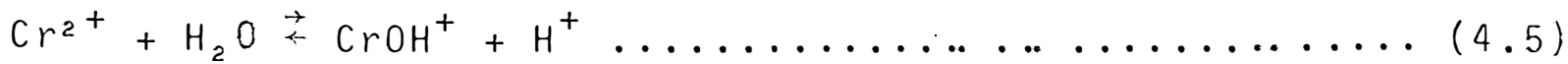




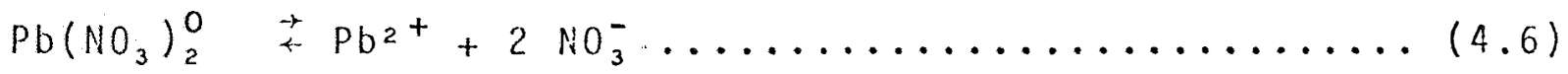

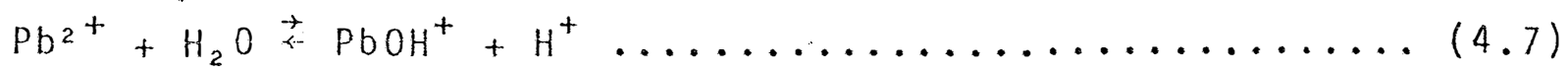

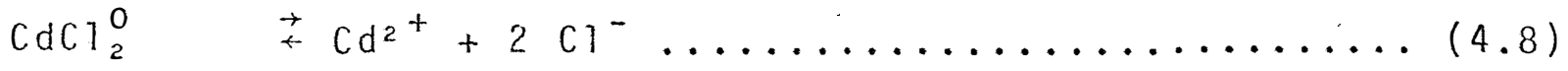

$\mathrm{Cd}^{2}+\mathrm{H}_{2} \mathrm{O} \stackrel{\leftarrow}{\leftarrow} \mathrm{CdOH}^{+}+\mathrm{H}^{+} \ldots \ldots \ldots \ldots \ldots \ldots \ldots \ldots \ldots \ldots \ldots \ldots \ldots \ldots \ldots \ldots \ldots$ (4.9)

Os valores de $\Delta G_{R}^{0}$ da Tabela 23 mostra que as reacões da equacão 4.4 a 4.9 requer menor energia livre.Por tanto, a forma predominante de adsorcão deve ser nesta forma iōnica.

Tabela 23 - Valores de $\Delta G_{r}^{0}$ de reacões de hidrólise calculados pela equacão 2.45 e $2.45^{\prime}$.

$\mathrm{Pb}^{2}+2 \mathrm{NO}_{3}^{-} \stackrel{+}{+} \mathrm{Pb}\left(\mathrm{NO}_{3}\right)_{2}^{\mathrm{O}}$

$-1,91$

$\mathrm{Pb}^{2}+\mathrm{H}_{2} \mathrm{O} \underset{\mathrm{PbOH}}{+}+\mathrm{H}^{+}$

10,50

$\mathrm{Pb}^{2}+2 \mathrm{H}_{2} \mathrm{O} \& \mathrm{~Pb}(\mathrm{OH})_{2}^{\mathrm{O}}+2 \mathrm{H}^{+}$

24,21

$\mathrm{Cd}^{2}+2 \mathrm{Cl}^{-} \rightarrow \mathrm{CdCl}_{2}^{\circ}$

$-3,55$

$\mathrm{Cd}^{2}+\mathrm{H}_{2} \mathrm{O} \rightleftarrows \mathrm{CdOH}^{+}+\mathrm{H}^{+}$

13,77

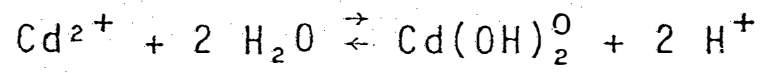

27,68 
Por outro lado, a hidrölise dos sais mostra (conforme equação 2.62) que os sais por ser do grupo de àcicios fortes e base fraca apresenta a seguinte reacão:

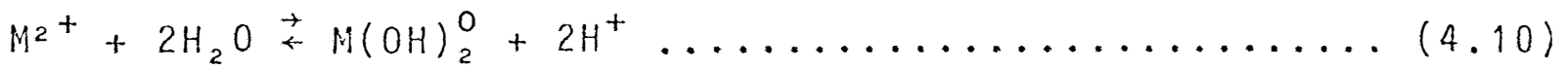

A adsorcăo iōnica do hidrōxido formado es táa longe de acontecer, uma vez que não hà carga. A constante de hidrólise (Tabela 24) mostra que a maior concentracão entre os elementos pesquisados esta $\left[\mathrm{M}(\mathrm{OH})_{2}^{0}\right]+\left[\mathrm{H}^{+}\right] \bar{e}$ na hidrōlis do sal de cromo. Assim a sua adsorção em relacão aos outros dois elementos deverä ser menor, o que è confirmado pelos resultados experimentais.

Tabela 24 - Constantes de hidrólises dos sais calculados com a equacão $2.63,2.78$ e $2.82 \mathrm{e} \mathrm{pH.}$

Sal pH mecido $25^{\circ} \mathrm{C}$ Ci noles $/ 1$

$K_{b}$

$k_{h}$

\begin{tabular}{lllll}
$\mathrm{CrCl}_{2}$ & 1,9 & 0,07505 & $4,73 \times 10^{-12}$ & $2,11 \times 10^{-3}$ \\
$\mathrm{~Pb}\left(\mathrm{NO}_{3}\right)_{2}$ & 2,5 & 0,06038 & $6,05 \times 10^{-11}$ & $1,65 \times 10^{-4}$ \\
$\mathrm{CdCl}_{2}$ & 5,2 & 0,08759 & $2,21 \times 10^{-5}$ & $4.52 \times 10^{-4}$ \\
\hline
\end{tabular}


As curvas de adsorcões dos metais $\mathrm{M}^{2}$ de acordo com o sistema de adsorcão das figuras 8 a 10 e 14 a 16 , deixam de ter as características clāssicas (conforme figura 4), salvo com metal $\mathrm{M}^{2}{ }^{+}$cádmio em PV-orto. Os outros dois metais são irregulares a baixas concentraçoes (ate os 250 ppm de concentração iniciall).

$\mathrm{Na}$ Tabela 25 , encontram-se os valores dos coeficientes das equações de Langmuir, calculados conforme item 3.2, na forma linear. 0 metal $\mathrm{M}^{+}$chumbo e o que apresenta o pior coeficiente de correlacão, tendo para o GH igual a 0,2310 e PV-orto 0,4994. De uma forma geral, O GH apresentam um indi.. ce bastante sofrível para o coeficiente de correlacăo para todos os metais. Entretanto a condicão è matemătica e não física ou quĩmica. As condicões matemāticas da equação impõe que a ca da aumento da concentracão do soluto no moles haja uma adsorcão $n^{j}$ moles pelo adsorvente proporcionalmente. Contuds, não é o que observamos no comportamento do GH. As trēs primeiras con centracões dos metais $\mathrm{M}^{2}$ apresentam adsorcão total. Logo, estes dados complicam sobremaneira o resultado analitico da reso lucão matemática. Para esta faixa de adsorcão tanto na equação de Langmuir como a de Freundlich não são felizes na reproducão do fenômeno para todos os tipos de solos pesquisado no presente trabalho. 


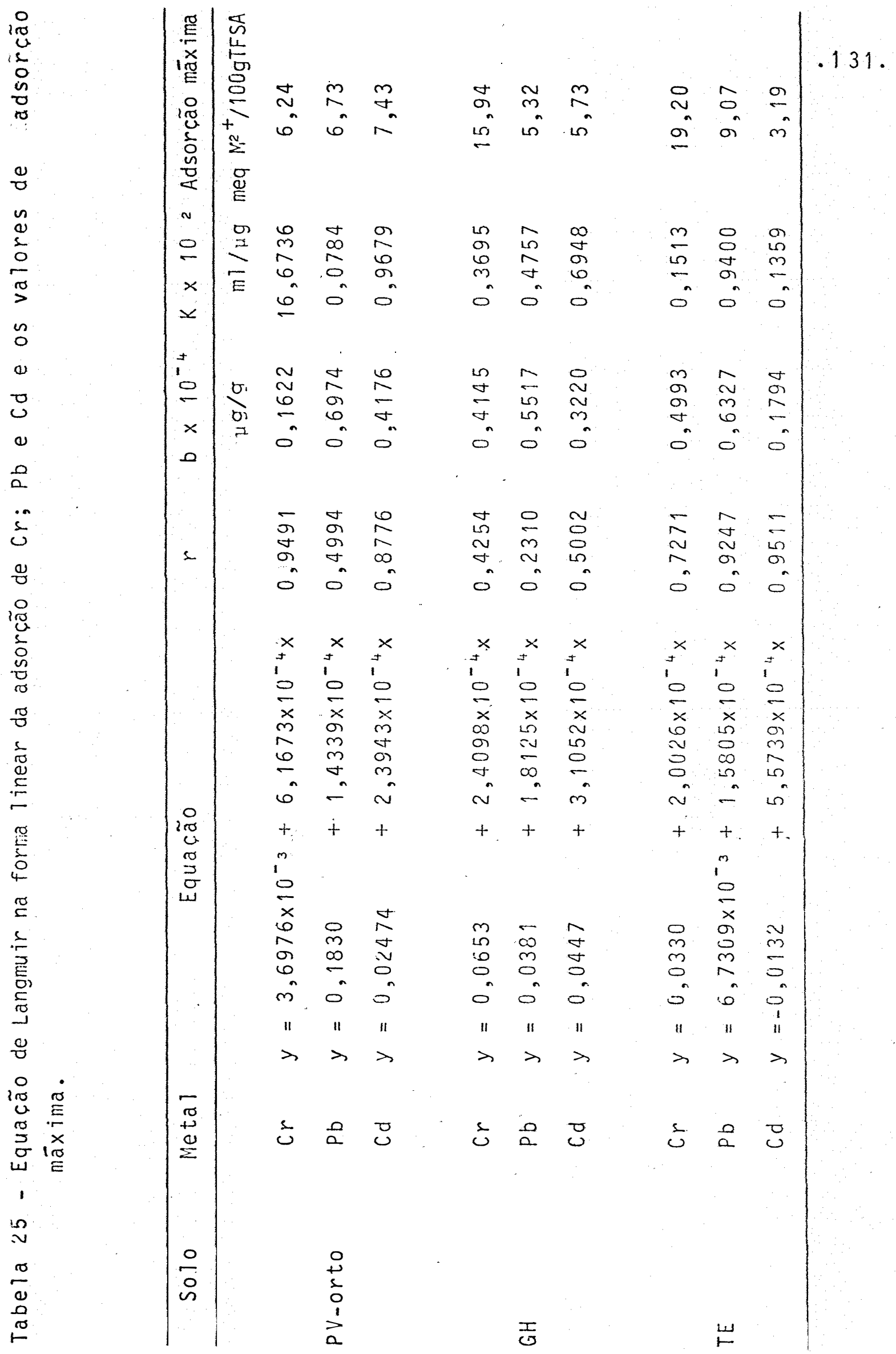


A maior influēncia do resultado analitico no GH é o valor encontrado a concentracão inicial ( $\left.C_{j}\right)$ de 250 ppm, onde para todos os solos apresentam os mesmos "fenómenos" (Figura 9). Pelas anālises dos gráficos 14 a 16, a princīpio poder-se-ia cogitar em erros acidentais do manuseio do expec trōmetro acoplado a computador plasma ATOM-COMP modelo 975. Erros acidentais de leitura humana não houve, uma vez que ē computadorizado, e por outra parte, foram efetuadas leituras em épocas diferentes. Assim sendo, forca concluir que o fenōme no seja uma caracteristica do solo. 0 GH apresenta baixa $\Sigma$ bases, isto é, apenas de 1,39 meq/100 g TFSA, entretanto a 100 ppm de Cr na $C_{i}$ estā adsorvido 5,63 meqCr/100 g TFSA, muito acima da prōpria CTC 7 que é de 4,91 meq/100 g TFSA, logo compe tindo com K $\mathrm{K}^{+} \mathrm{Ca}^{+}, \mathrm{Mg}^{2}$ e $\mathrm{Al}^{3+}$. A $250 \mathrm{ppm}$ de $\mathrm{Cr}$ na C $i$ notamos que a adsorcão passa a ser de $2,95 \mathrm{meqCr} / 100 \mathrm{~g}$ TFSA. Ora este valor está abaixo da CTC efetiva que é de 3,31 meq/100 g TFSA. Nota-se que houve um "colapso" na adsorcão e nas concentracões altas hā maiores retenções acimas das CTC $_{7}$.

Estas anomalias da adsorcão também é ver ficado em PV-orto e TE, pela simples anālises das Tabelas 19 a 21, porém ocorrem em forma proporcional, seguindo a equacão de Langmuir, pois os seus coeficientes de correlacão estão na or dem de $72 \%$ a $95 \%$ da equação teórica. 
As adsorcōes māximas obtidas a partir da equação de Langmuir (equacão 2.135) tabulados na Tabela 25, pa ra o GH deixa muito a desejar tendo em vista que matematicamen te não conseguiu-se o ajuste perfeito, nos tnes dados experimentais, cujos coeficientes de correlações estão abaixo de 0,5. Para outros dois solos, a confiabilidade são melhores. Nota-mse que a adsorção māxima obtida através da equação 2.135 para PV-orto e TE estäo praticamente iguais a CTC $_{7}$, observado tambēm por HARTER 1979. Isto mostra que as adsorcões a altas concentra cões do soluto, devem competir com toda sorte de cátions do so 10. (LAGERWERFF e BROWER 1972).

A Figura 10 e 16 mostra um decréscimo de adsorcão em TE a altas concentracões com o metal $\mathrm{M}^{2}{ }^{+}$cādmio e cromo. Uma das possiveis causas podem ser a competicão do ion $\mathrm{H}^{+}$na hidrōlise (equação 2.55), cuja concentração ē facilitada conforme podemos verificar pela Kh (Tabela 24, equacão 2.82, 2.55 e 2.63$)$. A competicão do jon $\mathrm{H}^{+}$faz-se presente havendo matēria orgānica, principalmente no caso de àcido hümico e fúl vico. Os trabalhos de TOLEDO (1976) mostram estes efeitos no grupo carboxila:
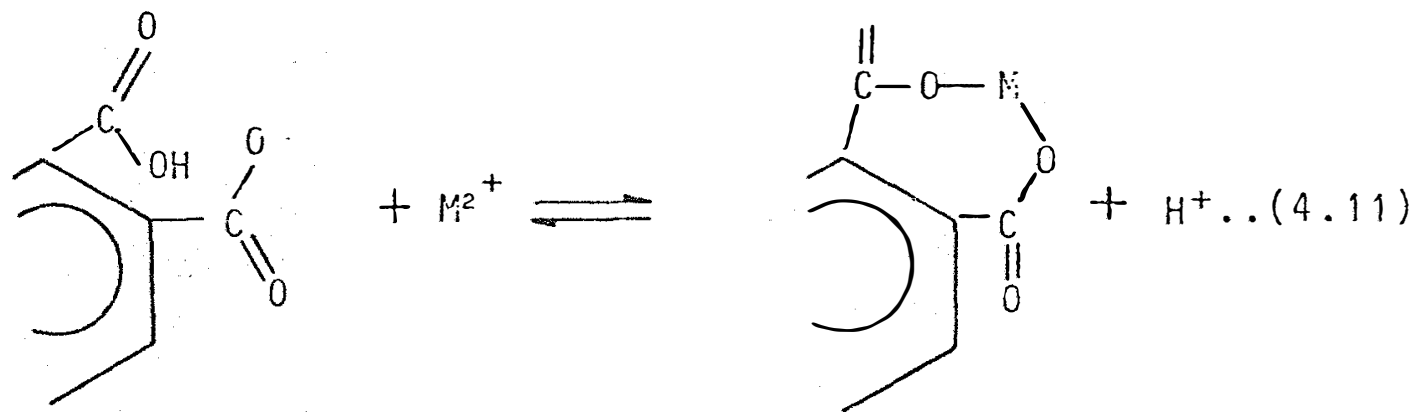
Conforme a reacão da equação 4.11 , o equi líbrio serā deslocado para esquerda quando a concentracão do ion $\mathrm{H}^{+}$aumentar.

Este equilíbrio é possîvel de ser desloca do quando hā aumento da concentracão $\left[\mathrm{MOH}^{+}\right]$conforme a reacõo:

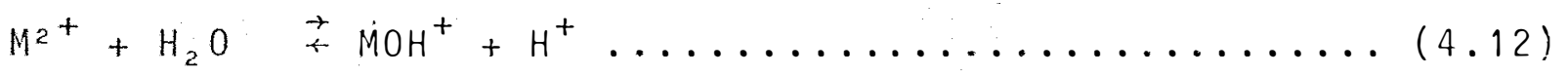

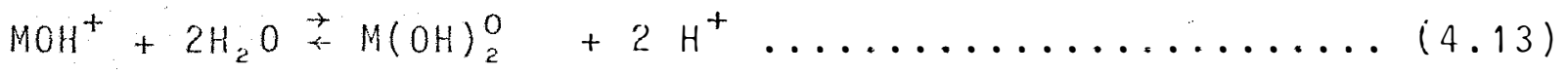

os trabalhos realizados por soon

mostram que na adsorcão de cādmio, o principal fator é o pH. Seria necessārio, repetir o experimento tamponando a solucão para confirmacäo destes dados.

A ocorrēncia da formaça dos hidröxidos (equacão 4.12 e 4.13) conforme HARTER (1979) seria necessārio que o pH esteja acima de 5,7. Estes fatos, mostram a estreita correlacão existente, pois na TE o seu pH é 6,1 (Tabela 2) e tambēn possue boa porcentagem de matēria orgānica (dos très solos é o que contém maior porcentagem de matéria orgànica em termos de carbono).

Os baixos coeficientes de correlacão $r_{1}$ apresentados na equacão de Freundlich da Tabela 22 são devidas a adsorcão total dos solutos até os $10 \mathrm{ppm}$. Uma vez que a equa 
cão de Freundlich è uma exponencial e a regressão matemātica è prejudicada quando os eventos são repetidos. Isto è facilmente notado em Terra Roxa Estruturada (TE) com chumbo onde possue o maior nümero de pontos repetitivos. Desprezando estes pontos repetitivos obtemos um ötimo coeficiente de correlacão $r_{a}$. Isto mostra que a aplicabilidade da equação de Freundlich é limi tado a determinadas concentrações de metais $\mathrm{M}^{2}{ }^{+}$que dependem ainda da características químicas dos solos e eventualmente dos elementos quỉmicos metālicos, dos quais é necessārio melhores pesquisas especîficas para sua melhor elucidacão.

4.2. Translocação dos metais $\mathrm{M}^{+}$atravēs da coluna de so10

Os dados das Tabelas nọ 26 a 31 são resul tados das anālises quîmicas (îtem 3.4) da coluna de solo a cada $\Delta x=5 \mathrm{~cm}$ em $\mu \mathrm{g} / \mathrm{g}$ solo e meq/100 g TFSA para cada tipo de solo.

As Tabelas 32 a 34 foram obtidas calculan do-se conforme item 3.6 a partir dos resultados experimentais obtidos da anālise quĩmica constantes da Tabela 26 a 31.

os gräficos correspondentes aos resultados das anālises quĩmicas (Tabela 26 a 31) são apresentados em dois grupos subdivididos em relação a massa do metal $\mathrm{m}^{2}+$ e outra em meq $\mathrm{M}^{2} / 100 \mathrm{~g}$ TFSA. 


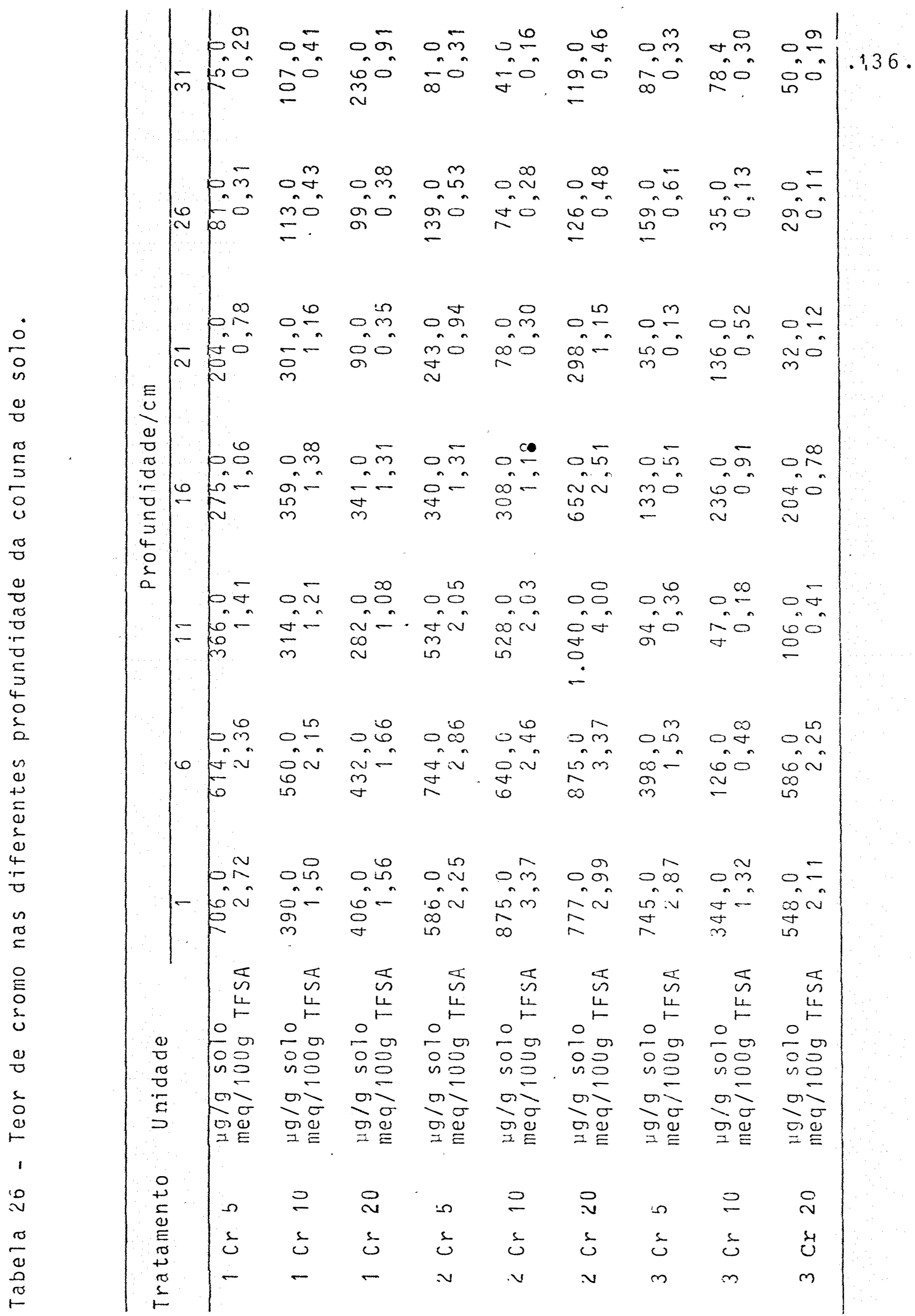




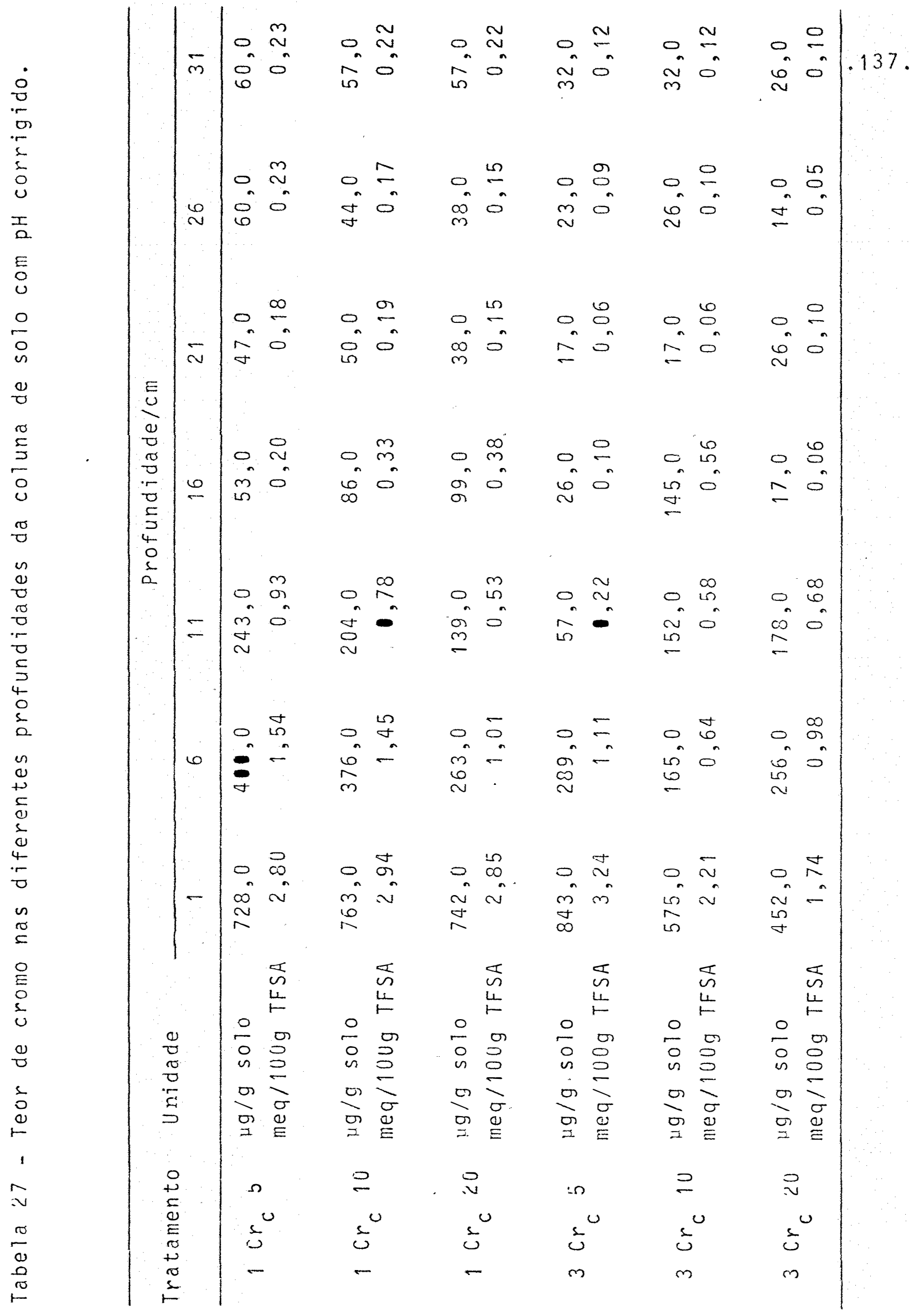




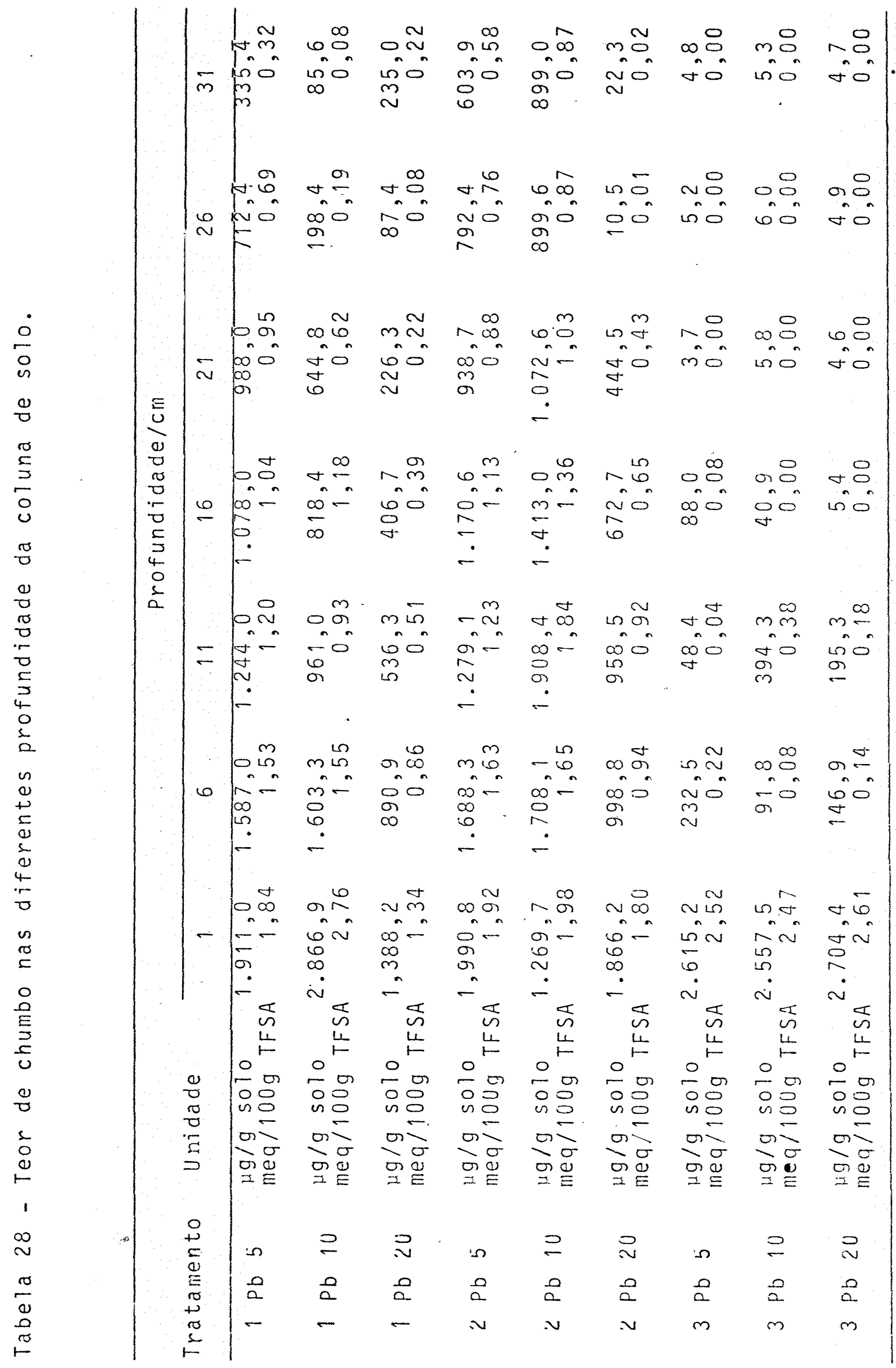




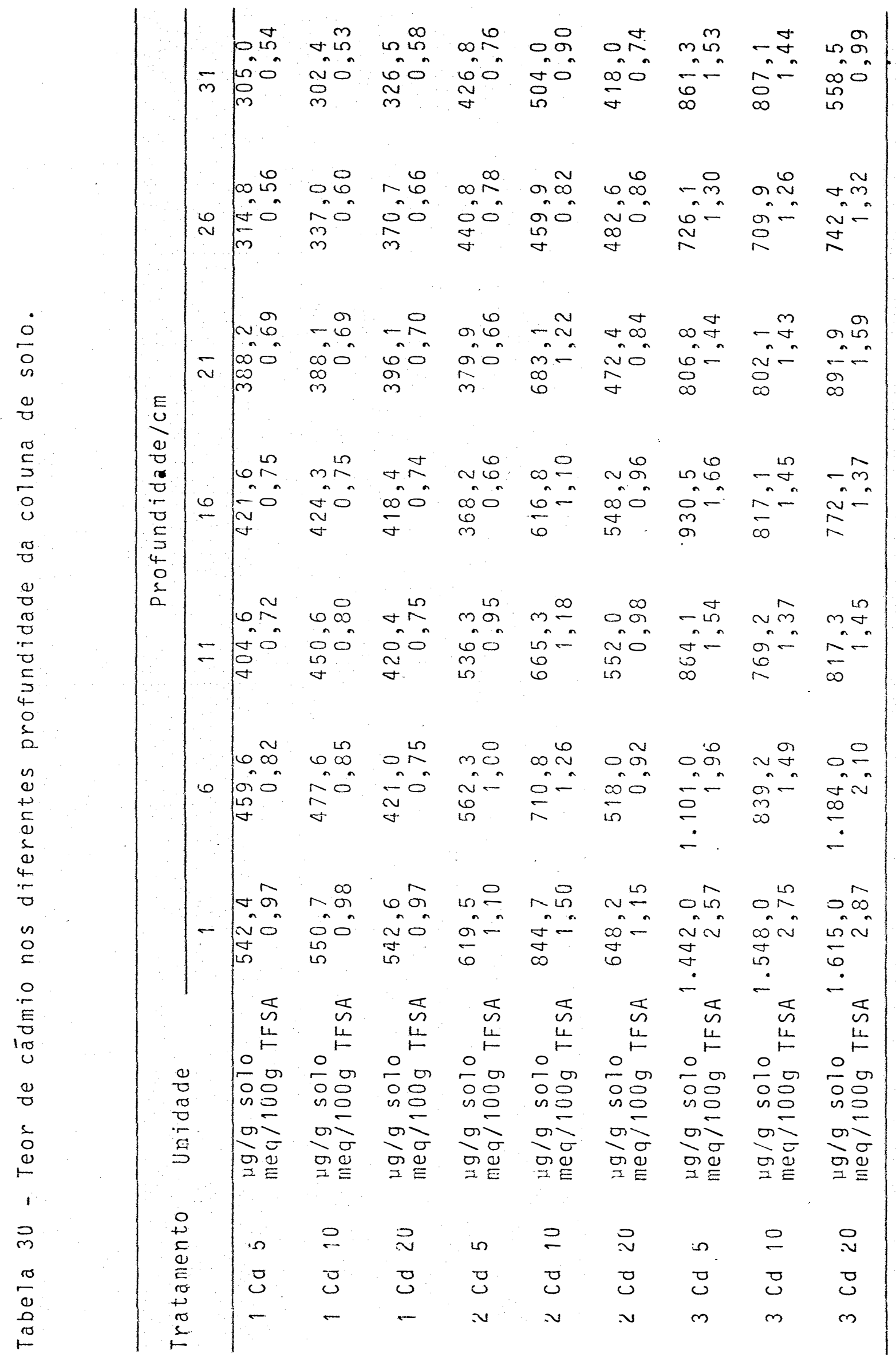


0
0
0
0
0
2
2
0
0
0
$x$
0
0
0
0
0

$\frac{0}{\circ}$

0

$\stackrel{0}{5}$

r

0
0
0
0
0
0
0
4
0
1
1

0
0
0
5
0
2
2
4
4
0
0

$\stackrel{n}{0}$

ह

O̊

¿ั

I

$\bar{m}$

$\div$

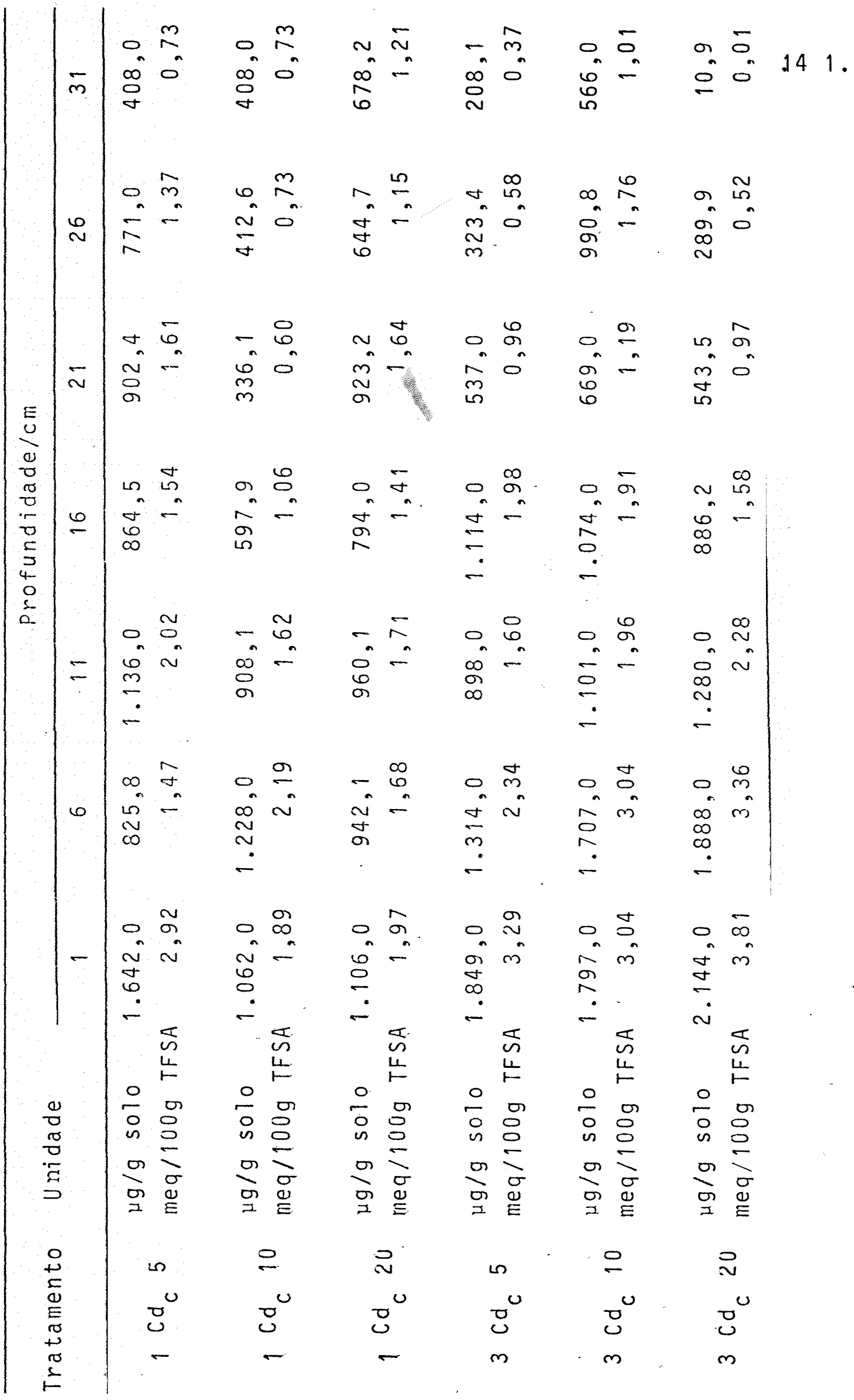


Tabela 32 - Cromo retidos na coluna de solo.

\begin{tabular}{|c|c|c|c|c|c|c|}
\hline \multirow{3}{*}{ Solos } & \multicolumn{6}{|c|}{ Volumes de poros } \\
\hline & \multicolumn{2}{|c|}{5} & \multicolumn{2}{|c|}{10} & \multicolumn{2}{|c|}{20} \\
\hline & média & equação & $m e ̄ d i a$ & equaç̃o & média & equaç̃o \\
\hline & & & $\mathrm{mg}$ & & & - \\
\hline PV-orto & 248 & 262 & 243 & 242 & 222 & 222 \\
\hline $\mathrm{GH}$ & 308 & 302 & 281 & 288 & 469 & 440 \\
\hline TE & 172 & 209 & 119 & 126 & 176 & 196 \\
\hline PV-orto & 162 & 201 & 161 & 200 & 133 & 174 \\
\hline TE & .123 & 163 & 174 & 140 & 143 & 122 \\
\hline
\end{tabular}

Obs.: Calculados conforme item 3.6 
Tabela 33 - Chumbos retidos na coluna de solos.

\begin{tabular}{|c|c|c|c|c|c|c|}
\hline \multirow{3}{*}{ Solos } & \multicolumn{6}{|c|}{ Volumes de poros } \\
\hline & \multicolumn{2}{|r|}{5} & \multicolumn{2}{|c|}{10} & \multicolumn{2}{|c|}{20} \\
\hline & mëdia & equacão. & média & equação & média & equação \\
\hline & & & $m g$ & 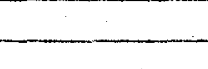 & & -2 \\
\hline$P V$-orto & 958 & 888 & 832 & 811 & 440 & 426 \\
\hline GH & 1.038 & 957 & 1.231 & 1.125 & 581 & 562 \\
\hline TE & 326 & 325 & 573 & 344 & 332 & 333 \\
\hline PV-orto & 380 & 388 & 377 & 385 & 381 & 387 \\
\hline TE & 283 & 285 & 392 & 395 & 321 & 340 \\
\hline
\end{tabular}

Obs.: Calculados conforme item 3.6 
Tabela 34 - Cádmio retido na coluna de solo.

\begin{tabular}{|c|c|c|c|c|c|c|}
\hline \multirow{3}{*}{ Solos } & \multicolumn{6}{|c|}{ Volumes de poros } \\
\hline & \multicolumn{2}{|c|}{5} & \multicolumn{2}{|c|}{10} & \multicolumn{2}{|c|}{20} \\
\hline & mé ia & equacão & média & equação & média & equacão \\
\hline & & 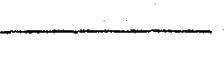 & $\operatorname{mg}$ & & & - \\
\hline PV-orto & 352 & 580 & 364 & 560 & 350 & 684 \\
\hline $\mathrm{GH}$ & 416 & 377 & 530 & 507 & 454 & 411 \\
\hline TE & 930 & 852 & 861 & 791 & 900 & 785 \\
\hline PV-orto & 8799 & 320 & 611 & 331 & 754 & 327 \\
\hline TE & 84.0 & 790 & 951 & 1.001 & 897 & 906 \\
\hline
\end{tabular}

Obs.: Calculados conforme item 3.6 
As Figuras 20 a $29 \bar{e}$ a translocação dos três metais $\mathrm{M}^{+}$atravēs de um tipo de solo em relação a massa do metal $\mathrm{M}^{+}$e meq $\mathrm{M}^{2+} / 100 \mathrm{~g}$ TFSA.

A Tabela 35 consta a concentração em moles/l considerando como se fossem diluidas a concentracão inicial ( $\left.C_{j}\right)$.para os volumes de poros em estudos e colocados para infiltracão. E evidente, que nas condič̃es do experimento exis te um gradiente de concentracão inicial maior.

A Tabela 36 é a média da tomada de 6 leituras dos efluxos e da soluç̃o.

A Tabela 37 foram calculadas a partir dos dados obtidos graficamente, entrando-se com os valores da Tabe 1 a 36 medidos experimentalmente.

4.2.1. Deslocamento dos metais $\mathrm{M}^{+}$na coluna de solo

Devido as condicões de contorno do presen te trabalho, as dispersões hidrodinâmicas conforme definida por BOAST (1973) poderão ser desprezadas devido ao pequeno com primento da coluna em estudo e o fluxo do soluto por difusão tambēm serā desprezível em face ao fluxo de massalequação 2.94 $2.95)$.

A anālise dos resultados dos metais $\mathrm{M}^{2+}$ retidos na coluna (Tabela 26 a 31) mostram que os três cations 
$\mathrm{M}^{2}+$ tem comportamentos distintos em relação a sua massa ao translocar pela coluna de solo. Nota-se também que o solo tem seus comportamentos distintos em relação ao metal $\mathrm{M}^{2}$ (Figura 20 a 29).

Em PV-orto os metais $\mathrm{M}^{2}$ cromo e cādmio mostra uma distribuicão mais uniforme ao longo da coluna em to das as camadas. 0 metal $\mathrm{M}^{+}$chumbo estão mais retidos nos primeiros $10 \mathrm{~cm}$ da coluna (Figura 20 a 29 e Tabela 26 a 31 ).

Em GH os comportamentos são semelhantes ao PV-orto, porēm com maior retenção dos metais $\mathrm{M}^{2}$ ao longo da coluna (Tabela 26 a 31 ).

As retencões dos metais $M^{2}$ são diferen ciados em TE, tendo as seguintes ordens em termos de massa:

$\mathrm{Cd}>\mathrm{Pb}>\mathrm{Cr}$ 


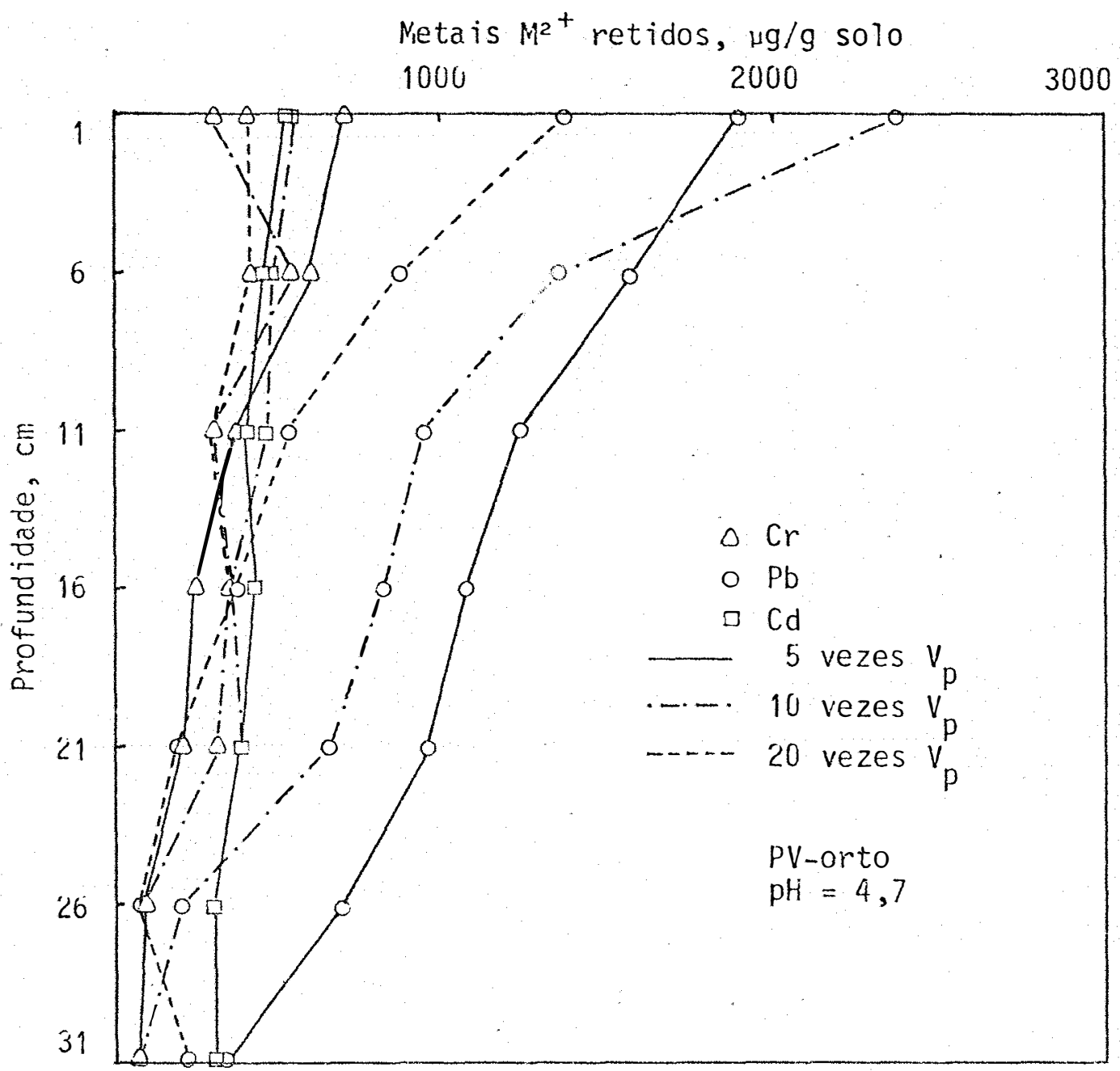

Figura 20 - Deslocamento dos metais $\mathrm{M}^{2}{ }^{+}$cromo, chumbo e cádmio e PV-orto em $\mu \mathrm{g} / \mathrm{g}$ terra. 


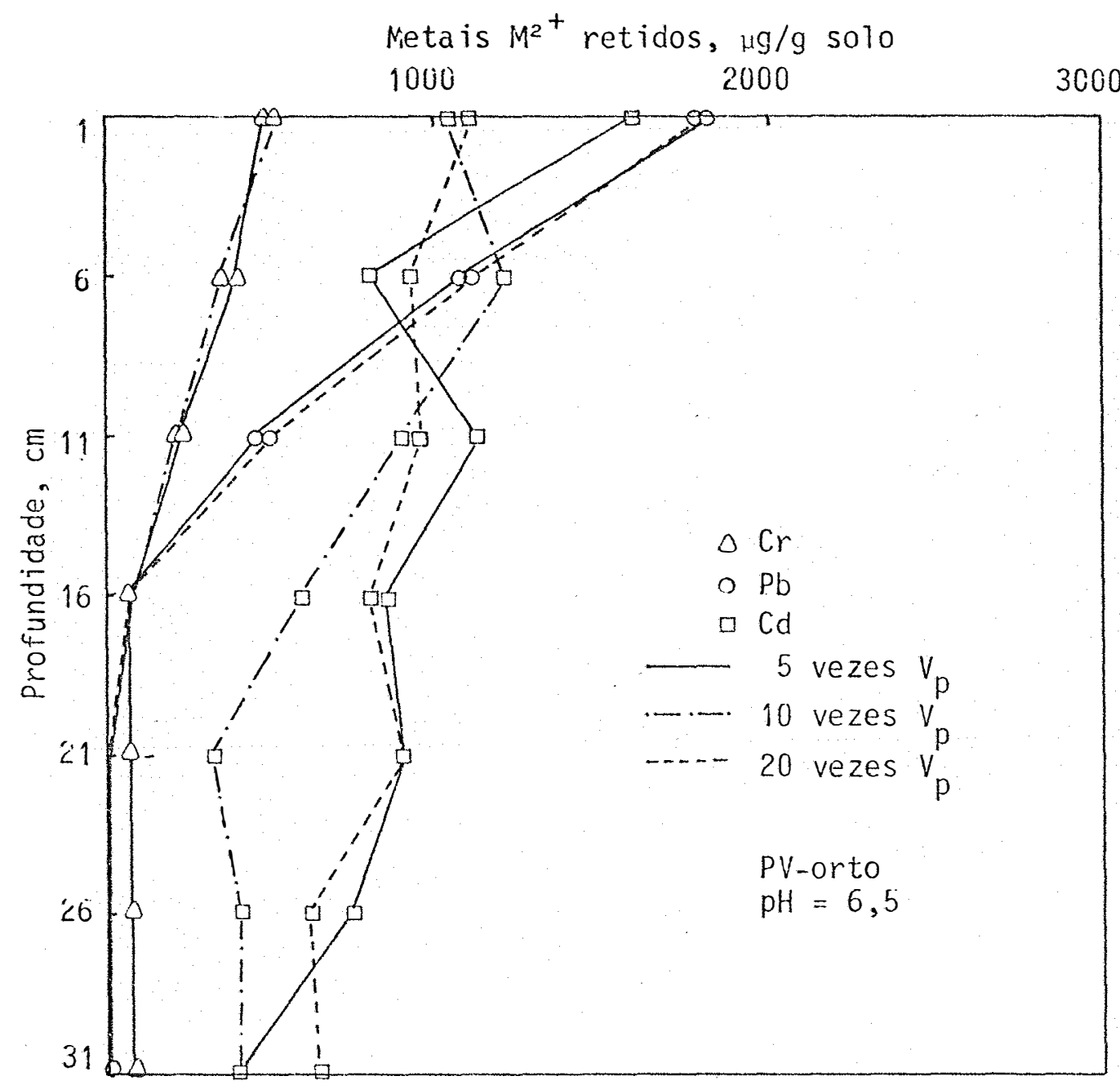

Figura 21 - Deslocamento dos metais $\mathrm{M}^{+}$cromo, chumbo e cádmio em PV-orto com pH corrigido em $\mu \mathrm{g} / \mathrm{g}$ terra. 


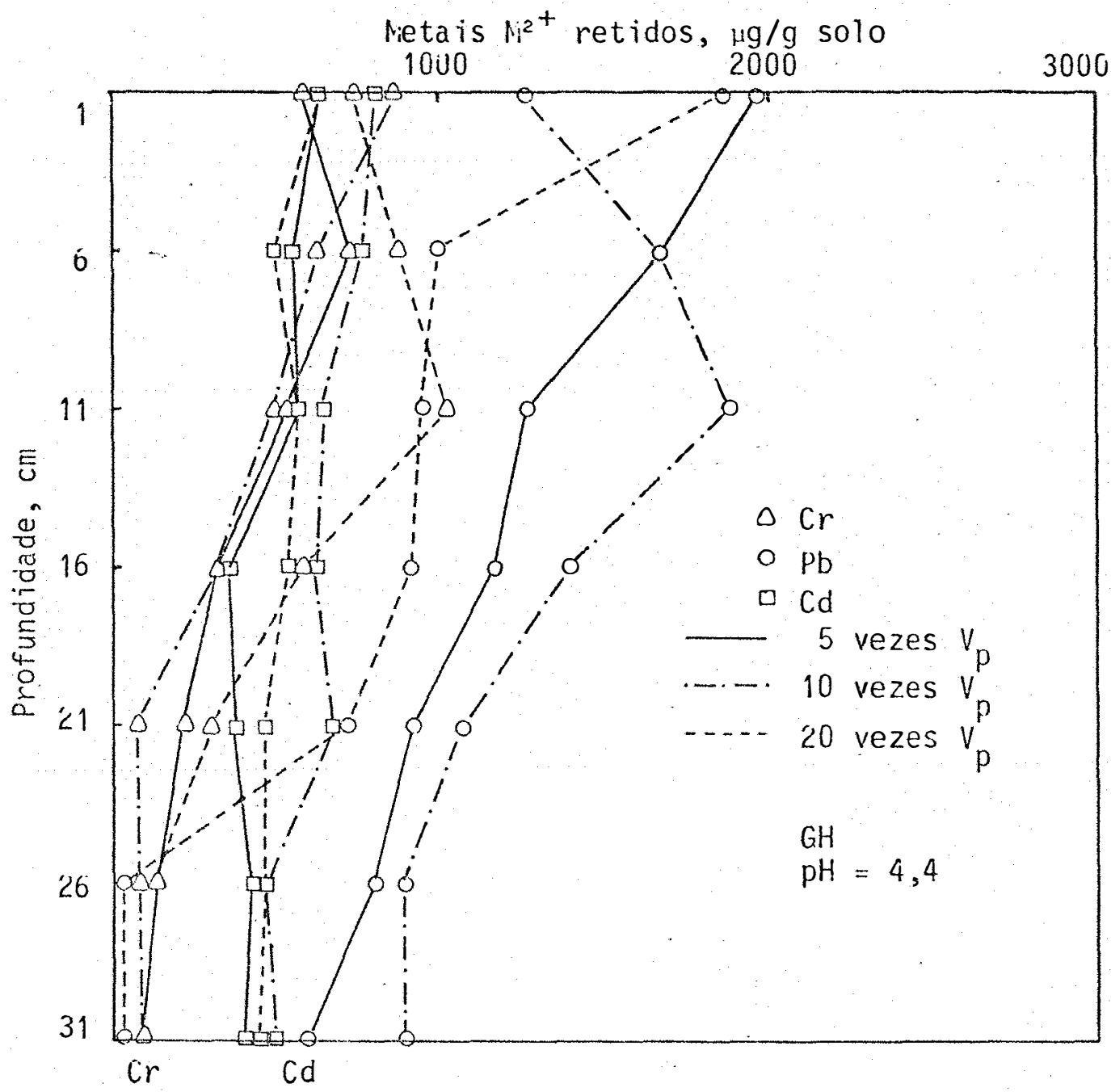

Figura 22 - Deslocamento dos metais $\mathrm{M}^{2}{ }^{+}$cromo, chumbo e cādmio em GH em $\mu \mathrm{g} / \mathrm{g}$ terra. 


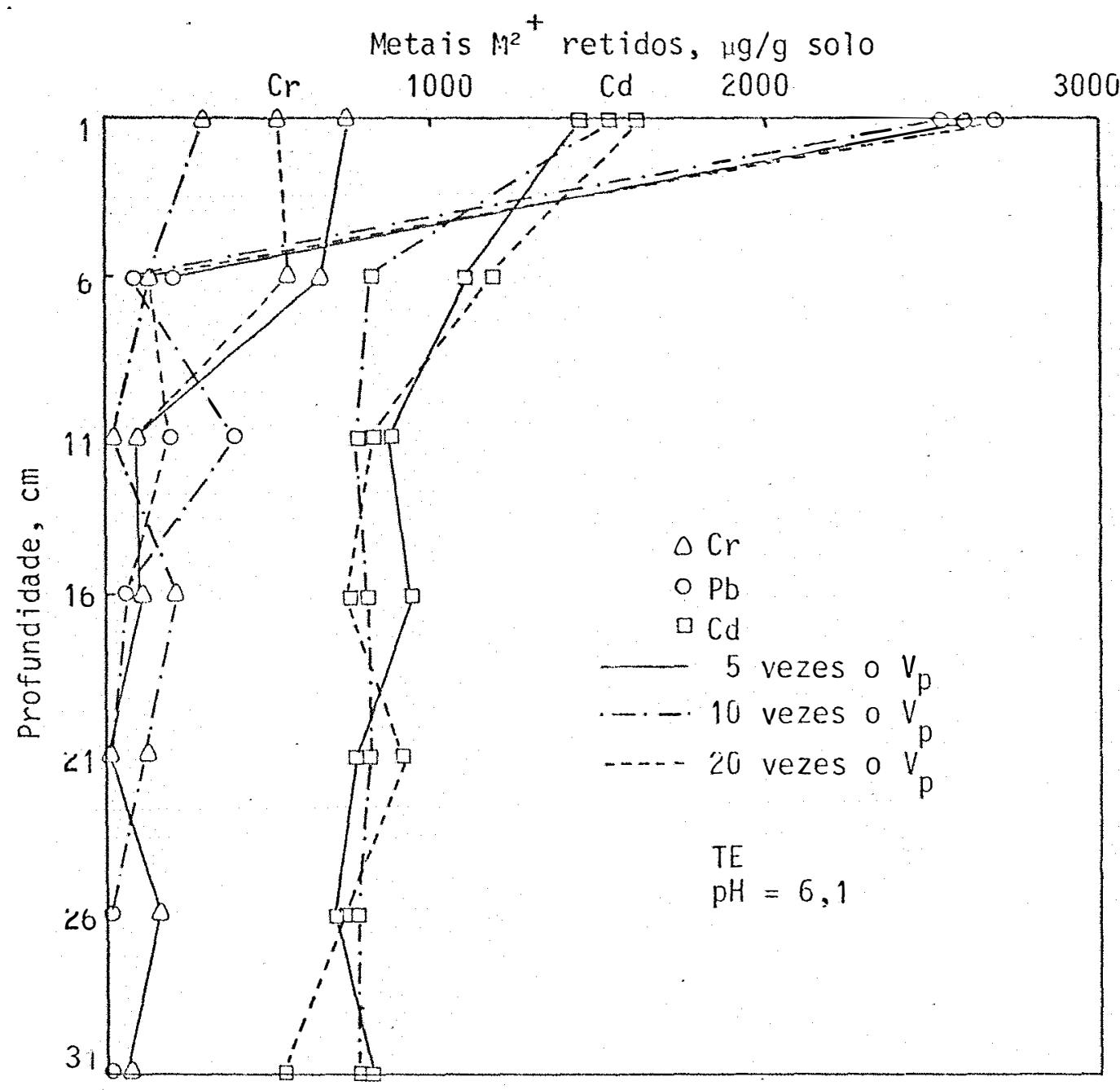

Figura 23 - Deslocamento dos metais $\mathrm{M}^{2}$ cromo, chumbo e cādmio em TE em $\mu \mathrm{g} / \mathrm{g}$ terra. 


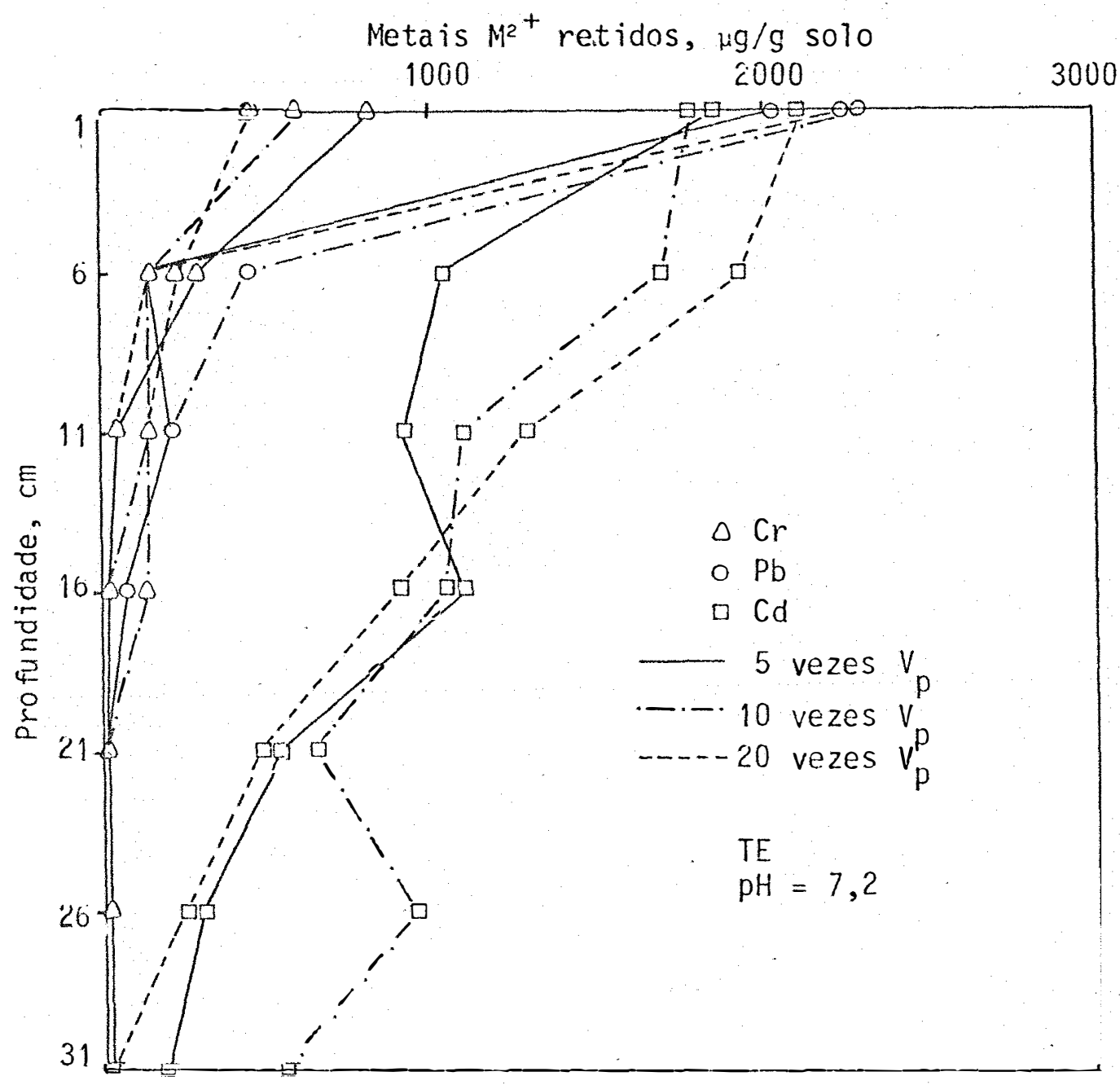

Figura 24 - Deslocamento dos metais $\mathrm{M}^{2}+$ cromo, chumbo e cādmio com pH corrido em TE em $\mu \mathrm{g} / \mathrm{g}$ terra. 


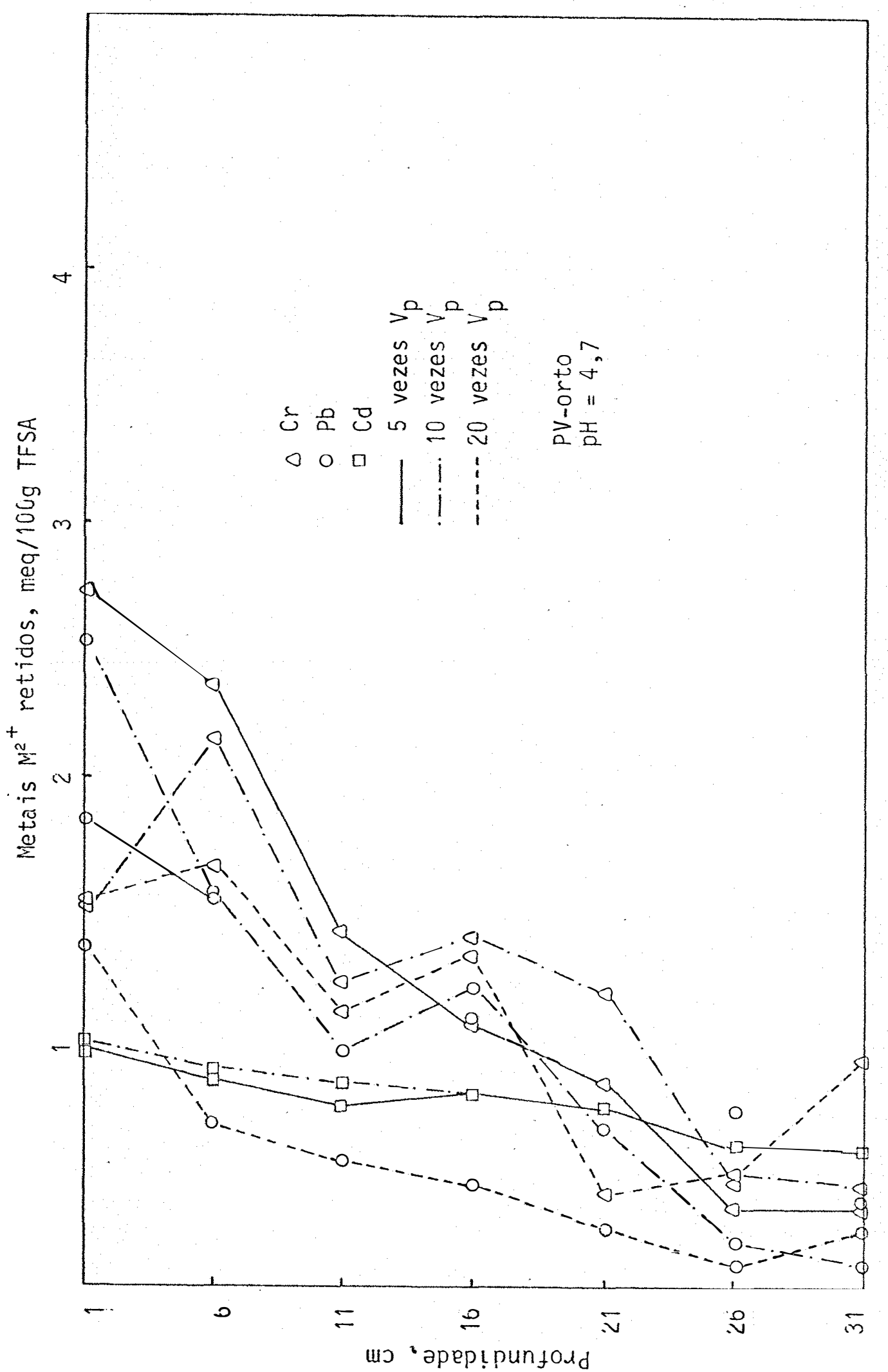

U⿱一⿻上丨)

$+$

$\sum$

n

$\pi$

ڤ્

@

$\begin{array}{ll}0 & \\ +0 & \\ E & \\ 0 & \\ \Xi & 0 \\ 0 & 0 \\ U & + \\ 0 & \vdots \\ 0 & 0 \\ \sim & 1 \\ 0 & 0 \\ 0 & 0\end{array}$

I

is

5
5
$\vdots$
5
$\frac{5}{4}$ 
.153.

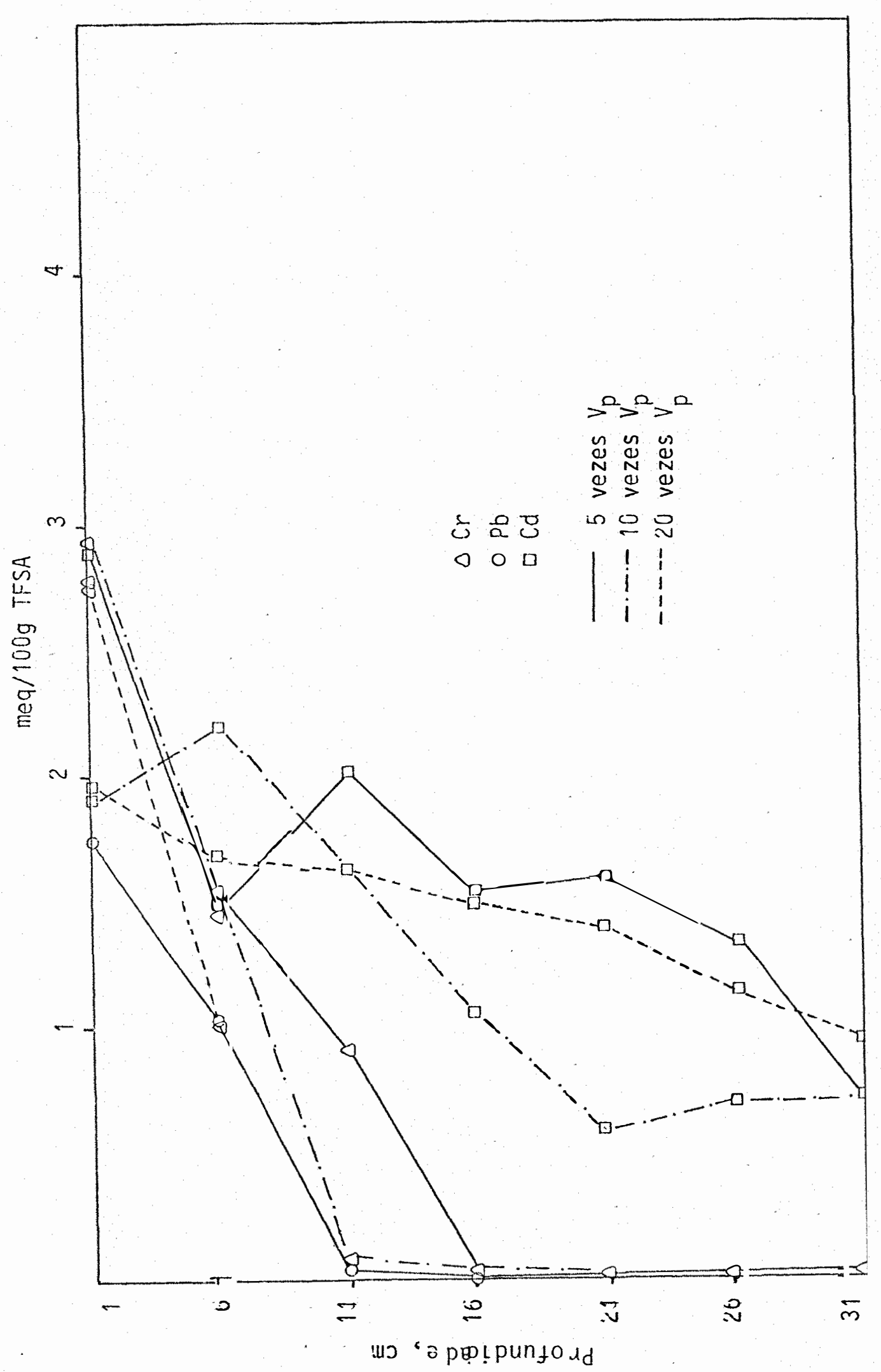

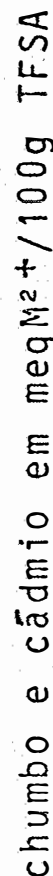

응

$\begin{array}{rr}0 \\ + & 0 \\ 2 & 0\end{array}$

$\sim \quad$ i

ro

E

$\begin{array}{ll}n & 0 \\ 0 & 0 \\ 0 & 0\end{array}$

o on

$\begin{array}{ll}0 \\ + & 2 \\ 0 & 0\end{array}$

E U

U I

气

1

ข

0
2
5
5
4 


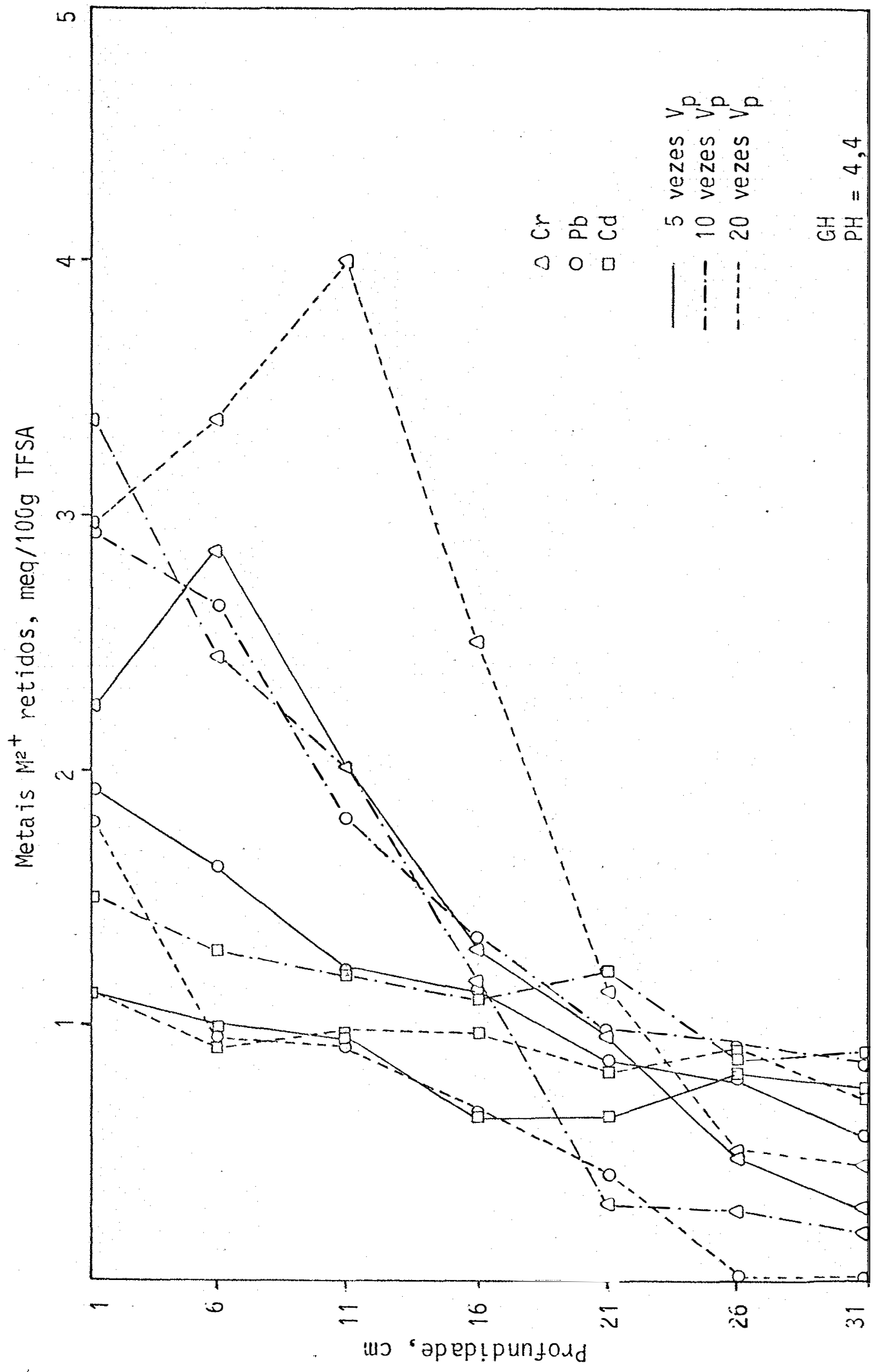

$x$

茫

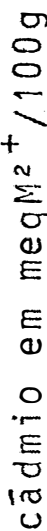

a

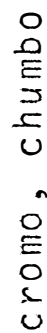

$\stackrel{+}{\Sigma}$

$\stackrel{N}{\Sigma}$

ฮั)

응

$\circ$

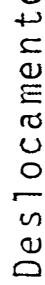

I

ก

5
$\vdots$
5
$\frac{5}{L}$ 


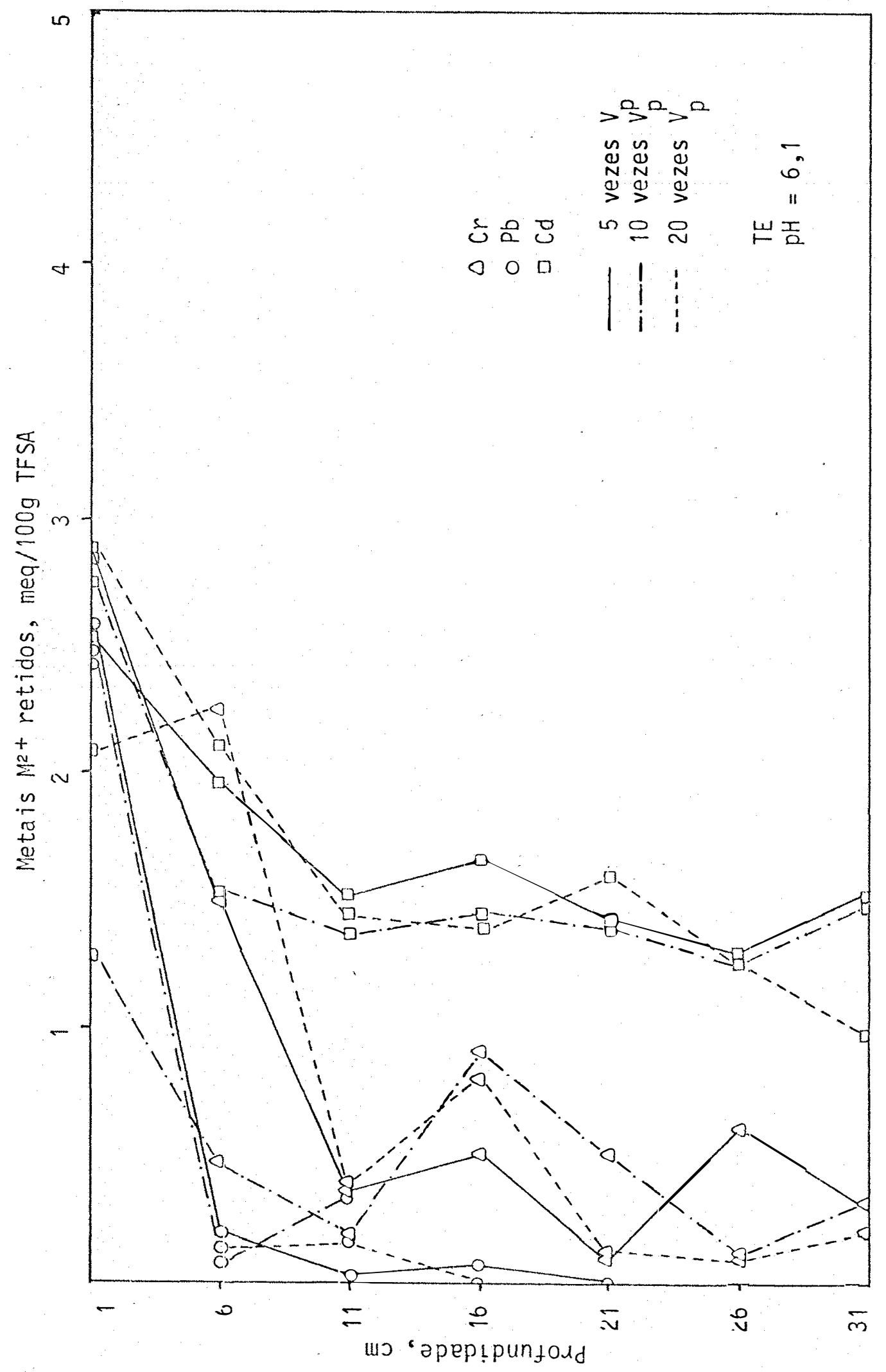



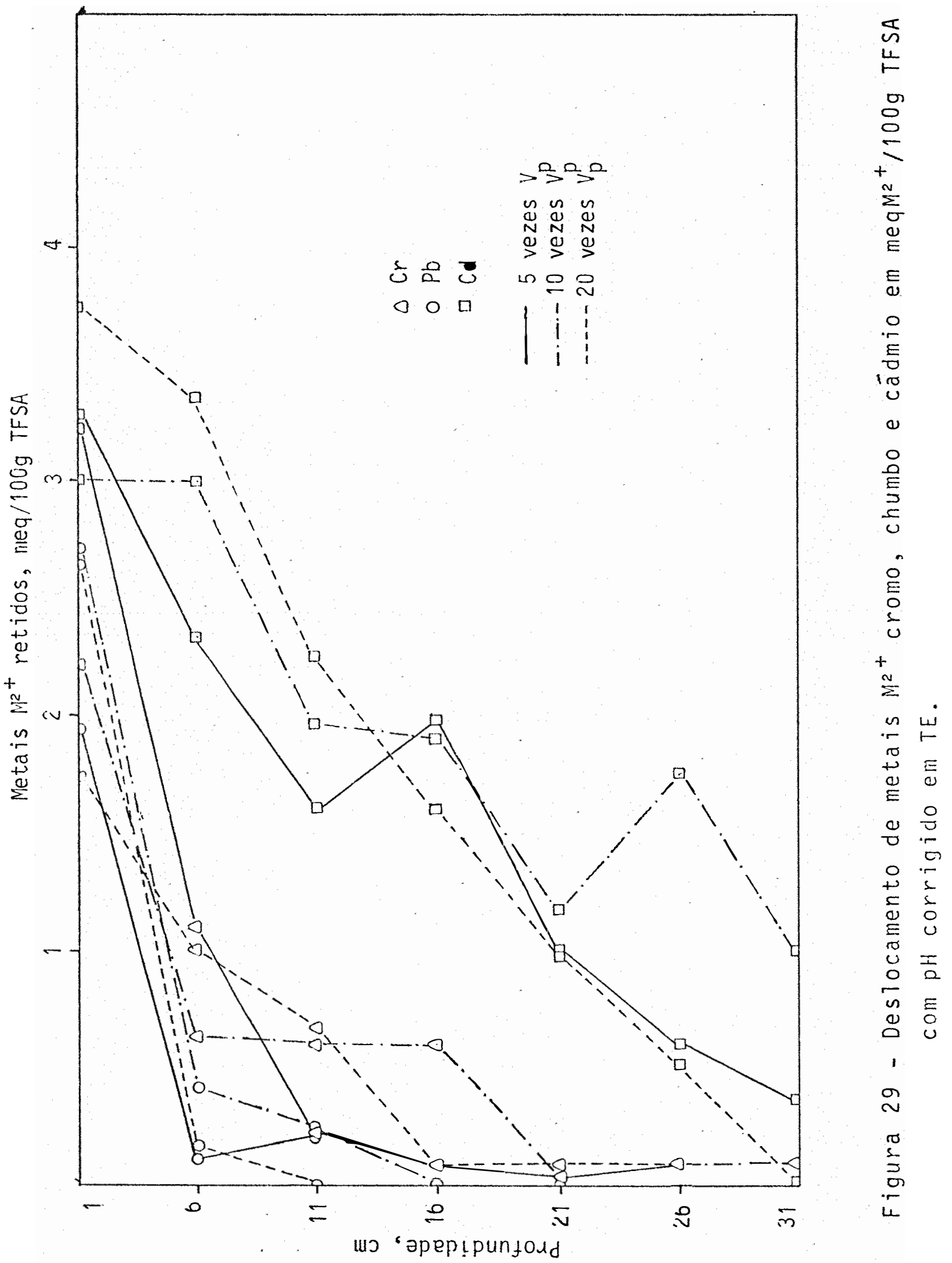
Verifica-se tambēm neste solo, as retencões serem maiores nos primeiros $10 \mathrm{~cm}$ da infiltracão na coluna.

As retenções nos primeiros $10 \mathrm{~cm}$ pode ser devida a precipitação destes metaïs em forma de hidróxidos. $M(\mathrm{OH})_{2}$, pois todos os sais são de ācido forte e base fraca (îtem ż.1.3.1). As reações processam--se conforme jā discutido nas equacões 4.4 a 4.13. As deposicões ou retencões serão maio res nas camadas superficiais caso seja precipitado em forma de hidröxidos destes metais. Desta forma, deverā estar ocorrendo a precipitação do metal $\mathrm{M}^{+}$chumbo ou "forte adsorção" em TE, pois nos primeiros $10 \mathrm{~cm}$ acham-se retidos quase a metade do so luto colocado (Tabela 33). Após esta camada não hā mais o metal $\mathrm{M}^{2}$ chumbo retido (Tabela.28 e 29 ).

Para discussão dos metais $\mathrm{M}^{2}{ }^{+}$cromo e cād mio, consideremos as reações abaixo (CLIFFORD, 1964).

$\mathrm{Cr}(\mathrm{OH})_{2} \stackrel{+}{\leftarrow} \mathrm{Cr}^{2+}+2 \mathrm{OH}^{-}$ $K_{\mathrm{Sp}}$
$1,0 \times 10^{-17} \ldots(4.14)$

$\mathrm{Pb}(\mathrm{OH})_{2} \stackrel{\rightarrow}{\leftarrow} \mathrm{Pb}^{2+}+2 \mathrm{OH}^{-}$ $4,0 \times 10^{-15} \ldots(4.15)$

$\mathrm{Cd}(\mathrm{OH})_{2} \stackrel{+}{\leftarrow} \mathrm{Cd}^{2}+2 \mathrm{OH}^{-}$ $2,0 \times 10^{-24} \ldots(4.16)$ 
Em uma dissolucão saturada dos hidrōxidos das equacôes 4.14 a 4.16 è necessārio que o segundo membro da equação (o produto da concentração iônica) atinja exatamente o valor de $K_{s p}$. Em uma dissolução não saturada o produto da concentracão iônica ē menor que $K_{\text {sp }}$, logo, não hä precipitacão do $\mathrm{M}(\mathrm{OH})_{2} \cdot$

A Tabela 35 mostra-nos que as concentra cões iniciais de infiltração são maiores que a constante do produto de solubilidade. Assim sendo, as reacões das equacões 4.14 a 4.16 serão deslocadas para direita não precipitando. Lo go no inicio da infiltracão da solucão deverā haver $M(O H)_{2}$ pre cipitados porque o pH do solo, é maior do que da solucão (Tabe la 36) o que é confirmado pelas anālises nas camadas superio res.

Com as dissoluções contínuas, o iequîi brio da equacões 4.14 a 4.16 poderā deslocar para direita, uma vez que as bases e $\mathrm{M}^{2}$ estarão serdo $\mathrm{lixiviadas}$ ou $\mathrm{M}^{2}$ adsorvi das. Desta forma teremos o deslocamento destes metais atravēs da coluna.

Assim, num incremento $\Delta x$ da coluna, devida a dissolucão pela lixiviação constante, o pH deve aumentar, o que é confirmado pelas leituras formadas nos efluxos (Tabela 36). Havendo o aumento de pH, o equilíbrio da equacão é novamente deslocado para esquerda, com possibilidade de nova preci pitacão, havendo um deslocamento por um "front". 
Tabela 35 - Concentracões molares dos metais $\left[\mathrm{M}^{+}\right]$no in icio da infiltração na coluna.

\begin{tabular}{|c|c|c|c|c|c|}
\hline \multirow[b]{2}{*}{ Metal } & \multirow[b]{2}{*}{ Solo } & \multirow[b]{2}{*}{$c_{i}$} & \multicolumn{2}{|c|}{ Volumeside poros } & \multirow[b]{2}{*}{20} \\
\hline & & & 5 & 10 & \\
\hline & & \multicolumn{4}{|c|}{ moles/l } \\
\hline Cromo & PV-orto & 0,07505 & 0,03338 & 0,02168 & 0,01220 \\
\hline Cromo & $\mathrm{GH}$ & 0,07505 & 0,02700 & $0 ; 01594$ & 0,00893 \\
\hline Cromo & $T E$ & 0,07505 & 0,03321 & 0,02040 & 0,01203 \\
\hline Chumbo & PV-orto & 0,06038 & 0,02617 & 0,01687 & 0,00985 \\
\hline Chumbo & $\mathrm{GH}$ & 0,06038 & 0,02171 & 0,01267 & 0,00723 \\
\hline Chumbo & TE & 0,06038 & 0,02566 & 0,01713 & 0,0944 \\
\hline Cádmio & PV-orto & 0,08759 & 0,03858 & 0,02464 & 0,01427 \\
\hline Cádmio & $\mathrm{GH}$ & 0,08759 & 0,03690 & 0,02355 & 0,01377 \\
\hline Cādmio & TE & 0,08759 & 0,03112 & 0,01869 & 0,01036 \\
\hline Cromo & PV-orto & 0,07505 & 0,03286 & 0,02125 & 0,01258 \\
\hline Cromo & $T E$ & 0,07505 & 0,03221 & 0,02020 & 0,01175 \\
\hline Chumbo & PV-orto & 0,06038 & 0,02584 & 0,01646 & 0,00953 \\
\hline Chumbo & TE & 0,06038 & 0,02553 & 0,01711 & 0,00953 \\
\hline Càdmio & PV-orto & 0,08759 & 0,03740 & 0,02457 & 0,01368 \\
\hline Càdmio & $T E$ & 0,08759 & 0,03837 & 0,02456 & 0,01363 \\
\hline
\end{tabular}


Tabela 36 - Valores de pH medidos nos efiuxos

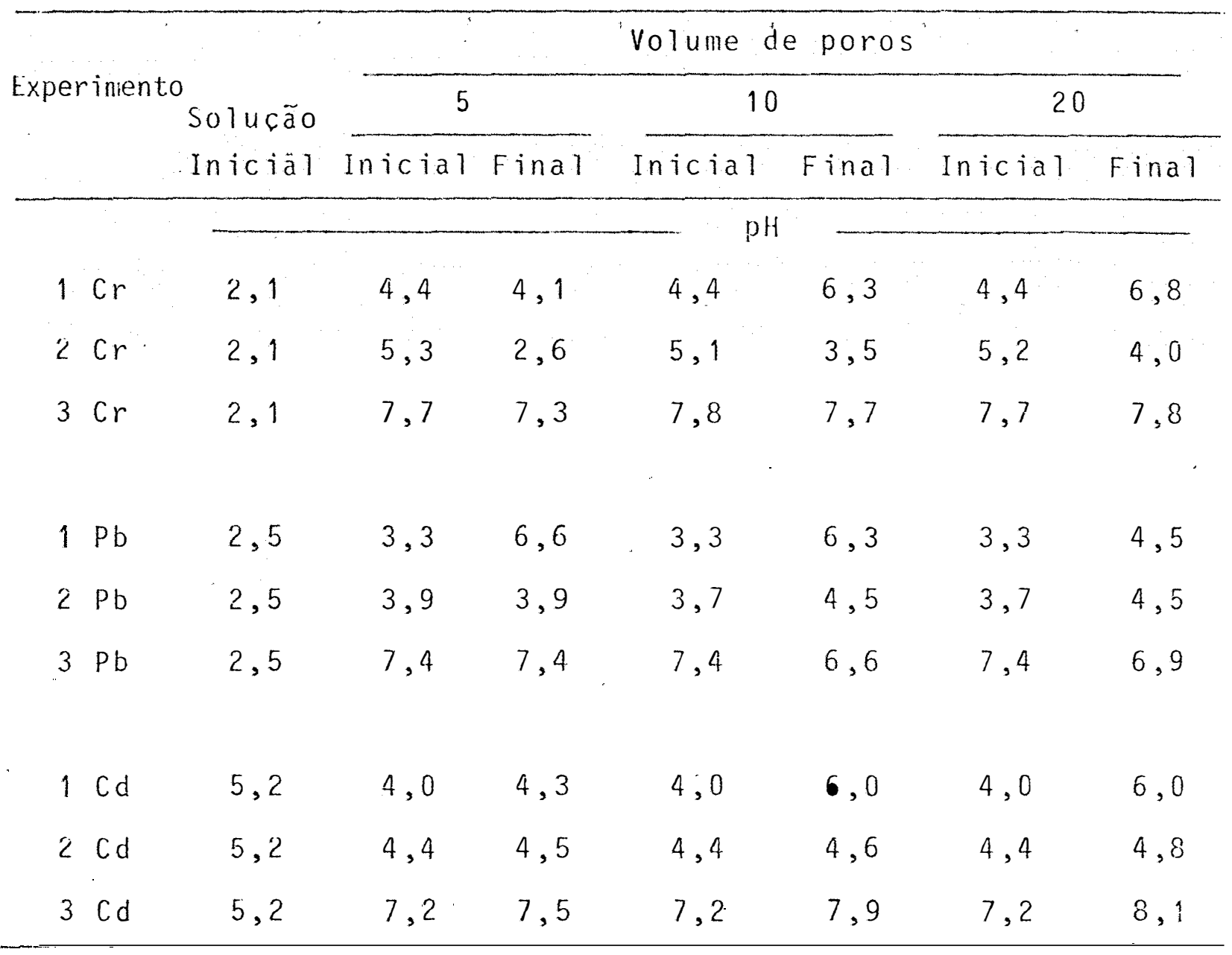


A precipitação pode ocorrer com adicão de ion comum $\left[\mathrm{OH}^{-}\right]$, conforme é verificado no equilíbrio químico. Isto pode ser visivelmente notado na Figura 21 , em PV-orto onde o solo foi corrigido com $\mathrm{Ca}(\mathrm{OH})_{2}$. As quantidades de cädmio retido duplicaram em PV-orto (Tabela 34 ) com pH corrigido. Os demais metais tiveram pouca alteração na retenção com o pH corrigido.

O sal de cádmio utilizado ē o que apresen ta maior expontaneidade na dissociação em ĩons $\left[\mathrm{Cd}^{+}\right]$e $\left[\mathrm{Cl}^{-}\right]$ devida a energia livre $\Delta G_{r}^{0}$ possuir maior valor negativo em relacão a outros dois sais utilizados. Portanto a sua hidrōlise é mais facilitada na forma $\mathrm{CdCl}_{2}^{0}$. Como este hidróxido não possue carga elétrica, a adsorção iōnica no solo não deverá ocorrer ao longo da coluna. E isto que se nota ao longo da coluna, praticamente não havendo nenhum gradiente de concentracão. 0 que temos è praticamente uma retenção uniforme, com ligeiro teor a maior na camada superficial. As lixiviacöes não influiram no seu deslocamento, uma vez que praticamente permaneceram constante em 5,10 ou 20 vezes o volume de poros.

As correlacões que apresentam na lixiviacão estão na granulometria do solo e característica do metal $\mathrm{M}^{+}$. Os solos que possuem maior teor de argila e silte, säo os que apresentam maior efeitos de lixiviacão, como no caso de GH que deslocam os metais retidos para os subniveis na coluna, a medida que aumenta a lixiviaça em 5,10 e 20 vezes o seu volu 
me de poro (Figura 20 e 22). 0 solo que possue teor de areia maior, como no caso do PV-orto, as Iixiviações parecem não haver efeito, pelo menos com os metais $\mathrm{M}^{2}$ em estudo neste traba Tho. Não se nota nenhum "front" de deslocamento dos metais M $^{+}$. 0 metal $\mathrm{M}^{2}$ chumbo é o que apresenta o maior efeito da lixivia cão (Figura 20 e 22) principalmente na PV-orto e GH. Como nestes dois solos, o pH são 4,7 e 4,4 relativamente baixos em relação a TE que está com $\mathrm{pH}=6,1$, podem ter facilitado a solubilização do hidróxido devido ao baixo pH, o que justificaria o seu deslocamento e também maior retenção em T'E nas camadas superficiais pelo pH prōximo do neutro e ter havido alguma pre cipitação. Poderia também ser levantada uma hipótese de hidratação neste metal devido ao seu raio atōmico ser menor dos três cátions $(r=4,5$ MEITES cap. 1 p. 7$)$, ter facilitada a sua hidratacão devida a condicões dos meios do solo. Por outro lado, a força iōnica calculada, estā na ordem de $3.98: 1$ em relação ao cromo, 1,84: 1 em relação ao cādmio se considerarmos nas mesmas concentracões. Para melhor compreensão seria ne cessārio melhores pesquisas específicas neste sentido.

$\mathrm{Na}$ Tabela 37 encontramos as concentrações cie cations $\left[\mathrm{M}^{+}\right]$em equilibrio calculados graficamente (Fig. 30) e verificamos que elas são maiores do que as próprias concentrações iniciais de infiltração (Tabela 35). Para que haja precipitação seriam necessárias que as concentrações dos cá- 
Tabela 37 - Concentracões de cations $\left[\mathrm{M}^{2}\right]$ calculados graficamente em função do pH dos efluxos em moles/l.

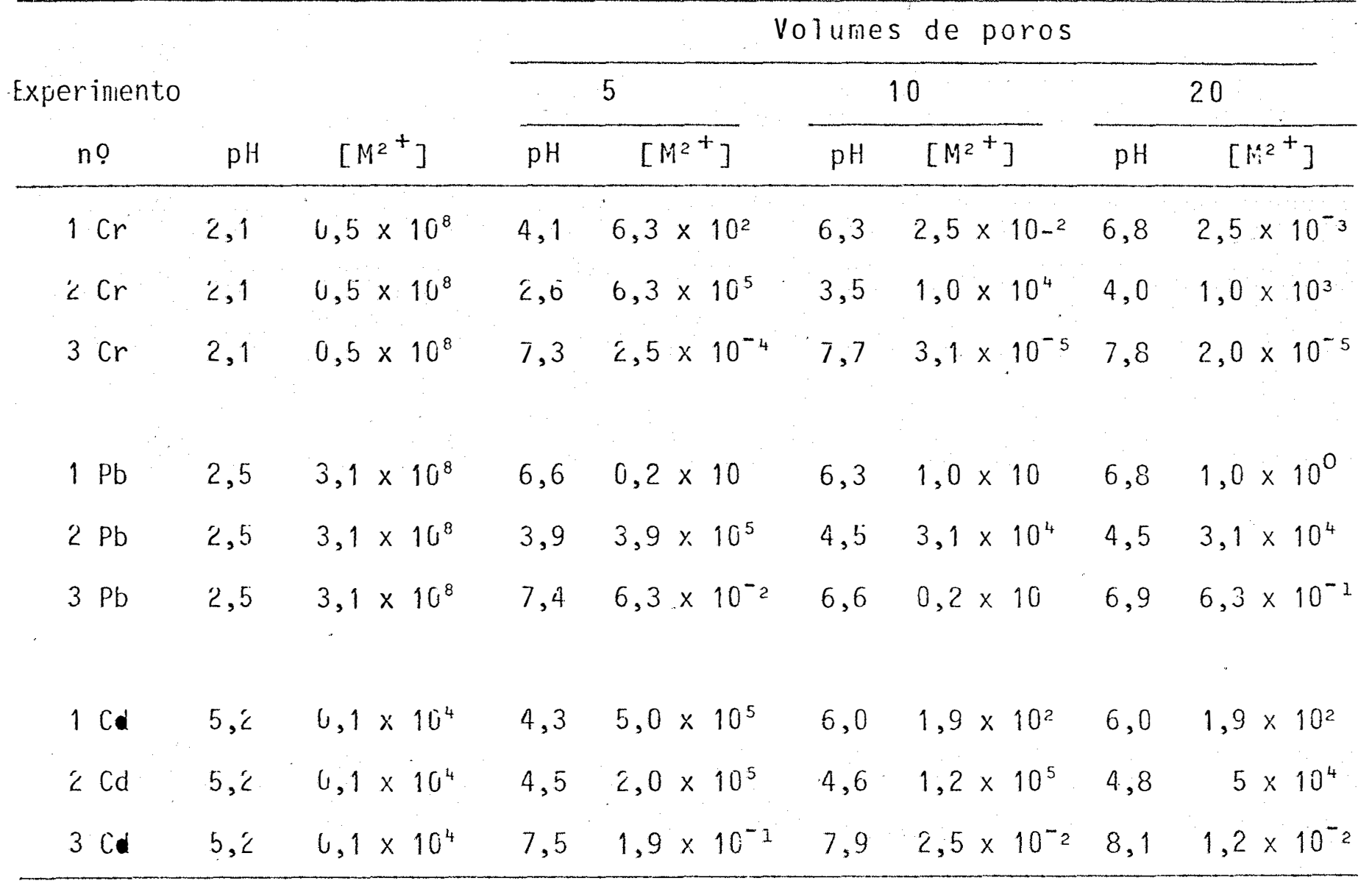




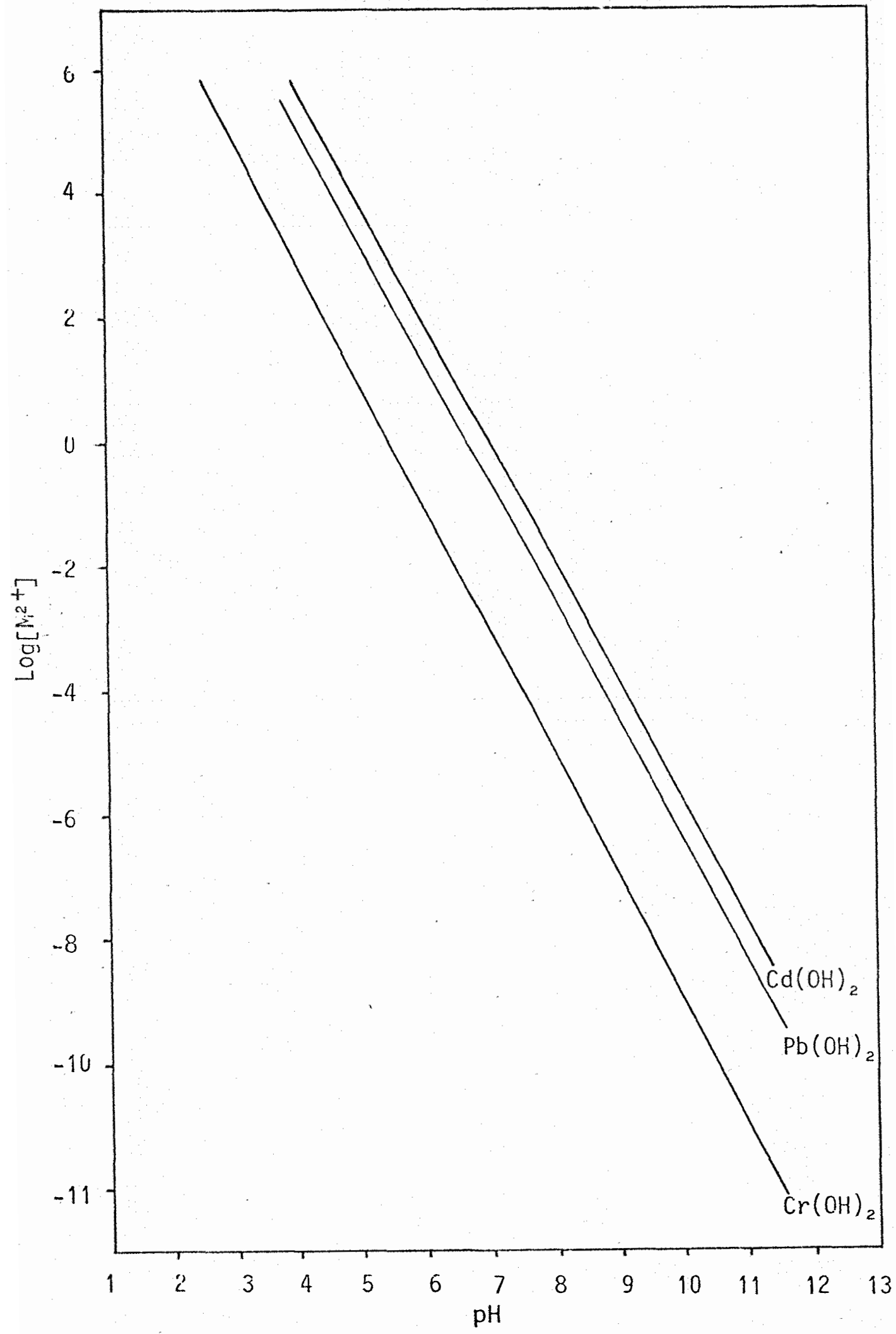

Figura 30 - Diayrama de variāveis dos hidróxidos de $\mathrm{Cr}(\mathrm{OH})_{2}$, $\mathrm{Pb}(\mathrm{OH})_{2}$ e $\mathrm{Cd}(\mathrm{OH})_{2}$. 
tions metālicos $\left[H^{+}\right]$presentes na solucão deslocadorá fossem maiores, no entanto em todas as 1 ixiviacões de 5,10 e 20 vezes o volume de poros estão abaixos dos equilĩbrios. o diagrama da Figura 30 facilmente pode fornecer a concentracão do cátion $\left[\mathrm{M}^{2}{ }^{+}\right]$que levariam a precipitação do hidróxido com a elevação do pH. A consulta na Tabela 37 , obtidos graficamente, mo tra que não hā condições de precipitação destes hidroxidos,pois as concentracões dos sais de infiltracões em 5,10 e 20 vezes o volume de poros estão aquém do limite de equijî́brio, com exceção do cromo que poderão precipitar-se com pH acima de 6,8 para as condicões ceste experimento.

A vista dos resultados, as concentrações existentes ao longo da coluna de solo estäo predominantemente na forma adsorvida. Por outra parte verifica-se nas Tabela 26 a 31 e nas figuras 25 a 29 , que em termos de retencão por meq $\mathrm{M}^{+} / 100 \mathrm{~g}$ TFSA săo praticamente iguais entre si, não havendo diferença notāieis entre os três cations. As diferencas podem ser observadas apenas em termos de retenção de massas. Por outra parte os valores encontrados, na Tabela 25 mostram que as retencões estão aquēm da adsorcão máxima calculadas pela equacão Langmuir.

Na Tabela 39 acham-se às condutividades hidrāul i cas dos solos eslias respectivas velocidades. Tomando-se a velocidade do GH que é o menor entre os trés solos como reféréncia unitāria, vemos que a velocidade da àgua em TE é 15 vezes maior, 
Tabela 38 - Condutividade hidrāulica e velocidade da ăgua na coluna.

\begin{tabular}{|c|c|c|c|}
\hline Solo & $\begin{array}{c}K \\
\mathrm{~cm}^{3} / \mathrm{cm}^{2} \mathrm{~h}\end{array}$ & $\begin{array}{c}v \\
\mathrm{~cm} / \mathrm{h}\end{array}$ & $\begin{array}{l}\text { Relacão de } \\
\text { velocidades }\end{array}$ \\
\hline PV-orto & 1,318 & 3,319 & 2,6 \\
\hline GH & 0,6953 & 1,251 & 1,0 \\
\hline TE & 7,997 & 18,880 & 15,0 \\
\hline
\end{tabular}


e o PV-orto 2,6 vezes. Estas condições evidentemente mudarão caso os diāmetros da coluna forem maiores, o que não aconteceu tendo em vista as condicões do experimento condicionado a um fluxo unidirecional. Estas diferencas de velocidades da āgua na coluna de solo parece não haver influência na adsorcão ou retencão, de acordo com os resultados constantes nas Tabelas 26 a 34 . Eventualmente poderia haver processos de oxi-reducão no caso de cromo.

Porém a prōpria estrutura do experimento conduzido foi praticamente em condicões anaeróbicas, o que dificultaria as transformações quĩmicas de oxi-redução e por outro lado para que o cromo fosse oxidado ou reduzido levaria um tempo maior do que 45 dias conforme os trabalhos de BLOOMFIELD e PRUDEN (1980), o que não aconteceu com este experimento.

A resolução da equação 2.105 tomando - se as condições de contorno abaixo:
$C=C_{0}$
$x=0$
$t>0$
$c=0$
$x>0$
$t=0$
$C=0$
$x \rightarrow 00$
$t>0$

onde:

$c_{0}=$ concentracão inicial do soluto

$C=$ concentração do soluto na solução

$x=$ distāncia dentro da coluna, sendo $x=0$ ponto de infiltra ç̃o

$t=$ tempo de infiltração do soluto, $t=0$ in ício infiltração 
conduz a seguinte resolução:

$c / c_{0}=1 / 1\left[\operatorname{erfc}\left(\frac{x-v t}{\sqrt{4} U T}\right)+\exp (v x) / D \operatorname{erfc}\left(\frac{x+v t}{\sqrt{4} D T}\right)\right] \ldots(4.17)$

onde:

erfc é função de erro complementar

Rearranjando a equação 4.17 em termos de nümeros de poros temos:

$C / C_{0}=1 / 2\left[\operatorname{erfc}\left(\frac{1-\frac{P}{\sqrt{4} \frac{U P}{V L}}}{\sqrt{ }}\right)+\exp (V L) / D \operatorname{erf}\left(\frac{1+P}{\sqrt{4 D P} \frac{P}{V L}}\right)\right] \ldots(4.18)$ onde:

$P=$ no de poros

$L=$ comprimento da coluna

Resolvendo a equacão 4.21 para 1. volume de poros verificamos que $C / C_{0}=0,5$, calculados também por NIL SEN e BIGGAR (196\%) e ROSE e PASSIOURA (1971). Entretanto, as quantidades adsorvidas ou retidas neste experimento não foram encontradas essas concentracões no final da coluna e estão muito aquém, embora o fluxo de massa da solucão tenha sido em 5,10 e 20 vezes o número de poros. Isto mostra que em solutos onde são adsorvidas a equação não é aplicāvel, enbora as prōprias condicões de contorno deste experimento sejam totalmente diferentes: 
BRESLER e HANKS (1969) apresentou tambēm um método para estimar o deslocamento de sais pelo fluxo de àgua pelo método de cālcu?o numérico, na equação 2.109

$[d Q / d t]_{X}=\left[-D p(d C / d x)+\bar{V}_{\Theta C}+s\right]_{X}$

onde desconsiderá o termo

$\bar{v}_{\ominus}$ e s

Verifica-se no presente trabalho que o termo despresado è que estā tendo maior influéncia no deslocamento, principalmente o s (sorcão ou adsorcão). E necessārio uma pesquisa no sentido de poder correlacionar o deslocamento do solu to em função da adsorção (s) e da distāncia do deslocamento. 


\section{$V$ - CONCLUSÃO}

A. vista dos resultados e discutidos

no presente trabalho, permite concluir:

1. a seletividade da adsorção dos metais $\mathrm{M}^{2}{ }^{+}$pelo solo depende da CTC efetiva do solo e não dos cătions metálicos. A ordem da grandeza de adsorção $\vec{e}$

$T E \geqslant P V$-orto $>G H$

2. a seletividade da adsorcão entre os metais $\mathrm{M}^{2}{ }^{+}$pelo solo de pende do pH e da CTC do solo, cuja ordem acha-se

$\mathrm{Pb}>\mathrm{Cr} \geqslant \mathrm{Cd}$ 
3. Os teores de argila não determinam a seletividade da adsorção.

4. o deslocamento dos metais $\left[\mathrm{M}^{+}\right]$ao longo da coluna estão na seguinte ordem:

$\mathrm{Cr}>\mathrm{Pb}>\mathrm{Cd}$

5. o pH é o fator preponderante tanto na adsorcão como no deslocamento dos metais $\mathrm{M}^{2}{ }^{+}$, que diminuindo o $\mathrm{pH}$ hä maior deslocação.

6. As caracteristicas físicas e quimicas determinam a deslocacão dos metais $\mathrm{M}^{+}$, que possuindo menor CTC e menores teores de argila e silte deslocam maiores quantidades te metais $\mathrm{M}^{2}$ e inversamente ficam mais retidos aqueles que possuirem maior CTC e argila.

7. Os metais $M^{+}$não deslocam significativamente na coluna, ficando retido nos primeiros $11 \mathrm{~cm}$ da coluna. Portanto, há for te risco de toxidez às plantas e aos animais que a consomem. 


\section{VI - BIBLIOGRAFIA}

ALBERT, Robert A. \& FARRINGTON DANIELLS. 1980. Chemical Equilibrium, IN: Physical Chemistry. Fifth Edition, John Wiley \& Son. Nova York. $691 \mathrm{p}$.

ALESII, B.A.; W.H. FULLER \& M.U. BOYLE, 1980. Effect of leachet flow rate on metal migration through soil. J. Environ. Qual., 9:119-126.

AMOOZEGAR-FARD, A.; W.H. FULLER \& A.W. WARRICK, 1984. An approach to predicting the movement of selected polluting metals in soils. J. Environ. Qual.; 13:290-297. 
AVNIMELECH, Y.; V. SHAHAM \& A. FEDER, 1970. Elution of potassium in soil. Soil. Sci. Soc. Amer. Proc. Madison, $34: 407-411$.

BARD, A.J., 1966. Equilíbrios de ions complexos. IN: Chemical Equilibrium. Version Espanhola. Ediciones del Castilho S.A. Madrid. $222 \mathrm{pg}$.

BARROW, N.J., 1979. The description of phosphate adsorption curves. J. of soil sci. 29:447-462.

BETT, K.E.; J.S. ROWLINSON \& G. SAVILLA, 1975. Thermodynamics for chemical engineers, The Mit Press, Cambridge, Mass. USA. 325 p.

BIGGAR, J.W. \& D.R. NILESEN, 1976. Mechanisms of chemical movement in soil: Relatöri॰ apresentado na reunião. International Soil science Society, 29 p. (mimeografado).

BITTEL, J.E., \& R.J. MILLER. 1974. Lead, cadmium and calcium selectivity coefficients on montmorillonite, Illite and Kaolinite. J. Environ. Qual. 3:250-253.

BLOOMFILD, C. \& G. PRUDEN, 1980. The behaviour of Cr (VI) in soil under aerobic and anaerobic conditions. Env. Pollution (series A), 23:103-114. 
BOAST, C.W. 1973. Modeling the movement of chemical in soil by water. Soil Sci. Baltimore, 115:224-230.

BORZANI, W.; MARINA.L.R. VAIRO \& Regina B. BROWA, 1974. A modified adsorption method for measuring the specific areas of microbial cells. J. Ferment Techonol. 52:364-368.

BRESLER, E. \& R.J. HANKS, 1969. Numerical method for estimating simultaneus flow of water and salt in unsatured soil. Soil Sci. Soc. Amer. Proc. Madison, 33:827-832.

CAStellan, G.W., 1971. Physical chemistry. $2^{\text {th }}$ Edition ADDISON-WESLEY Pubhishing Co. Inc. Mass. USA. 489 p.

CASTELLAN, G.W. 1975. Físico Quĩmica. Versão portuguesa da 2 ạ edicão pela Livros Técnicos e Cientîficos Editora S/A. Rio de Janeiro. $476 \mathrm{p}$.

CASTILHO, J.J. \& V. MIRSHAWKA. 1966. Nomografia. Livraria Nobel S/A. $260 \mathrm{p}$. 
CLIFFORD, A.F., 1964. Inorganic chemistry of qualitative analysis. Printice-hall, Inc. Englewood Cliff, N.Y. fourth Printing. $515 \mathrm{p}$.

COOK, E.L. \& N. HAKERMAN, 1951. Adsorption of polar organic coumpounds on steel. J. Phys. Colloid Chemistry. $55: 549-557$.

DACORSO NETTO, C., 1966. Elementos de cälculo infinitesimal. Ed. USP, Cia Editora Nacional. SP. 478 p.

DENARO, A.R., 1974. Teoria da ionização cap. 2. In:

Fundamentos de eletroquĩmica. Versão Portuguesa. Ed. Edgard Blucher Ltda. $160 \mathrm{p}$.

DENBIGH, K.G. 1971. The principles of chemical: equilibrium, with applications em chemistry and chemical engineering. 3 rd ed. Cambridge University Press, Cambridge, London. 494 p.

FERRERONI, M.C., 1972. Estudo da adsorção de um soluto em uma mistura de adsorventes. Tese de doutoramento apresentado ao Instituto de Quĩmica da USP - São Paulo $104 \mathrm{p}$. 
FORBES, E.A., A.M. POSNER \& J.P. QUIRK, 1976. The specific adsorption of divalent $\mathrm{Cd}, \mathrm{Co}, \mathrm{Cu}, \mathrm{Pb}$ and $\mathrm{Zn}$ on goethife. J. of soit sci. 27:154-156.

FRANGISKOS, N.Z.; C.C. HARRIS \& A. JOWETT, 1961. IN: Proceedings of the third International Congress of Surface Activity. Verlag der Universitatsdruxkerei. Mainz. Vol. 4, p. 404 .

GARCIA, J.W.; C.W. BLESSIN; G.E. INGLETT \& W.P. KWOLER, 1981. Metal accumalation and crop yield for variety for edible crops grown. IN: Diverse soil média amended with sewage sludge. Env. Science and Tecnology; 15:793-804.

GARCIA-MIRAGAIA, J. \& A.L. PAGE. 1978. Sorption of trace quantities of cadmium by soils with different chemical and mineralogical composition. Water, Air and Soil Pollution. $9: 289-299$.

GLASSTONE, S. 1976. Fenömenos de superfīcie, IN: Tratado de Química Física, version espanhola de 2 a edicion norteamericana, Physical chemistry d'ran nostrand Co. INC. N. Y. - 7ạ edicion - AGUILAR - Madrid - Espanha. 1179 p. 
HARA, T. \& H. SONODA. 1979. Comparison of the toxicity of heavy metal to cabbage growth. Plant and Soil; 51:127-133.

HARTER, R.D. 1979. Adsorption of copper and lead by Ap and $B_{2}$ horizons of several north eastern united stated soils. Soil Sci. Soc. Am. J. Vol. 43:679-683.

HARVEY, K.B. \& G.B. PORTER, 1967. Hydration, IN: Chemistry. Addison-Wesley Publ. Co. 436 p.

HESSE,P.R. 1971. Text book soil chemical analisis - Ed. Jackson, London. $590 \mathrm{p}$.

JAMES, R.0.; J.P. STIGLICH \& T.W. HEALY. 1975. Analysis of models of adsorption of metal ions at oxide/water inter faces. Faraday Disc. of the Chemical Soc., 59:142-156.

JoHN, N.K., 1972. Cadmium adsorption maxima of soils as measured by the Langmuir isotherm. Can. J. Sci., $52: 343-350$.

JURY, W.A., 1982. Simulation of solute transport using a transfer function model. Water Resources Research, $18: 363-368$. 
JURY, W.A., L.H. STOLZY \& P. SHOUSE, 1982. A field test of the transfer function model for predicting solute transport. Water Research, 18:369-375.

KASTEN, P.R., L. LAPIDUS \& N.R. AMUNDSON. 1952. Mathematics of adsorption in beds. V. Effect of Intra partide Diffusion in flow Systems in fixed Beds. J. Phys. Chem. $56: 683-688$.

KIPLING, J.J. \& E.H.M. WRIGHT, 1962. Adsorption from binary systems of 1 imited concentration range: aplication of some fundamental concepts. J. Chem. Soc. p. 855-860.

KIRKHAM, D. \& W.L. POWERS, 1972. IN: Advanced soil Physics. John.Wiley. N.Y. cap. 8, p. 379-427.

KIRKHAM, D. \& W.L. POWERS. 1972. Micible displacemente. IN: advanced soil physics. John Wiley. N.Y. 427 p.

KWO, S. \& A.S. BAKER. 1980. Sorption of copper, zinc and cadmium by some acid soil s. Soil. Sci. Soc. Am. J., $44: 969-974$. 
LANGERWERFF, J.Y. \& D.L. BROWER. 1972. Exchange adsorption of trace quantities of cadmium in soils treated with chlorides of aluminum, calcium and sodium. Soil. Sci. Soc. Amer. Proc., Vol. 36:734-737.

LANGERWERFF, J.V. \& W.D. KEMPER, 1975. Reclamation of soils contaminated with radioactive strontium. Soil. Sci. Amer. Proc., Madison, 39:1077-1080.

LAGERWERFF, J.Y., 1972. Lead, mercury and cadmium as enviromental contaminants. IN: Micronutrientes in Agriculture, edited by J.J. Mortredt, P.M. GIORDAND e W.L. LINDSAY. Soil Science Soc. of America. INC. USA. $666 \mathrm{p}$.

LAGERWERFF, J.V., 1971. Uptake of cadmium, lead and zinc by radish from soil and air. Soil Sci. $111: 129-133$.

LAPIDUS, L. \& N.R. AMUNDSON, 1952. Mathematics of adsorption in beds. VI. The effect of longitudina? diffusion in ion exchange and chromatographic columns. J. Phys. Chem., $56: 984-988$.

LEE, K.C., B.A. CUNNINGHAM, G.M. PAULSEN, G.H. LING \& R.B. MOORE, 1976. Effects of cadmium on respiration rates and activities of several enzimes in soybean seeding. Phys. Plant, $36: 4-6$. 
LEVI-MINZI, C., G.F. SOLDANTINI \& R. RIFFALDI. 1976.

Cadmium adsorption by soils. J. of Soil Sci., $27: 10-15$.

LINDSAY, W.L. 1979. Methods of handling chemical equilibria. IN: Chemical equil ibria in soil. John Wiley \& Sons, INC. N.Y. -449 p.

MEITES, L. Handbook of analytical chemistry. McGraw Hill Book Company. N.Y. First Edition. Sec. 1, p. 7.

MIRSHAWKA, V. 1984. Ajustes de curvas. IN: Cālculo numérico. 601 p. 4 ạ ed. Livraria Nobel S.A.

MOORE, W.J., 1962. Physical chemistry. Versão Portuguesa. Ed. USP, 1968, ao Livro Técnico S/A. Rio de JaneiroBrasil. $1001 \mathrm{p}$.

NASCIMENTO FILHO, V.F. DO, 1978. Variabilidade espacial do deslocamento miscivel do ion cloreto em solo saturado. Tese de doutoramento apresentado a ESALQ-USP - Piracicaba SP. 
NAVROT, J.; A. SINGER \& A. BANIN, 1978. Adsorption of cadmium and its exchange characteristics in some ISRAEL soil s. J. of soil Sci. . 29:505-511.

NIELSEN, D.R. \& J.W. BIGGAR, 1961. Miscible displacement in soils. I. Experimental Information Soil. Sci. Soc. Amer. Proc. Madison, 25:1-5.

NIELSEN, D.R. \& J.W. BIGGAR, 1962(a) Miscible displacement. III. Theorical considerations. Soil. Sci. Soc. Amer. Proc. Madison, $26: 216-227$.

NIELSEN, D.R. \& J.W. BIGGAR, 1962(b) Miscible displacement. III. Theoretical consideration. Soil Sci. Soc. Amer. Proc. Madison, $26: 216-221$.

NIELSEN, D.R. \& J.W. BIGGAR, 1962(c) Miscible displacement in soils. III. Theoretical considerations. Soil. Sci. Soc. Amer. Proc. Madison, 26:216-221.

NIELSEN, D.R.; R.D. JACKSON; R.W. CARY \& D.D. EVANS, 1972. Soil Water. Madison, American Society of Agronomy, $175 \mathrm{p}$. (p. 37$)$. 
PERRY, J.H., EDITOR, 1963. Filtration. IN: Chemical Engineers' Handbook. McGraw - Hill Book Company, TOKYo JAPAN - 4 ạ ed.

PINDER, G.F. \& H.H. COOPER, Jr., 1970. A numeral techinique for calculating the transient position of the saltwater front. Water Res. Research, 6:875-882.

REICHARDT, K., 1978. IN: Processos de transferēncia no sistema-solo-planta atmosfera. Fundação Cargill. 286 p.

REUS, J.; H.L. DOOLEY \& W. GRIFFIS, 1976. Plant uptake Cd from phosphate fertilizer. Envroomental Protection Ageny. PB. 255-314.

ROSE, D.A. \& J.B. PASSIOURA. 1971. The analysis of experiments on hydrodynamic dispersion. Soil Sci. $111: 253-257$.

SCHROEDER, H.A. \& J.J. BALASSA, 1961. Abnormal trase metals in man: cadmium. J. Chron. Diseases, 14:236-258.

SCHOROEDER, H.A. \& J.J. BALASSA, 1963 - Cadmium: Uptake by vegetable from super phosphate in soil. Soil Sci., $140: 819-820$. 
SCHOROEDER, H.A., 1965. Chromium, cadmium and lead in rats. Effects in life span, tumors and tissue levels. J. Nutr. $1: 86-51$.

SIDLE, R.C.; L.T. KARDOS \& M.Th. van. GENUCHTEN, 1977. Heavy metals transport model in a sludge - treated soil. J. Environ. Qual., 6:438-433.

SLOYAN, P.J. 1971. Mercūrio: Novo agente poluidor. IN: Atualidade cientîfica - Jornal "O Estado de São Paulo". Edição do dia 29/08/1971 - pāg. 174.

SMITH, H.A. \& J.F. FUZER, 1946. The adsorption of fatty acids on nickel and platimum catalysts. J. Amer. Chemiscal Soc., $68: 229-231$.

SANTILLAN-MEDRANO, J. \& J.J. JURINAK. 1975. The chemistry of lead and cadmium in soil: solid phase formation. Soil. Sci. Soc. Am. Proc., 39:851-856.

SoON, Y.K. 1981. Solubility and sorption of cadmium in soils amended with sewage studge. J. of Soil Sci. $32: 85-95$. 
STEVENSON,F.J. \& M.S. ARDAKANI, 1972. Organic matter reactions involving micronutrients in soils. IN: Micronutrient in agriculture - Ed. J.J. Mortvedt, P.M. Giordano and W.L. Lindsay. Soil Scie. Soc. of Am., Madison, Wiscensim. p. 79-114.

TOLEDO, A.,. P. PACHECO de, 1973. Contribuicão ao estudo físico-quĩmico de ācido hümico extraîdo de sedimento. Dissertacão de mestrado. Instituto de Química. USP. $122 \mathrm{p}$.

TOLEDO, A.P.P., 1976. Estudo das interacões de ions cúpricos com àcidos hümicos e fūlvicos. Tese de doutoramento. Instituto de Química. USP. $154 \mathrm{p}$.

VOGEL, A.I., 1960. Text..book of quantitative inorganic analysis. Versão espanhola da 2 a ed. de Longmans, Green and Co, Londres por Editorial Kapeluts, S.A. Buenos Aires. $(1960) .812 \mathrm{p}$. 